
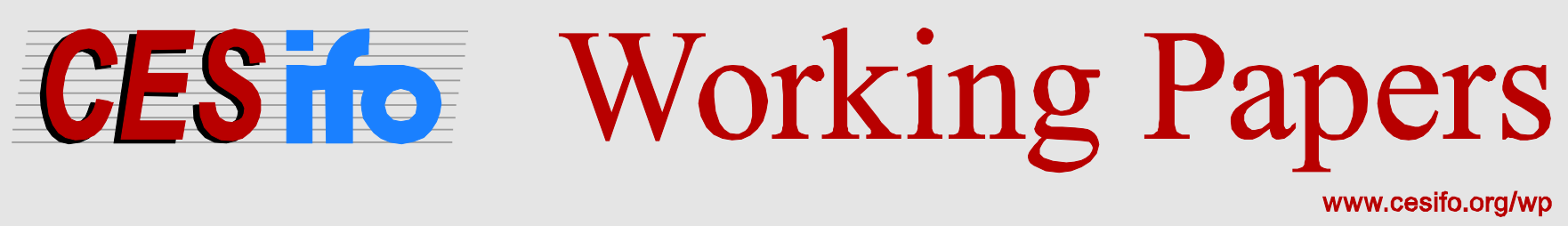

\title{
Financial Constraints and Nominal Price Rigidities
}

\author{
Almut Balleer \\ Nikolay Hristov \\ Dominik Menno
}

\author{
CESIFO WORKING PAPER NO. 6309 \\ CATEGORY 7: MONETARY POLICY AND INTERNATIONAL FINANCE \\ JANUARY 2017
}

An electronic version of the paper may be downloaded

- from the SSRN website:

- from the RePEc website:

- from the CESifo website:

www.SSRN.com

www.RePEc.org

www.CESifo-group.org/wp 


\title{
Financial Constraints and Nominal Price Rigidities
}

\begin{abstract}
This paper investigates how financial market imperfections and the frequency of price adjustment interact. Based on new firm-level evidence for Germany, we document that financially constrained firms adjust prices more often than their unconstrained counterparts, both upwards and downwards. We show that these empirical patterns are consistent with a partial equilibrium menu-cost model with a working capital constraint. We then use the model to show how the presence of financial frictions changes profits and the price distribution of firms compared to a model without financial frictions. Our results suggest that tighter financial constraints are associated with lower nominal rigidities, higher prices and lower output. Moreover, in response to aggregate shocks, aggregate price rigidity moves substantially, the response of inflation is dampened, while output reacts more in the presence of financial frictions. This means that financial frictions make the aggregate supply curve flatter for all calibrations considered in our model. We show that this differs fundamentally from models in which the extensive margin of price adjustment is absent (Rotemberg, 1982) or constant (Calvo, 1983). Hence, the interaction of financial frictions and the frequency of price adjustment potentially induces important consequences for the effectiveness of monetary policy.
\end{abstract}

JEL-Codes: E310, E440.

Keywords: frequency of price adjustment, financial frictions, menu cost model.

\author{
Almut Balleer \\ RWTH Aachen / Germany \\ balleer@ewifo.rwth-aachen.de
}

\author{
Nikolay Hristov* \\ Ifo Institute - Leibniz Institute for \\ Economic Research \\ at the University of Munich / Germany \\ hristov@ifo.de
}

\author{
Dominik Menno \\ Aarhus University / Denmark \\ dmenno@econ.au.dk
}

*corresponding author

January 9, 2017

We would like to thank Christoph Boehm, Tobias Broer, Zeno Enders, Giorgio Fabbri, Andrei Levchenko, Stefan Pitschner, Morten Ravn, Andreas Schabert, Marija Vukotic, and numerous participants at the DFG Priority Programme 1578 workshops, the ifo Macro and Survey data workshop, SED Warsaw, VfS-Annual Conference, joint BoE, ECB, CEPR and CFM Conference on Credit Dynamics and the Macroeconomy, ESSIM Helsinki, ICMAIF-Annual Conference 2016, CESifo Area Conference on Macro, Money and International Finance 2016, Belgrade Young Economists Conference, and NORMAC 2016 as well as seminar participants at the ifo Institute, Riksbank Sweden, Bundesbank, IWH Halle, and the Universities of Augsburg, Basel, Berlin, Konstanz, Linz, Louvain-la-Neuve, Michigan and Warwick. Financial support from the DFG Priority Programme 1578 is gratefully acknowledged. 


\section{Introduction}

How do financial frictions affect macroeconomic outcomes? This paper investigates the interaction between financial frictions and the frequency of price adjustment in the economy. We document empirically that financially constrained firms adjust prices more often than their unconstrained counterparts, both up- and downwards. We replicate this pattern in a partial-equilibrium menu cost model with a working capital constraint. Based on this model, we then explore the cross-sectional distribution of pricing decisions in response to idiosyncratic and aggregate shocks and show how it interacts with financial frictions. In particular, we document that financial frictions impose important asymmetries in the profits and the price gap distribution of both financially constrained and unconstrained firms. Based on this, we show that aggregate price rigidity and prices increase, while output falls in the presence of financial frictions. Moreover, in response to aggregate shocks, aggregate price rigidity moves substantially, the response of inflation is dampened, while output reacts more in the presence of financial frictions. Hence, financial frictions potentially induce important consequences for the effectiveness of monetary policy.

We explore rich plant-level data for Germany: the ifo Business Survey, a monthly representative panel of 3600 manufacturing firms covering the years 2002-2014. The survey contains information about the extensive margin, i.e., whether and in what direction individual firms change prices. In addition, the survey provides two high-frequency, direct firm-specific measures of financial constraints: Firms give appraisals of their access to bank credit which is the predominant way of financing operational costs and investment externally in Germany. Firms also report whether they are experiencing production shortages due to financial constraints. Regardless of the measure of financial constrainedness used and the frequency of data, we find that financially constrained firms adjust prices more often than unconstrained firms. In particular, the typical financially constrained firm exhibits a significantly higher frequency for both an upward and a downward price adjustment. These patterns are also statistically significant in different subperiods: before, during and after the Great Recession. To check the robustness of our results, we exploit balance-sheet based indicators of the individual access to credit for a subset of firms in our sample.

The existing empirical literature on the relationship between pricing decisions of firms and financial constraints is relatively scarce. It has mainly focused on price adjustment along the intensive margin ${ }^{1}$ and has also mostly not included evidence on the Great Recession period. At the same time, it mostly relies on indirect measures of individual financial conditions such as the state of the business cycle or balance sheet measures. ${ }^{2}$ Our evidence stands out since we report high-frequency survey-based measures and evidence for a large European economy. Since we have balance sheet information for a subset of firms in our sample, we can compare direct and indirect measures of financial constraints. The study that is closest to ours is a recent study for the US by Gilchrist et al. (2013). Based on balance sheet measures, Gilchrist et al. also show that among price adjusters financially constrained firms adjust prices up more often than unconstrained firms with the relationship being significant only during the Great Recession. Unlike in the current paper, they focus on the intensive margin of price adjustment rather than on the interaction between financial constraints and the frequency of price changes.

Our interpretation of the empirical facts is guided by a partial-equilibrium menu cost model with financial frictions which provides an explicit rationale for the interactions between financial constraints and nominal rigidities. Here, we extend the standard menu-cost model with heterogeneous firms by adding a working capital constraint. ${ }^{3}$ In this model, financial frictions and price setting may affect each other in several ways. On the one hand, being financially constrained may affect the pricing decision of a firm: firms with initially low prices that sell large quantities may not be able to finance their production inputs and may therefore find it optimal to scale down production and/or to adjust prices up. On the other hand, firms seeking to gain market share may want to lower their prices. However, by doing so, they may run into financial constraints when expanding production. Finally, firms trade-off current and

\footnotetext{
${ }^{1}$ See for example Chevalier and Scharfstein (1996) for the US or Gottfries (2002) and Asplund et al. (2005) for Sweden.

${ }^{2}$ Only Bhaskar et al. (1993) use a small-sample one time cross-sectional survey for small firms in the UK.

${ }^{3}$ In contrast, existing studies on the interaction between financial frictions and pricing decisions consider the intensive margin only, i.e., the fraction of firms that adjust prices is always equal to one, see e.g. Gilchrist et al. (2013), Gottfries (1991), Chevalier and Scharfstein (1996) or Lundin and Yun (2009). The literature on menu costs has in turn not focused on financial frictions, e.g. Barro (1972), Caplin and Spulber (1987), Dotsey et al. (1999), Golosov and Lucas (2007) or Gilchrist et al. (2013). Extensions as stochastic idiosyncratic menu costs and leptokurtic productivity shocks are analysed in Dotsey and King (2005) and Midrigan (2011) respectively. Multi-sector and multi-product versions of the model are developed by Nakamura and Steinsson (2010) and Alvarez and Lippi (2014). Vavra (2013) and Bachmann et al. (2013) investigate the consequences of uncertainty shocks for the price distribution and the effectiveness of monetary policy.
} 
expected future profits and may be inclined to set prices such that future expected menu-costs can be reduced (as the expected time until the next price adjustment is maximized).

We document that the presence of financial constraints makes the individual firm's profit function more concave in the price and introduces important asymmetries. Profits fall more quickly for prices below compared to above the constrained optimal reset price, since these prices imply rationing output which is very costly to firms. This means that the inaction region in which it is optimal for firms not to adjust prices is more narrow and more asymmetric around the optimal constrained reset price compared to the optimal unconstrained reset price. As a result, for any given beginning-of-period price, firms are more likely to adjust prices. At the same time, the presence of financial frictions reduces the elasticity of the optimal reset price with respect to productivity, i.e., the optimal reset price falls less strongly with increasing productivity. Financial frictions also change the stationary distribution of beginning-ofperiod prices as the price gap distribution becomes less dispersed. This distributional effect reduces the frequency of price changes.

For the bulk of empirically plausible parameterizations, the width of the inaction region effect is stronger than the distributional effect for financially constrained firms compared to financially unconstrained firms. Hence, our model replicates the empirical finding that financially constrained firms adjust prices more often than unconstrained firms. We also decompose this effect for different productivity levels of firms and show that the frequency of price changes is generally low for intermediate productivity levels. Moreover, most unconstrained firms have intermediate productivity realizations. Financially constrained firms tend to adjust prices down very often for high productivity realizations. At the same time, many financially constrained firms have low productivity realizations at which the price adjustment (upwards) is still substantial. It is important to note however, that the above holds in a world with financial frictions. When comparing a world with to a world without financial frictions, the distributional effect is very strong at all productivity levels and for all types of firms, the unconstrained firms in particular. Hence, even though financially constrained firms adjust their prices more often than their unconstrained counterparts, the overall frequency of price changes falls in the presence of financial frictions.

To investigate the implications of financial frictions on the economy, we consider the responses of average inflation and real output to aggregate nominal demand shocks. In our partial-equilibrium model, these shocks can be interpreted as responses of a single sector to aggregate business cycle shocks. Doing so, we obviously ignore important general equilibrium effects, in particular the response of real wages. We nevertheless believe this to be an instructive exercise as real wages might be sticky or downward rigid in the short run. We find that, due to the asymmetry in the price distribution, firms adjust prices more often in a boom and less often in a recession when financial constraints are present. In addition, due to the lower average frequency of price adjustment, the aggregate demand shock induces a smaller change in inflation and a stronger reaction of output relative to an economy without credit market imperfections. This means that financial constraints alter a central trade-off faced by the central bank: In order to engineer an increase in inflation by a certain amount the monetary authority needs to generate larger changes in nominal demand. At the same time, it needs to take into account that larger changes in nominal demand induce even stronger responses of average output. This model implication is very similar to what has been highlighted as the "cost channel" of financial frictions by Gilchrist et al. (2013). In our framework, this means that financial frictions decrease the slope of the aggregate supply curve. In contrast, we show that other sources of nominal rigidities such as exogenous probabilities of price adjustment as in Calvo (1983) or convex price adjustment costs as in Rotemberg (1982) generate the opposite result, i.e. the inclusion of financial frictions generates larger inflation and smaller output responses to aggregate shocks with compared to without financial frictions. Hence, menu costs and the associated endogenous link between the fraction of price adjusters and the presence of credit market imperfections play a crucial role for aggregate fluctuations.

The remainder of the paper is organized as follows. Section 2 documents the data and the empirical relationship between financial frictions and the price setting of firms. Section 3 presents the model, derives the central insights from the static model, discusses the calibration and documents the implications for the cross-section of firms. Section 4 documents and discusses the aggregate implications, compares the results to alternative sources of nominal rigidities, discusses robustness of the results and considers the special case of a financial recession. Section 5 concludes. 


\section{$2 \quad$ Empirical Evidence}

\subsection{Data}

We use data from the ifo Business Survey which is a representative sample of 3600 plants in the German manufacturing sector in 2002-2014. The survey starts as early as the 1950's, but our sample is restricted by the fact that the questions about financial constrainedness were added in 2002. The main advantages of the dataset relative to data used in other studies on price stickiness are twofold. First it enables us to link individual plant's pricing decisions to both direct survey-based measures of plant-specific financial constrainedness and to indirect proxies for the financial situation based on balance sheet information. Second, the survey is conducted on a monthly basis which enables us to track important aspects of a plant's actual behavior over time as it undergoes both phases of easy and such of subdued access to credit while at the same time facing the alternating states of the business cycle. Since plants respond on a voluntary basis and, thus, not all plants respond every month, the panel is unbalanced.

In particular, we have monthly information about the extensive margin of price adjustment, i.e. whether and in what direction firms adjust prices. More precisely, firms answer the question: "Have you in the last month increased, decreased or left unchanged your domestic sales prices?". " Since we do not have information about the intensive margin of price adjustment in our dataset, the calibration and implications of our model will be compared to information from other data sources (see Section 3 below). More than $97 \%$ of the cross-sectional units in our sample are single-product plants. Additionally, some plants fill in a separate questionnaire for each product (product group) they produce. In what follows, we use the terms "firm", "plant" and "product" interchangeably.

The ifo survey encompasses two questions regarding the financial constrainedness of firms. In the monthly survey, firms are asked about their access to bank lending: "Are you assessing the willingness of banks to lend as restrictive, normal or accommodating?". We flag firms as financially constrained when they answer that bank lending is restrictive and we will use this as our baseline measure of financial constraints. Note that this answer might imply that firms experience restrictive bank lending in general, but do not necessarily need to borrow more or have been declined credit. This means that they are potentially not restricted in the way they invest, hire or produce. ${ }^{5}$ However, assessing the current situation as one with restricted access to credit may still affect firm behavior, e.g. via the future lending conditions the firm expects to face.

Bank lending is the key financing channel in Germany. Appendix A.1 exhibits information about the financing structure in Germany in general and in the ifo dataset in particular. Generally, German firms show a much higher share of loans in their balance sheets than their US counterparts, while the equity share is comparable. External financing through securities and bonds is marginal in Germany. Further, a flow-of-funds analysis of the Bundesbank documents that within equity, internal financing works through retaining profits, while market-financing plays almost no role, not even in the Great Recession. ${ }^{6}$ Restrictions in bank lending therefore pose serious constraints to the firms in our sample. Below, we will additionally consider to role of firm size, multi-products or exports for the results as these may reflect different financial possibilities of firms.

A second question in the survey relates financial and production constraints more closely: "Are your domestic production activities currently constrained due to difficulties in financing?". This question is very close to the actual definition of financial constraints in the economic model that we present below. However, it is only available at quarterly frequency. In addition, the response rate on this and other questions about production shortages is very low. The question is only answered positively, not negatively which means that we cannot tell apart missing data from unconstrained firms. We will use this question in order to explore robustness. A fraction of $84 \%$ of the firms that qualify as restricted according to the banking measure respond positively to the production shortage question.

Our sample exhibits an average of $32 \%$ of constrained firms according to the banking measure and $5 \%$ of constrained firms according to the production measure. In Appendix A.1 we show a time-series plot

\footnotetext{
${ }^{4}$ These prices are home country producer prices and refer to the baseline or reference producer price (not to sales, etc.). Bachmann et al. (2013) have used the same dataset to assess the effect of uncertainty shocks on price setting. Strasser (2013) uses the dataset to study the role of financial frictions for the exchange rate pass through of exporting firms.

JBased on a similar survey with a similar question about refinancing conditions for Austria Fdrmuc, Hainz and Hoelzl (2016) confirm that a firm's own recent experience regarding credit negotiations with banks is by far the main driver of its appraisals of banks' willingness to lend. In contrast, aggregate or sector-specific conditions are of minor importance.

${ }^{6}$ See DeutscheBundesbank (2013) and DeutscheBundesbank (2014).
} 
of the fraction of constrained firms according to both measures of financial constraints. One can see that the fraction of constrained firms increases in a boom and decreases in a recession. One can also see that the banking measure is available at monthly frequency from 2009 onwards, and semi-annually before. In our estimations below, we interpolate all measures to monthly frequency throughout the sample.

We would like to know whether financially constrained and unconstrained firms are systematically different in some important aspect. The literature has discussed that small rather than large firms tend to be financially constrained. ${ }^{7}$ For our baseline measure, our data does not exhibit this feature. In Appendix A.1, we show that firms that have restrictive access to bank lending are not significantly smaller than other firms in terms of employment, sales or total assets. We also show that the fraction of constrained firms varies greatly between sectors.

Existing evidence on financial constraints is primarily based on balance sheet data rather than survey data. For a subsample of the firms in our survey, we have access to annual balance sheet information and we can calculate liquidity ratios similar to Gilchrist et al. (2013). ${ }^{8}$ In Appendix A.1 we show that liquidity ratios are a little lower for firms that are constrained according to our survey questions. The difference is minimal for our baseline measure, however. The conventional balance-sheet based measure defines firms to be financially constrained if they are below the median liquidity ratio with respect to all firms in the sample. The overlap between this type of balance sheet measure and both of our survey questions is very small (see Appendix). Generally, a low liquidity ratio can be the result of easy access to credit, while not affecting production possibilities of firms. It may therefore not measure financial constraints per se. For example, consider a firm experiencing a sudden decline in its marginal costs. Such a firm will typically decrease its prices and try to scale up the level of operation. If expanding the production capacity requires external funding, the firm may hit the upper limit of its financial constraint, but may still enjoy a relatively high liquidity ratio. Hence, one may wrongly conclude that it is financially unconstrained today. Below, we document that the relationship between price setting and financial constrainedness does not crucially depend on the measure of financial constraints.

Table 1 shows the relationship between price adjustments and being financially constrained in our dataset. In general few German firms adjust their prices on a monthly basis: a little more than $20 \%$ on average. Out of these, $10 \%$ of firms adjust prices up and down on average (not shown in the Table). These will be three central moments that we target when calibrating our model in Section 3 below.

In Appendix A.1, we document that there is a lot of variation in price changes and hence changes in nominal rigidities over time. We also document that all firms (both constrained and unconstrained firms) decrease prices more often and increase prices less often in a recession. Over time, financially constrained firms decrease prices more often than unconstrained firms, regardless of the business cycle state. While the differences between price increases of constrained and unconstrained firms is small, more unconstrained firms leave prices constant relative to constrained firms in a recession compared to outside a recession. Clearly, the time series variation of pricing decisions may be driven by two facts: the business cycle itself, sector-specific aspects and a possible selection of firms over the business cycle. Based on our estimations below, we can however exclude that these effects are driving the differences in pricing decisions.

\subsection{Estimation}

In order to control for time and individual fixed effects, we decompose the correlation between price changes and financial constrainedness using the following specification

$$
\mathcal{I}\left(\Delta p_{i j t} \lesseqgtr 0\right)=\beta_{0}+\beta_{1} F C_{i j t}+\Delta p_{i j t-1}+c_{j}+\theta_{t}+x_{i j t}+u_{i j t} .
$$

Based on this equation, we estimate independently three linear models for which the dependent variable measures whether the prices change, increase or decrease. ${ }^{9}$ The left-hand side, $\mathcal{I}\left(\Delta p_{i j t} \lesseqgtr 0\right)$, is an

\footnotetext{
${ }^{7}$ See Carpenter et al. (1994) for an early contribution on the topic.

${ }^{8}$ The data source here is the EBDC-BEP (2012): Business Expectations Panel 1/1980 12/2012, LMU-ifo Economics and Business Data Center, Munich, doi: 10.7805/ebdc-bep-2012. This dataset links firms' balance sheets from the Bureau van Dyk (BvD) Amadeus database and the Hoppenstedt database to a subset of the firms in the ifo Business Survey. See Kleemann and Wiegand (2014) for a detailed description of this data source. Liquidity ratios are defined as cash and cash equivalents over total assets.

${ }^{9}$ We also considered a multinomial specification. Doing so does not alter the main conclusions, see Appendix A.1 for details.
} 
Table 1: Financial Constraints and Price Setting

\begin{tabular}{lcc}
\hline & unconstrained & constrained \\
\hline & & \\
$\frac{\text { Bank lending }}{\text { Fractions }}$ & & \\
$\Delta p=0$ & 0.68 & 0.32 \\
$\Delta p<0$ & 0.80 & 0.76 \\
$\Delta p>0$ & 0.08 & 0.14 \\
& 0.13 & 0.10 \\
Production shortage & & \\
Fractions & & \\
$\Delta p=0$ & 0.95 & 0.05 \\
$\Delta p<0$ & 0.80 & 0.75 \\
$\Delta p>0$ & 0.08 & 0.12 \\
\hline
\end{tabular}

Source: ifo Business Survey, 2002-2014. Numbers shown are sample averages of fractions of constrained and unconstrained firms in all firms and fractions of price changes within unconstrained and constrained firms. Numbers for production shortage question are based on quarterly data, interpolated to monthly frequency.

indicator function that takes the value 1 if the price stays constant, increases, or decreases, respectively. The right-hand side contains the measure of being financially constrained, the lagged pricing decision to control for the fact that firms may have been affected by different shocks previously as well as sector and time fixed effects. The coefficient $\beta_{1}$ then measures the within-firm variation over time between being financially constrained and the probability of adjusting the price at all, up or down. Note that this coefficient should not be interpreted as causal, since it may well be that price adjustments influence whether a firm is financially constrained or not (as is motivated in the introduction and documented in detail in Section 3 below). Instead, this specification seeks to control for variation over time, i.e., business cycle effects, possible selection of firms into being financially constrained or not and other aspects that could have influenced the unconditional moments in Table 1 .

The first column in Table 2 shows the baseline results for our bank lending measure of financial constraints. Financially constrained firms adjust prices more often than unconstrained firms, the difference in probability is about $4 \%$. This differences is composed of financially constrained firms increasing prices about $1 \%$ more often and decreasing prices about $3 \%$ more often than unconstrained firms. All of these differences are highly significant. The Table documents that the results are robust to various subsamples. Small and medium sized firms may be particularly affected by restricted bank lending, exporting firms may be less affected. West German firms are potentially less affected by financial frictions and single-product firms may be less able to shift funds to avoid restrictions. In addition, we consider two subsamples that end and start before and after the Great Recession period respectively. Our results are robust to all of these subsamples.

Appendix A.1 shows further results investigating robustness along a number of dimensions. For example, we add various control variables that could affect both price setting and whether firms are financially constrained or not. These include firm size, receiving wage subsidies in the form of short-time work programmes, lagged and current assessment of the state of business, current assessment of the state of orders and future assessment of commercial operations. All of these variables stem from the ifo survey and are answered qualitatively according to three categories: improved, unchanged, worsened. We also conduct robustness with respect to different specifications. Among others, we add seasonal (quarterly) fixed effects and an interaction term between sector $j$ and seasonal fixed effects. We further cluster the standard errors at the sectoral level and allow for product-specific (i.e. individual) fixed effects rather than sectoral fixed effects. In order to investigate possible effects of attrition of the sample, we consider a long-coverage panel (firms are in panel at least 8 years) and a completely-balanced panel. Furthermore, in the Appendix we document that our results do not depend on the specification being linear, as a logit model estimation leaves the results virtually unchanged.

We have replicated all of the above results using our production constraint measures instead of the bank lending measure for financial constrainedness. The results are shown in the Appendix. Generally, 
Table 2: Financial Constraints and Price Setting: Subsample robustness

\begin{tabular}{|c|c|c|c|c|c|c|c|}
\hline & baseline & SMEs & west & exporting & post 2009 & pre 2009 & single product \\
\hline$\rightarrow$ & $\begin{array}{c}-0.036^{* * *} \\
(0.000)\end{array}$ & $\begin{array}{c}-0.048^{* * *} \\
(0.000)\end{array}$ & $\begin{array}{c}-0.037^{* * *} \\
(0.000)\end{array}$ & $\begin{array}{c}-0.036^{* * *} \\
(0.000)\end{array}$ & $\begin{array}{c}-0.036^{* * *} \\
(0.000)\end{array}$ & $\begin{array}{c}-0.034^{* * *} \\
(0.000)\end{array}$ & $\begin{array}{c}-0.036^{* * *} \\
(0.000)\end{array}$ \\
\hline$\uparrow$ & $\begin{array}{c}0.008^{* * *} \\
(0.000)\end{array}$ & $\begin{array}{c}0.016^{* * *} \\
(0.000)\end{array}$ & $\begin{array}{c}0.009 * * * \\
(0.000)\end{array}$ & $\begin{array}{c}0.009 * * * \\
(0.000)\end{array}$ & $\begin{array}{c}0.008^{* * *} \\
(0.000)\end{array}$ & $\begin{array}{c}0.009^{* *} \\
(0.011)\end{array}$ & $\begin{array}{c}0.008^{* * *} \\
(0.000)\end{array}$ \\
\hline$\downarrow$ & $\begin{array}{c}0.028^{* * *} \\
(0.000)\end{array}$ & $\begin{array}{c}0.032^{* * *} \\
(0.000)\end{array}$ & $\begin{array}{c}0.028^{* * *} \\
(0.000)\end{array}$ & $\begin{array}{c}0.027^{* * *} \\
(0.000)\end{array}$ & $\begin{array}{c}0.029 * * * \\
(0.000)\end{array}$ & $\begin{array}{c}0.025^{* * *} \\
(0.000)\end{array}$ & $\begin{array}{c}0.028^{* * *} \\
(0.000)\end{array}$ \\
\hline Observations & 180871 & 77130 & 146647 & 144441 & 150774 & 30097 & 179589 \\
\hline
\end{tabular}

Notes: Survey dataset. Sample: 2002:1 - 2014:12. OLS estimation with time $t$ and sector $j$ fixed effects. Considering subsamples: small and medium-sized firms only (50-250 employees), west only, exporting firms only, before and after 2009, single product firms. Results including very small firms (below 250) are not shown in the table, but available upon request. Standard errors in parentheses, ${ }^{* *} \mathrm{p}<0.01,{ }^{*} \mathrm{p}<0.05, * \mathrm{p}<0.1$.

the difference in the frequency of price adjustment between financially constrained and unconstrained firms is slightly larger in this measure. As before, financially constrained firms adjust prices more often than unconstrained firms, but the difference is now equally driven by upward as by downward price adjusters.

In a related paper, Gilchrist et al. (2013) show that US firms that are financially constrained increase prices more often than their unconstrained counterparts, but do not decrease their prices more often. While the first finding is supported using our estimation, the second finding is not. A potential source of this difference is the measure of financial constrainedness of firms. While we use direct survey questions to identify financially constrained firms, Gilchrist et al. employ an indirect measure based on balance sheet information of firms. In the Appendix we show results when using the liquidity ratio (measured as described above) in order to measure financial constrainedness. In line Gilchrist et al. (2013), constrained firms are those with liquidity ratios below the median value of all firms. Our analysis shows that our results support the results by Gilchrist et al. (2013) as financially constrained firms change their prices more often. Constrained firms increase and decrease prices more often, but only the price increases are statistically significant. Note that potentially, our results could be very different from Gilchrist et al. (2013), since we consider a central European economy, the manufacturing sector only and many small firms in addition to large publicly traded firms.

\section{Model}

In this section, we develop a simple partial-equilibrium model which replicates the empirical facts presented in the previous section. In particular, the model combines menu costs as a source of price rigidity with a working capital constraint as a source of a financial friction. Section 3.1 presents the model and Section 3.2 develops the economic intuition based on a static version of the model. Section 3.3 presents the calibration and quantitative results of the dynamic model.

\subsection{Baseline Model}

Our model consists of a firm's problem only. There is a continuum of firms in the economy indexed by $i$. Each firm produces using a linear technology

$$
y_{i t}=z_{i t} h_{i t} .
$$


Here, $y_{i t}$ denotes the output of the firm in period $t, z_{i t}$ denotes the productivity of the firm's labor input in period $t$, and $h_{i t}$ is the amount of labor hired by the firm in period $t$. The logarithm of firm-specific productivity follows an exogenous $\operatorname{AR}(1)$, or

$$
\log \left(z_{i t}\right)=\rho_{z} \log \left(z_{i t-1}\right)+\varepsilon_{i t}
$$

We assume that demand $c_{i t}$ for the good produced by firm $i$ in period $t$ is given by

$$
c_{i t}=\left(\frac{p_{i t}}{P_{t}}\right)^{-\theta} C_{t},
$$

where $p_{i t}$ is the nominal price the firm charges in period $t, P_{t}$ denotes the aggregate price level in period $t$, and $C_{t}$ determines the potential total size of the market for the firms' goods in period $t$. The parameter $\theta$ is the elasticity of substitution between different goods. ${ }^{10}$ Aggregate consumption $C_{t}$ and the aggregate nominal price level $P_{t}$ are exogenously given. We assume that nominal total demand $S_{t}=P_{t} C_{t}$ follows an exogenous stochastic process. In line with Nakamura and Steinsson (2008), the logarithm of nominal demand fluctuates around a trend:

$$
\log \left(S_{t}\right)=\mu+\log \left(S_{t-1}\right)+\eta_{t}
$$

where $\mu$ is the average nominal demand growth rate in the economy. ${ }^{11}$

Working hours are hired at a real wage $w$. Following Nakamura and Steinsson (2008), $w$ is assumed to be constant and equal to

$$
w=\frac{W_{t}}{P_{t}}=\frac{\theta-1}{\theta},
$$

where $W_{t}$ denotes the nominal wage in period $t .^{12}$

The first friction included in our theoretical set-up is a standard menu-cost. That is, the firm has to hire an extra fixed amount of labor $f$ in case it decides to adjust its price. We assume that the fixed cost $f$ has to be paid at the end of the period after revenues have been realized.

The second friction is a financial constraint in the form of a working capital constraint, i.e., we assume that payments of wages have to be made prior to the realization of revenues. Accordingly, the firm faces a cash flow mismatch during the period and has to raise funds amounting to $l_{i t}=w h_{i t}$ in the form of an intra-period loan. However, the firm cannot borrow more than the a fraction of the sum of the real liquidation value of its capital plus its sales. ${ }^{13}$

$$
w h_{i t} \leq \xi\left(k_{i t}+\frac{p_{i t}}{P_{t}} z_{i t} h_{i t}\right)
$$

Here, $\xi$ is the fraction of the real value of capital $\left(k_{i t}\right)$ plus real sales that firms can pledge as collateral to lenders. In principle, we can allow $k_{i t}$ to be a firm-specific choice variable. In the baseline model, however, we abstract from heterogeneous availability of collateral across firms and assume that capital

${ }^{10}$ The demand function reflects the optimal decision of the consumer if her consumption basket is given by the CES index:

$$
C=\left(\int_{i=0}^{1} c_{t}(i)^{\frac{\theta}{\theta-1}} d i\right)^{\frac{\theta-1}{\theta}}
$$

\footnotetext{
${ }^{11}$ In the numerical simulations we assume for simplicity that the size of the market $C_{t}=C=1$ is constant over time. This is without loss of generality in this partial equilibrium setting. As a consequence, the shock specification for nominal demand is equivalent to assuming that the logarithm of the price level follows a random walk.

${ }^{12}$ We use this normalization for simplicity, it is not essential for the quantitative results. The expression of the real wage above arises in the steady state of a general equilibrium model with a linear aggregate production function depending only on labor input and no financial constraint, monopolistic competition among firms in the goods market, and a good-specific demand function given by 3 .

${ }^{13}$ As in Jermann and Quadrini (2012), we assume that debt contracts are not enforceable as the firm can default. Default takes place at the end of the period before the intra-period loan has to be repaid. In case of default, the lender has the right to liquidate the firm's assets. However, the loan $l_{i}$ represents liquid funds that can be easily diverted by the firm in case of default. The implicit assumption is that firms can divert parts of their revenues, so lenders can only access part $\xi$ of the value of the firm's capital stock plus its current cash-flow. The lower the resale value of capital and the more cash-flow the firm can divert, the lower the recovery value of the lenders in case of default. The working capital constraint can therefore be viewed as an enforcement constraint.
} 
is fixed, $k_{i t}=\bar{k}=1 \forall t$. The parameter $\xi$ is a constant and can be interpreted as the expected real liquidation value of capital and sales in the economy. ${ }^{14}$

Firms start the period with a given nominal price $p_{i t}$ and observe the exogenous realizations of the aggregate nominal price level $P_{t}$ as well as idiosyncratic shocks to productivity $z_{i t}$, respectively. Before producing, they choose whether to change the price to $q_{i t} \neq p_{i t}$ or to leave the nominal price unchanged. In case the firm is unconstrained, given the new price, the demand function then pins down the desired level of output and the necessary amount of labor associated with that level of output. The financial constraint, in turn, determines whether the desired demand and therefore output level is feasible or not. If not, the financial constraint pins down the amount of labor that can be used for production and therefore determines the output level. In case the firm leaves the price unchanged, financially constrained firms might find it optimal to ration supply, in the sense that the financially constrained firm does not supply the amount demanded at the given price.

The formal structure of the firm's optimization problem is as follows: Given $\left(p_{i t}, P_{t}, z_{i t}\right)$, the firm's real profit stream each period is given by

$$
\Pi_{i t}=\left(\frac{p_{i t}}{P_{t}}-\frac{w}{z_{i t}}\right) z_{i t} h_{i t}
$$

The associated value function is

$$
V\left(p_{i t} / P_{t}, z_{i t}\right)=\max \left\{V^{a}\left(z_{i t}\right), V^{n a}\left(p_{i t} / P_{t}, z_{i t}\right)\right\}
$$

with

$$
V^{n a}\left(p_{i t} / P_{t}, z_{i t}\right)=\max _{h_{i t}}\left\{\begin{array}{l}
\left(\frac{p_{i t}}{P_{t}}-\frac{w}{z_{i t}}\right) z_{i t} h_{i t}+\beta E_{t} V\left(p_{i t} / P_{t+1}, z_{i t+1}\right) \\
\text { s.t. } z_{i t} h_{i t} \leq \frac{p_{i t}}{P_{t}}-\theta \\
w h_{i t} \leq \xi\left(1+\frac{p_{i t}}{P_{t}} z_{i t} h_{i t}\right)
\end{array}\right\}
$$

and

$$
V^{a}\left(p_{i t} / P_{t}, z_{i t}\right)=\max _{q_{i t} \neq p_{i t}, h_{i t}}\left\{\begin{array}{l}
\left(\frac{q_{i t}}{P_{t}}-\frac{w}{z_{i t}}\right) z_{i t} h_{i t}-w f+\beta E_{t} V\left(q_{i t} / P_{t+1}, z_{i t+1}\right) \\
\text { s.t. } \quad z_{i t} h_{i t} \leq \frac{q_{i t}}{P_{t}} C \\
w h_{i t} \leq \xi\left(1+\frac{q_{i t}}{P_{t}} z_{i t} h_{i t}\right)
\end{array}\right\}
$$

where $V^{a}$ and $V^{n a}$ are the firm's value functions in the case the firm adjusts its nominal price $\left(V^{a}\right)$ or leaves the nominal price unchanged $\left(V^{n a}\right)$, respectively. The fix cost $f$ needs to be paid if the firm decides to change its price. Note that through $y_{i t} \leq c_{i t}$ we allow the firm to produce less than the amount of goods demanded.

\subsection{Special Case: Myopic Firms}

The most important insights from the model can be discussed in a simpler version of the model where firms are perfectly myopic, or $\beta=0$. To enhance readability we drop time indices wherever appropriate. When firms adjust their price and are financially unconstrained, their optimal reset price is given by

$$
\frac{q^{u c}}{P}=\frac{\theta}{\theta-1} \frac{w}{z}=\frac{1}{z}
$$

where the last equation follows from the definition of the real wage. Hence, financially unconstrained firms optimally charge a constant mark-up over marginal costs. Figure 1 exhibits the relationship between the real optimal price $\tilde{q}^{u c} / P$ and productivity $z$ (blue dashed line).

In Appendix A.2 we show that if the firm decides to adjust the price, demand is always satisfied with equality, independent of whether the firm is financially constrained or not. Hence, when the financial

\footnotetext{
${ }^{14}$ In Appendix A.7 we present a model version with idiosyncratic financial shocks, where we allow $\xi$ to be time-varying and to follow an idiosyncratic exogenous stochastic process.
} 
Figure 1: Pricing policy function

(a) Myopic firms $(\beta=0)$

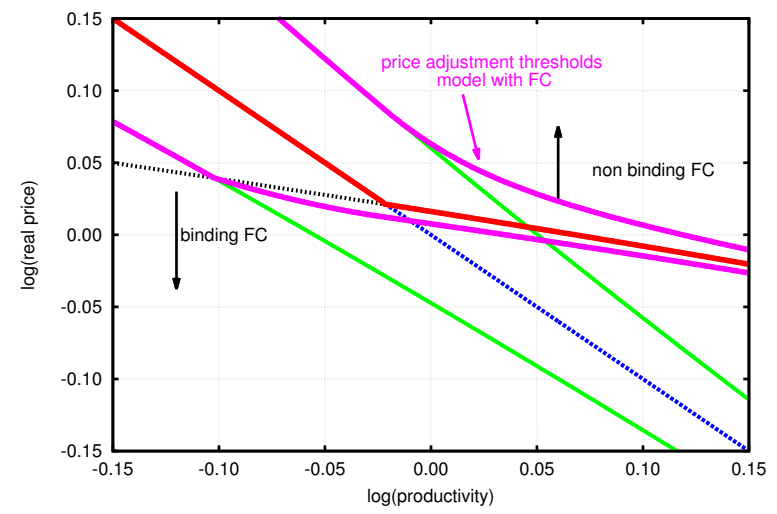

(b) Dynamic Model (benchmark)

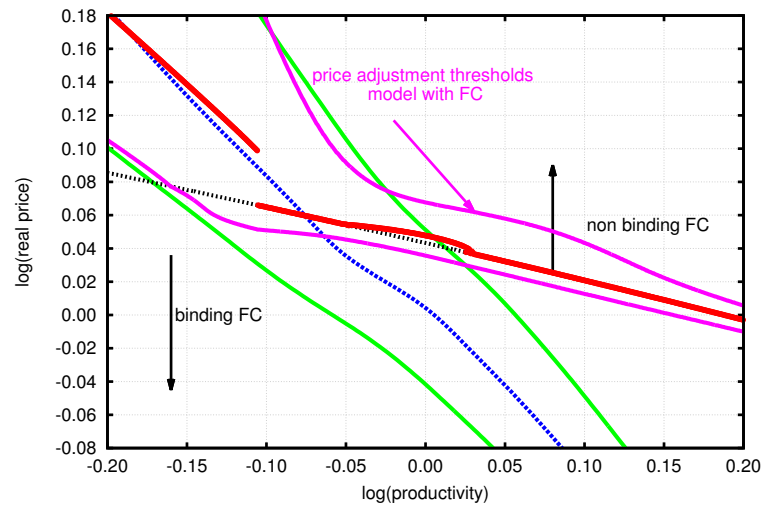

Notes: The x-axis displays the logarithm of the productivity levels $z_{i}$ and the y-axis shows the logarithm of the real price of the firm $\tilde{p_{i}}=p_{i} / P$. Panel (a) shows the policy function in the model with myopic firms, hence shutting down the intertemporal channel. The corresponding calibration can be found in the robustness Section in the Appendix A.7 Panel (b) shows the policy function for the benchmark calibration of the dynamic model, see Table 3 In both Panels, the blue dashed line is the optimal reset price in case there is no financial constraint. The green lines limit the inaction region in the model without financial friction: A firm with a pair $(z, p)$ in the interval spanned by the green lines will optimally not adjust its price. The dashed black line is the maximum feasible price of a firm that is financially constrained and adjusting its price (hence, the price where both the financial constraint and demand are binding with equality). The red dashed line displays the optimal reset price in the model with financial constraint. The purple lines limit the inaction region in the model with financial constraint.

constraint is binding, the optimal reset price is given by:

$$
\frac{q^{f c}}{P}=\frac{(1+\mu)}{(1+\mu \xi)} \frac{\theta}{\theta-1} \frac{w}{z}
$$

where $\mu \geq 0$ is the Lagrangian multiplier associated with the financial constraint. This means that the financially constrained firm charges a mark-up over marginal costs $w / z$ that is larger than the mark-up of unconstrained firms whenever $\mu$ is strictly positive. Further, it can be shown that $\mu$ is increasing in productivity whenever $\xi<1 .{ }^{15}$ Accordingly, any increase in productivity has two opposing effects on the financially constrained firms' effective marginal costs: it decreases them via the standard marginal cost channel by reducing the term $w / z$ but it also increases them via the Lagrangean multiplier $\mu$ as the borrowing constraint becomes more painful. Consequently, the elasticity of the financially constrained optimal price $q^{f c}$ with respect to productivity $z$ is smaller than (or at most as large as) the corresponding elasticity of the optimal price without a financial constraint $q^{u c} \cdot{ }^{16}$ Figure 1 illustrates this result graphically: the black dashed line displays price-productivity combinations for which both the financial constraint and the firm's demand schedule is binding. This means that price-productivity combinations exactly on as well as below the black dashed line are associated with a binding financial constraint, price-productivity combinations above the black dashed line imply that the constraint is slack. Note that to the right of the intersection between the black and the blue dashed line, the unconstrained profit maximum can no longer be achieved. For each productivity level, the red line displays the optimal reset price in the model with financial constraint.

With menu costs, firms trade off the gain in revenue from changing the price and the cost of adjusting the price. That gain is determined by the curvature of the profit function, especially in the neighbourhood of the optimal reset price where most firms will be located. The higher the curvature, the larger the profit losses for prices away from the optimal reset prices and, hence the stronger the incentives to pay the menu costs in order to adjust the price. Accordingly, firms will adjust prices more frequently (as a reaction to smaller shocks) if their profit function declines more steeply to the left and to the right of the optimal reset price.

The introduction of the working capital constraint affects the behavior of an individual firm by

\footnotetext{
${ }^{15}$ Henceforth we will assume that this condition is satisfied. See Appendix A.2 for a formal proof.

${ }^{16}$ Appendix A.2 we show that revenues per unit labor employed $q z$ are increasing in productivity. This means that the elasticity of the price changes with respect to productivity changes is less than unity for financially constrained firms, while it is equal to unity for unconstrained firms).
} 
Figure 2: Value function for $z=1$, myopic firms $(\beta=0)$

(a) Model without financial constraint

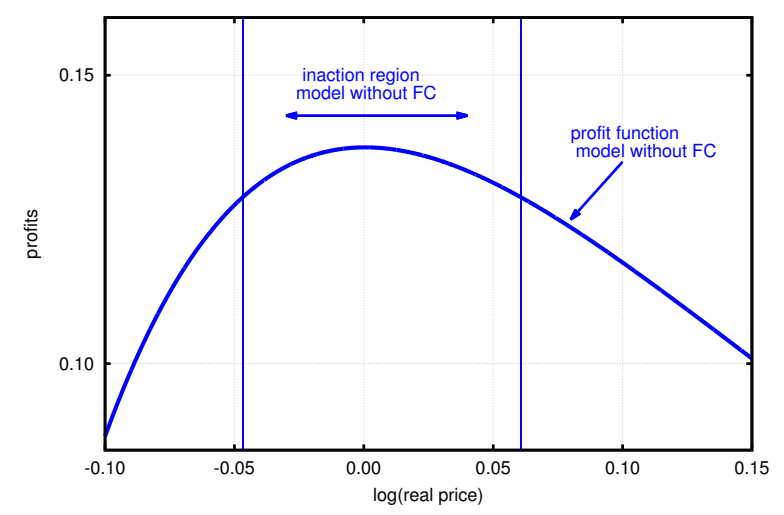

(b) Model with financial constraint

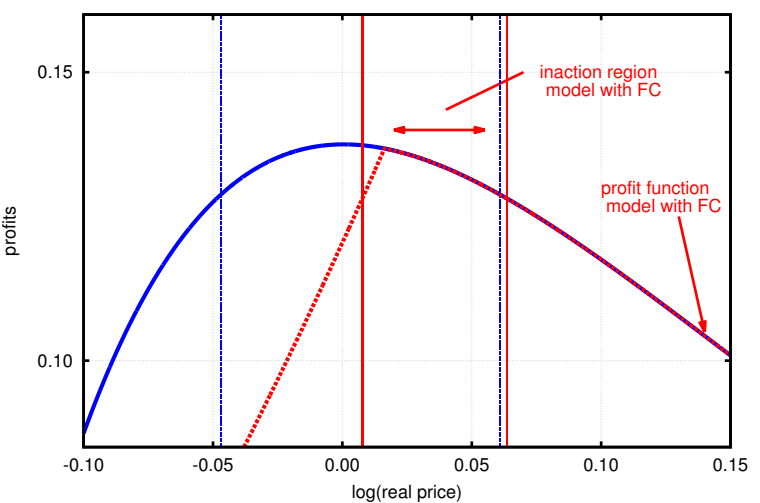

changing the shape of its profit function. This is illustrated in Figure 2 for an exemplary productivity level of $\log (z)=0$. In Panel (a), the concave solid blue line corresponds to the profit of a financially unconstrained firm as a function of the logarithm of its real price $\tilde{p}$. The profit function has its maximum at $\tilde{p}=1$ which corresponds to the optimal price in a world with fully flexible prices. The vertical dashed lines around the maximum mark the inaction region: only firms whose real prices lie outside the inaction region, e.g. due to trend inflation or the realization of exogenous shocks, will adjust their price towards the profit maximum. Firms whose prices are still within the region spanned by the dashed vertical lines will not adjust their price as in that case, the gain in profits would be smaller than the menu-cost. Profit functions for different productivity levels are shown in Figure A.4 in Appendix A.4 The inaction regions for all different price-productivity combinations are also depicted by the area in between the green lines in Figure 1 .

Panel (b) in Figure 2 shows profits in an economy without financial frictions (solid blue) and with financial frictions (dashed red) for the same level of productivity $\log (z)=0$. The red profit function displays a kink at the price where both the financial constraint and demand hold with equality. As shown in the Appendix, this point corresponds to the constrained optimal reset price in the myopic model (for productivity level $\log (z)=0$ ). For prices higher than the price at (or to the right of) the kink, the constrained profit function coincides with the unconstrained one. Since the constrained optimal reset price is higher than the unconstrained optimal reset price, profits fall more quickly when prices increase relative to the optimal reset price. Prices lower than the price at (or to the left of) the kink correspond to binding financial constraints. This means that for smaller prices, firms cannot finance, produce and sell more output. In the special case of non-pledgable sales (a constraint of the form $w h_{i} \leq \xi$ ), the profit function becomes linear in the real price, i.e. the level of output is fixed by the constraint while any decrease in the individual price leads to a proportional decline in unit profits and thus in total profits. Unlike in the unconstrained case, this decline is not offset by higher demand at lower prices. Instead, demand is slack and output is rationed. Since this is very costly to the firm, the red profit function is substantially steeper than the blue profit curve left of the optimal reset price. Both right and left of the constrained optimal reset price, profits decline more steeply than for the constrained price. Consequently, the inaction region is more narrow in this case.

Figure 2 documents that the inaction region is more narrow in the presence of a working capital constraint for a specific productivity level. The magenta lines in Figure 1 show that this holds for all productivity levels respectively. Figure A.4 in the Appendix further establishes that most of the firms face kinked profit functions in an economy with financial constraints. Due to the smaller width of the inaction region, firms have a higher probability to adjust their price in the presence of financial constraints. This effect, however, describes the individual probability of adjusting prices for a given size of a productivity shock and a given distribution of beginning-of-period prices. This price gap distribution, however, changes with the strength of the working capital constraint. Figure 3 shows for average productivity $\log (z)=0$ that the price gap distribution for a model with financial constraints (Panel (b)) is more bunched around the optimal reset price than in the model without financial constraints (Panel (a)). We 
call the fact that the introduction of the financial constraint changes the stationary price gap distribution the distributional effect.

Also, the mode of the price gap distribution is no longer in the center but asymmetrically located towards the lower bound of the inaction region. This reflects the asymmetry in the profit function in Figure 1. This means that firms with negative productivity realizations have a higher probability to adjust their price than firms with positive productivity realizations. Moreover, the asymmetry of the distribution within the inaction region implies that the height and the slope of the distribution at the inaction cutoffs is very different at both ends of the distribution with financial constraints and also different to the respective ones without financial constraints. This will be important for the aggregate implications discussed in Section 4 below.

In Appendix A.4 we show the price gap distributions like the ones in Figure 3 at different productivity levels. This provides a graphical illustration of the distributional effect. On the one hand, the distributional effect is due to the more narrow inaction region itself which makes the inaction region shrink at all productivity levels. On the other hand, this effect is due to the lower elasticity of the optimal reset price with respect to productivity when financial constraints are present. This means, in the model with financial constraints, ceteris paribus, a relatively larger idiosyncratic shock is needed to make the firm adjust its price. To understand this, note that a productivity shock of the same size leaves firms in a position much closer to the optimal price when the slope of the optimal reset price is flat (low elasticity) compared to when it is steep (high elasticity). This is easy to see from Figure 1). As an approximation, one may view these as firms that switch between different productivity levels as shown in the detailed price gap plots in Appendix A.4 ${ }^{17}$ Due to the lower elasticity of the optimal reset price in a world with financial constraints, the inaction regions and optimal prices overlap more across productivity levels in the model with financial constraint compared to the model without financial constraint. Hence, firms that switch between productivity levels exhibit smaller price gaps and adjust prices less often in a world with financial constraints.

Our calibration below documents firms adjust prices less often on average in an economy with compared to without financial frictions. This means that the distributional effect drives the differences in nominal rigidities which can also easily be seen when comparing the left to the right column in Figure A-9 in the Appendix. It is important to note, however, that the calibrated dynamic model still generates that financially constrained firms adjust their prices more often than unconstrained firms within an economy with financial frictions. In fact, as the calibration in Section 3.3 documents, our dynamic model replicates our empirical findings from Section 2 well. The main reason is that the inaction width effect is stronger than the distributional effect for financially constrained firms, so that the probability to adjust prices, conditional on being financially constrained is larger than the probability to adjust prices conditional on being financially unconstrained.

Intuitively, the higher frequency of price changes among constrained compared to unconstrained firms comes from the fact that most of the optimal reset prices correspond to a binding constraint (see Figure 1) and, hence, to a narrow inaction region. At the same time, financially constrained firms tend to exhibit positive price gaps within the inaction region and, hence, do not adjust their prices. The asymmetry of the price gap distribution towards the lower bound of the inaction region intensifies this effect. In order to shed further light on this result, we provide an detailed decomposition of constrained and unconstrained firms by productivity level in Section 3.3 .4 .

From Figure 1, it is easy to see that the presence of financial constraints implies on average higher prices and lower output compared to a situation without financial constraints. This is due to the firms that adjust prices to the constrained optimal reset price which is higher than the one that firms with the same productivity level would choose in an economy free of financial frictions. Obviously, for price adjusting firms, the model implies that firms with a relatively high productivity are more likely to be constrained. The intuition straightforwardly stems from the working capital constraint: a higher productivity level is associated with lower marginal costs and thus, with a stronger relative competitiveness position. Accordingly, high productivity firms will be willing to expand by lowering prices and thus attracting more demand. However, the desired expansion is associated with a higher labor input, a higher wage bill, a higher level of borrowing and a higher likelihood of being constrained. The models proposed by Cooley and Quadrini (2001), Azariadis and Kaas (2012), Buera et al. (2013), Khan and

${ }^{17}$ Given the calibration in the benchmark model, the firms switching between productivity levels make up for the majority (roughly 70 percent) of all price adjusting firms. 
Figure 3: Price-gap distribution

(a) Myopic firms $(\beta=0)$, no financial constraint

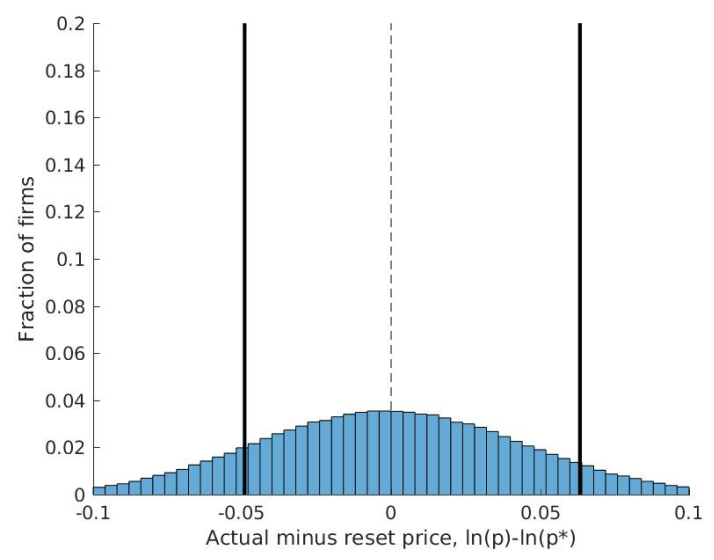

(c) Dynamic model (benchmark), no financial constraint

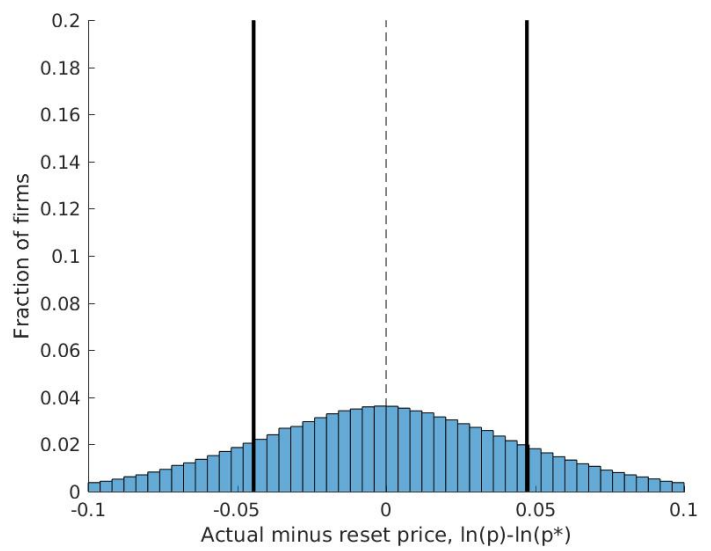

(b) Myopic firms $(\beta=0)$, with financial constraint

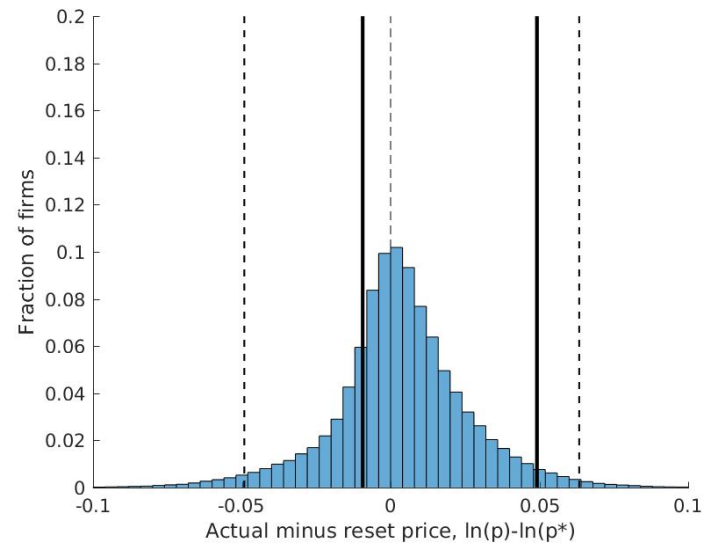

(d) Dynamic model (benchmark), with financial constraint

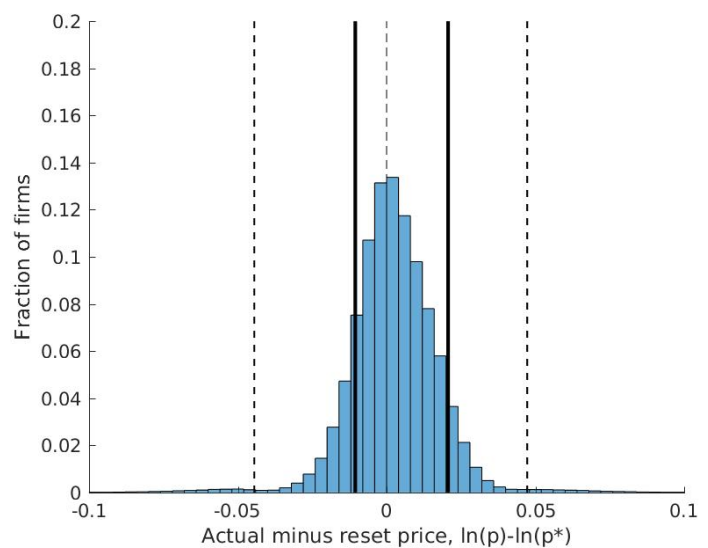

Notes: The histograms display the distribution of the price gap, defined as the actual (pre-adjustment) price minus the optimal reset price, or $\log \left(p_{i}\right)-\log \left(p_{i}^{*}\right)$, where $p_{i}^{*}$ is firm $i$ 's optimal reset price and $p_{i}$ is firm $i$ 's price before price adjustment. The solid vertical lines mark the inaction region for a firm with average productivity (i.e. $\log (z)=0)$ in the model with and without financial constraint, respectively. The dashed line at zero shows the location of the optimal reset price. The dotted lines in Panels (b) and (d) are the same as the vertical solid lines for the 'No FC'-model shown in Panels (a) and (c), respectively.

Thomas (2013), Midrigan and Xu (2014) also predict a positive relationship between the level of idiosyncratic productivity and the likelihood of being constrained - conditional on the firm specific capital stock. In these models, firms receiving a sequence of favourable productivity shocks tend to accelerate the accumulation of capital which, in the long run, enables them to outgrow the credit constraint. This mechanism is absent here as capital is assumed to be fixed.

There are three reasons why we abstract from a more complicated setup than presented here. First, our model already delivers rich predictions about the relationship between productivity and being financially constrained. On the one hand, the prediction that more productive firms are the ones that are financially constrained only applies to firms that optimally choose to adjust their price. On the other hand, among the firms that optimally decide not to adjust the price, the relationship is reversed: relatively less productive firms will be financially constrained. These are firms that draw a negative productivity shock that is large enough to make their financial constraint bind (due to their increased wage bill) but not large enough to drive them out of the inaction region, so they do not find it optimal to adjust the price. ${ }^{18}$ Second, in the dynamic version of our model, Figure 1 documents that both firms with low and high productivity levels will end up being financially constrained even when adjusting the price. Third, as we will show below, the aggregate implications do not depend on whether more productive

\footnotetext{
${ }^{18}$ See Appendix A.2 for a formal proof of these claims.
} 
or less productive firms are likely to be constrained. Instead, the effect of aggregate shocks depends on which firms select into adjustment, which depends on the width of the inaction region, the distributional effect and the asymmetry of the price gap distribution within the inaction region. It is important to not that, as we discussed above, the presence of financial frictions changes the desired price gap distribution for all firms, i.e. for both financially constrained and unconstrained firms.

Figures 1, 2 and 3 display the results of the static model for specific model parameters that align with our benchmark calibration discussed in Section 3.3. These parameters affect the differences between the model with and without financial constraints and therefore the aggregate implications discussed in Section 4. For example, the more symmetric the profits without financial constraints, the larger the effect from introducing asymmetries associated with the financial constraint. In Appendix A.7 we show that a lower value for the demand elasticity $\theta$ increases the symmetry of the profit function of unconstrained firms and makes the profit function flatter and the inaction region wider. In other words, the impact of financial constraints is expected to be larger in industries with lower elasticity of substitutions. Also, when sales can be pledged as collateral as in our benchmark model, the elasticity of the constrained optimal reset price with respect to productivity decreases less compared to a situation in which sales are non pledgable. This will play a role for ability of the model to match the data moments. ${ }^{19}$

\subsection{Dynamic Model}

In the previous section, we have documented that the interaction between financial frictions and the pricing decisions of firms works in both directions. On the one hand, the presence of the credit constraint affects the profit function and thus the policy function of firms by changing the location and the width of the inaction region. The presence of credit constraints also affects the price gap distribution of firms. On the other hand, the optimal pricing decision determines whether the firm will end up facing a binding or a slack financial constraint. In a dynamic set-up with forward looking firms $(0<\beta<1)$, firms now trade-off the effect of their pricing decision on current and expected profits. Unlike in the model with myopic firms, the flex-price optimum in a dynamic economy does no longer necessarily coincide with the maximum of the current profit function. As Figure 1 shows, the optimal constrained and unconstrained reset prices differ in the static and the dynamic model. As a consequence, firms are financially constrained or unconstrained at different productivity-price combinations in both versions of the model. The presence and size of these effects depends on the calibration of the model. Below, we discuss how the calibration affects the policy functions of the dynamic model in detail.

\subsubsection{Calibration and Parametrization}

We assume that time is measured in months which is consistent with the frequency of our data. The elasticity of substitution between individual goods $\theta$ is set to 7.25. This value implies an average markup of prices over marginal costs of about 16 percent which corresponds to the estimate provided by Christopoulou and Vermeulen (2012) for the German manufacturing sector. Producer mark-ups in the German manufacturing sector are relatively small compared to the European average and the U.S. as well as relative to the typical mark-ups in other sectors of the German economy like services (53\%) and construction (20\%). Therefore, the value for the elasticity $\theta$ is higher relative to what is typically used in the macro literature. We discuss implications of the high value of $\theta$ below. Without loss of generality, we assume that $C=1$, so that the $\log$ of aggregate nominal demand is equal to aggregate inflation. ${ }^{20}$ The shock to nominal aggregate demand is calibrated to match the average growth rate and the standard deviation of the month to month growth rate of the seasonally adjusted German manufacturing producer price index between the years 2001 and 2015 , hence we set $\mu=0.001$ and $\sigma_{\eta}=0.002$. In addition, we set the discount factor $\beta$ at $0.96^{1 / 12}$ which is a value commonly used in the literature. Collateralizable capital is also normalized to $\bar{k}=1$.

\footnotetext{
${ }^{19}$ We have also conducted robustness with respect to decreasing returns and different values of the super-elasticity using the Kimball (1995) aggregator. Both, more decreasing returns and higher values for the super-elasticity are associated with flatter optimal price schedules for unconstrained firms, flatter in the sense that firms respond less to idiosyncratic shocks. As a consequence, the difference between a world with and without financial constraint is lower. However, all these models performed worse in matching the micro data moments when compared to the benchmark with CES demand schedule and constant returns.

${ }^{20}$ Recall that aggregate demand is defined by $S_{t}=P_{t} C_{t}$. With $C_{t}=1, S_{t}=P_{t}$ for all $t$.
} 
The remaining four model parameters - the menu cost $f$, the autocorrelation $\rho_{z}$ and the standard deviation $\sigma_{\epsilon}$ of the idiosyncratic productivity process and the coefficient shaping the borrowing limit $\xi$ are calibrated such that the model simultaneously matches four central moments: (i) the fraction of firms that adjust prices each month $P(\Delta p)$, (ii) the fraction of firms that adjust prices upwards each month $P(\Delta p>0)$, (iii) the fraction of firms that are financially constrained each month, $P(F C)$, and (iv) the median percentage price change conditional on firms increasing their price. All moments are from our firm-level evidence documented in section 2, only moment (iv) is taken from Vermeulen et al. (2012). The criterion function used to calibrate the four model parameters $\left(f, \rho_{z}, \sigma_{\epsilon}, \xi\right)$ is the sum of squared deviations of the moments in the simulated model from those in the data. The respective values of the distance measure are displayed in Table 3.

Our benchmark model delivers the moments that minimize our criterion function. The resulting parameter values and moments are documented in the column 'Benchmark' in Table 3 . The menu cost is 1.02 percent of the average wage bill, a value that is in the ballpark of fix costs used in previous literature (see e.g. Midrigan, 2011). The standard deviation of idiosyncratic productivity shocks is equal to 4.34 percent. This is a relative high value given the relative small size of the menu cost and implies that idiosyncratic shocks are relatively large compared to the aggregate nominal shocks. This stems from the fact the median size of monthly price changes in German manufacturing is very large - roughly $2 \%$ per month, as compared to the average yearly inflation rate in Germany of about $2 \%$.

The persistence of idiosyncratic shocks is relatively low (a monthly value of 0.41 ). ${ }^{21}$ The persistence of the productivity shocks is important in the model, since firms take into account that their position in the productivity-price diagram will automatically change in the following months. A smaller persistence means quicker reversion to the mean $\log (z)=0$. We will discuss the implications further below and address robustness in section 4.3 .

To approximate the value and policy functions we resort to value function iteration on a discretized state space. The latter has two dimensions - one with respect to idiosyncratic productivity $z_{i}$ and the other for the individual beginning-of-period relative real price $p_{i} / P$ conditional on current-period's realization of aggregate inflation (entering through the aggregate price level $P$ ). ${ }^{22}$ For certain parameter constellations, the value function is potentially no longer single peaked for all price-productivity combinations, since firms face a strong trade-off between optimizing current and future expected profits. ${ }^{23}$ This means that the optimal reset price is not necessarily unique in certain cases so that a firm may be indifferent between the optimal constrained and unconstrained price. Also, the inaction thresholds may not be unique in this case and the inaction region is no longer continuous. While we are not aware of any theoretical remedy to these issues, we check numerically during our value function iteration that these cases do not apply for our baseline calibration and different parameterizations presented here. ${ }^{24}$

\subsubsection{Benchmark Model}

Panel B in Table 3 displays the values of several moments implied by our benchmark model. At the bottom, additional non-targeted moments show that the benchmark model replicates median price inand decreases as well as the overall fractions of upward and downward price adjustment of financially constrained and unconstrained firms well. To further discipline the comparison between the theory and our empirical results, we run the same regressions as the baseline in Section 2, however, on the simulated data generated by the benchmark model. The Panel "Regression coefficients" reports the regression

\footnotetext{
${ }^{21}$ In Appendix A.7 we report robustness with respect to persistence of the idiosyncratic shocks.

${ }^{22}$ See Appendix A.3 for further details on the numerical solution and the simulation of impulse responses.

${ }^{23}$ Notice that precisely for this reason the price policy function in the dynamic model shown in Panel (b) of Figure 1 exhibits a discrete jump at productivity level around $\log (z)=-0.11$.

${ }^{24}$ In particular, when the firm would be indifferent between two prices, we assume that it would choose the unconstrained price. However, this never happens in any of our simulations, most likely due to the fact that we have discretized the state space. In addition, we check whether for any given productivity level $z$ there are no more than two inaction thresholds, so that there is only one inaction region for any given productivity level. This is also always satisfied in any of our simulations. To further deal with this issue, we restrict the productivity grid to lie in the range $\left[-2 \sigma_{z}, 2 \sigma_{z}\right]$. This allows us to make sure that the value function is single peaked for any productivity/price pairs for all parameter combinations considered when matching the moments in the calibration exercise. As shown in Appendix A.7 the numerical results of the truncated model are not distinguishable from the benchmark model and the calibrated parameters are very similar. The reason is that this range is not restrictive at all as it contains 95 percent of all firms in the simulated stationary distribution. We therefore conclude that potential double peaks of the value function for some productivity levels is not an issue for our main quantitative results.
} 
Table 3: Calibration

\begin{tabular}{|c|c|c|c|c|}
\hline & $\operatorname{Data}^{a}$ & $\begin{array}{l}(1) \\
\text { Benchm }\end{array}$ & $\begin{array}{l}(2) \\
\text { No FC }\end{array}$ & $\begin{array}{l}(3) \\
\text { No FC recal. }\end{array}$ \\
\hline \multicolumn{5}{|l|}{ A. Parameter values } \\
\hline \multicolumn{5}{|l|}{ Assigned } \\
\hline$\theta$ & & 7.25 & 7.25 & 7.25 \\
\hline$\beta$ (annualized) & & 0.96 & 0.96 & 0.96 \\
\hline$\mu$ (percent) & & 0.10 & 0.10 & 0.10 \\
\hline$\sigma_{\eta}($ percent $)$ & & 0.20 & 0.20 & 0.20 \\
\hline$C$ & & 1 & 1 & 1 \\
\hline$k$ & & 1 & 1 & 1 \\
\hline$\Delta p_{\text {grid }}$ (percent) & & 0.01 & 0.01 & 0.01 \\
\hline$\Delta z_{\text {grid }}($ percent $)$ & & 0.09 & 0.09 & 0.09 \\
\hline \multicolumn{5}{|l|}{ Calibrated } \\
\hline$f$ (percent of wages) & & 1.02 & 1.02 & 1.47 \\
\hline$\sigma_{\varepsilon}($ percent $)$ & & 4.34 & 4.34 & 4.34 \\
\hline$\rho_{z}$ & & 0.41 & 0.41 & 0.41 \\
\hline$\xi$ & & 0.35 & - & - \\
\hline
\end{tabular}

\section{B. Moments}

Used in calibration ${ }^{b}$

\begin{tabular}{|c|c|c|c|c|}
\hline 1. $P(\Delta p)$ & 0.22 & 0.20 & $\underline{0.31}$ & 0.22 \\
\hline 2. $P(\Delta p>0)$ & 0.12 & 0.15 & $\underline{0.17}$ & $\underline{0.12}$ \\
\hline 3. $P(F C)$ & 0.32 & 0.32 & $\underline{0.00}$ & $\underline{0.00}$ \\
\hline 4. Median price change & 0.02 & 0.02 & 0.07 & $\underline{0.07}$ \\
\hline
\end{tabular}

Regression coefficients
5. $\hat{\beta}_{F C}^{\text {cons }}$
6. $\hat{\beta}_{F C}^{u p}$
$-0.04$
$-0.11$
7. $\hat{\beta}_{F C}^{\text {down }}$
0.01
0.01
0.03
0.09

Additional Moments

$\begin{array}{lllll}\text { 8. Median price incr. } & 0.02 & 0.01 & 0.06 & 0.07 \\ \text { 9. Median price decr. } & 0.02 & 0.03 & 0.07 & 0.07 \\ & & & - & - \\ \text { 10. } P(\Delta p=0 \mid F C) & 0.75 & 0.72 & 0.69 & 0.78 \\ \text { 11. } P(\Delta p=0 \mid U C) & 0.80 & 0.84 & - & -\end{array}$

Notes: Values refer to monthly frequency unless indicated otherwise.

${ }^{a}$ Data on median price changes of German manufacturing producer prices are from Vermeulen et al. (2012). The remaining data moments come from the Ifo panel data, for details see the empirical section.

${ }^{b}$ The benchmark model in column (1) is calibrated on all empirical moments listed. Model (2) has the same calibration as the benchmark model but removing the financial constraint. Model (3) is based on the parameters of the productivity process as calibrated in the benchmark model but on a recalibrated menu cost. Moments not included in the criterion function in the calibration are underlined. 
coefficients on the dummy variable indicating wether a firm is financially constrained or not. As can be seen, becoming financially constrained makes firms adjust prices more often (row 5). As in the data, our model implies a significantly higher frequency of both upward and downward adjustments (rows 6 and 7). As discussed in Section 3.2, the main effect responsible for this is the more narrow inaction region in the area where the optimal reset price is associated with a (just) binding working capital constraint.

Panel (b) of Figure 1 shows the price policy function for the benchmark model. As in the static economy described in section 3.2 , the red line reflecting the optimal reset price becomes flatter around the mean productivity level $\log (z)=0$. However, the dynamic optimal reset price differs from the static optimal reset price, in particular in the neighbourhood of the mean productivity $\operatorname{level}$ of $\log (z)=0$. The reason is that in the dynamic model, the firm trades off the maximization of current profits against operating near the static profit maximum and avoiding payments of menu costs in the future. In doing this, it takes into account expected productivity realizations. In particular, if the autocorrelation of idiosyncratic productivity is relatively low, the firm rationally anticipates that, in the following periods, its productivity will quickly converge towards the mean $\log (z)=0$. Accordingly, in the case of a positive draw $\log (z)>0$, it is optimal to set a price which is lower than the one maximizing current profits since, by doing this, future deviations from the profit maximum and the associated payments of menu costs can be avoided for a longer period of time. The same but with opposite sign happens in the case of a negative shock $\log (z)<0$. However, if the level of idiosyncratic productivity deviates sufficiently strongly from its mean, i.e. $\log (z)>>0$ or $\log (z)<<0$, foregone profits today become much more important relative to possible future menu costs. Accordingly, for $z$-values sufficiently far away from its mean, the optimal reset price is again very close to the one that maximizes the current profit function, i.e. the static optimal reset price.

Moreover, for a higher autocorrelation in idiosyncratic productivity, the optimal reset price around $\log (z)=0$ becomes steeper, ${ }^{25}$ thus, lying closer to the price that maximizes current profits. The reason is that in this case, the firm rationally expects to retain its current productivity level over an extended period of time. Accordingly, possible deviations from the static profit maximum and the associated payments of menu-costs are pushed further into the future and thus, become much less important than maximizing current profits.

Note that the effects described above break the direct link between productivity, output and being financially constrained. This then explains that the dynamic benchmark model generates a ratio of sales of constrained versus unconstrained firms of about one which is close to the one observed in the data (row 12 in Table 3). These effects become smaller (i.e. the region in which the constraint is not binding spans a wider interval of productivity levels) when autocorrelation of productivity shocks is higher and, hence, mean reversion is slower (see Panel (a) in Figure A-12 for policy plots whit $\rho_{z}=0.9$ ). The effects are stronger if sales are not pledgable, since the constrained optimal reset price falls even less with increasing productivity (see Panel (b) in Figure A-12). Our benchmark model therefore replicates the cross-sectional moments in our data in the best possible way. Tables A-16 and A-17 in the Appendix show robustness of our calibration results to various model specifications.

\subsubsection{The Role of Financial Frictions for the Overall Price Adjustment}

In addition to our benchmark model, Table 3 exhibits the parameters and output from the model without financial frictions. In the first version (column (2)), we keep all parameters from the benchmark and set $\xi$ such that the financial constraint never binds. Without financial frictions, nominal rigidities decrease, i.e. firms adjust their price more often (31 percent versus 20 percent in the model with frictions and the data). They also change prices by more both upwards and downwards. We can understand these effects from the price gap distributions which are displayed in Panels (c) and (d) in Figure 3 . These distributions exhibit similar differences between the model with and without financial frictions as the static model discussed in section 3.2. As we have discussed for the static model, the smaller width of the inaction region in the model with financial constraints makes every single firm reset prices more often when financially constrained. However, the distributional effect changes the typical position of every single firm in the productivity-price space when financial frictions are present. In particular, the price gap distribution is less dispersed in the presence of the financial constraint which decreases the probability to reset the price if menu costs stay the same. For the comparison of an economy with compared to without

\footnotetext{
${ }^{25}$ See Panel a) in Figure A-12 in the Appendix for the optimal price policy function for $\rho_{z}=0.9$. With higher persistence the value function is always single-peaked and there is no discrete jump in the policy function.
} 
Table 4: Decomposition of price adjustment in the benchmark model with financial frictions

\begin{tabular}{lcccc}
\hline & \multicolumn{2}{c}{$\mathrm{U}$} \\
& $\mathrm{UC}$ & & $\mathrm{FC}$ \\
\cline { 2 - 5 }$Z$ & $P(\Delta p \neq 0 \mid Z, X)$ & $P(Z \mid X)$ & $P(\Delta p \neq 0 \mid Z, X)$ & $P(Z \mid X)$ \\
\hline high product. & 7.88 & 27.74 & 68.81 & 19.26 \\
mid product. & 14.27 & 58.16 & 6.44 & 33.66 \\
low product. & 42.51 & 14.10 & 27.17 & 47.07 \\
\hline$P(\Delta p \neq 0 \mid X)$ & \multicolumn{3}{c}{28.21} \\
\hline
\end{tabular}

Notes: This table shows the probabilities of price adjustment conditional on financial constrained status and conditional on productivity level. FC refers to financially constrained, $\mathrm{UC}$ to unconstrained firms. Denote by $X=F C, U C$ the financial constrained status. Then the overall price adjustment, conditional on $X$, is computed as $P(\Delta p \neq 0 \mid X)=\sum_{Z} P(\Delta p \neq$ $0 \mid Z, X) P(Z \mid X)$.

financial frictions, the second channel dominates. Moreover, smaller inaction bounds in the presence of financial frictions imply that firms typically adjust their prices by relatively smaller amounts.

The second model without financial constraints keeps the productivity process constant compared to the other model versions, but recalibrates the menu cost to match the percentage of price adjusters in our data (column (3) in Table 3). Also in the recalibrated version of the model without financial constraints, the intensive margin of price adjustment is too large compared to the respective moments in the data. When recalibrating the model without financial frictions, matching the empirical price adjustment probability of $20 \%$ means that the menu cost increases. This represents the mirror image of the above result: The presence of financial frictions increases nominal rigidities.

\subsubsection{Why Do Financially Constrained Firms Adjust More Often Than Unconstrained Firms On Average?}

As discussed in Section 3.2 above, our model predicts both the fact that the presence of financial friction increases nominal rigidities and the fact that financially constrained firms adjust prices more often than unconstrained firms in a world with financial frictions. While we have just argued that the distributional effect drives the first phenomenon, the inaction width effect now dominates the second fact that is also reflected in our empirical findings. Below, we decompose the overall effect for financially constrained and unconstrained firms, respectively, by productivity level. This exercise is useful because it reveals that the relative strength of the inaction width and the distributional effect is not uniformly distributed across productivity levels.

Table 4 displays the probabilities of price adjustment conditional on being financially constrained or unconstrained $(X=F C, U C)$ and conditional on three productivity levels $(Z)$ : low, middle and high. ${ }^{26}$ Low productivity refers to productivity levels below the first quartile of the productivity distribution, intermediate productivity refers to productivity levels within the first and the third quartile, and high productivity refers to productivity levels above the third quartile of the productivity distribution. This means that low and high productivity levels each contain 25 percent of all firms in the productivity distribution and intermediate productivity levels contain 50 percent of all firms. One can then decompose the overall price adjustment probability of constrained and unconstrained firms into $P(\Delta p \neq 0 \mid X)=$ $\sum_{Z} P(\Delta p \neq 0 \mid Z, X) P(Z \mid X)$.

First, consider the probabilities of price adjustment $P(\Delta p \neq 0 \mid Z, X)$. For financially constrained firms, the probability to adjust prices conditional of productivity $P(\Delta p \neq 0 \mid Z, F C)$ is u-shaped in the productivity level. 68.81 percent of the firms that have both high productivity realizations and are financially constrained firms adjust their prices. Most of these price changes are price decreases (not shown). In contrast, only 6.44 percent of the financially constrained firms with intermediate productivity levels adjust their price. For low productivity levels, the probability of price adjustment for financially

\footnotetext{
${ }^{26}$ Table A-11 in the appendix shows the underlying joint probability distribution by productivity levels and financial constraint status, as well for price increases and decreases separately.
} 
constrained firms increases again to 27.17 percent. Most of these price changes are price increases (not shown). For financially unconstrained firms the probability to adjust prices conditional on productivity $P(\Delta p \neq 0 \mid Z, U C)$ is decreasing in productivity. 7.88 percent of unconstrained firms with high productivity levels adjust their price, while 42.51 percent of unconstrained firms with low productivity levels change their price. This means that for high productivity levels, the inaction width effect relative to the effect on the price gap distribution has to be relatively stronger for the financially constrained firms than for unconstrained firms. In contrast, the opposite is true for intermediate and low productivity levels. For high productivity levels, most firms that adjust are financially constrained. For low and intermediate productivity levels, unconstrained firms adjust prices more often than constrained firms. Note that price adjustment of all firms is very low in general for intermediate productivity. In this productivity range, the distributional effect is very strong (Figure A-9 documents this). For low productivity, the price adjustment of constrained firms is lower than that of constrained firms, but is still substantial. This can be understood from the asymmetry of the optimal reset price towards the lower bound of the price gap distribution. Firms towards this lower bound tend to be financially constrained. For these firms, the very narrow inaction region towards the lower bound buffers parts of the strong distributional effect.

Second, note that firm composition is important to understand the overall adjustment probabilities of financially constrained and unconstrained firms. In fact, the conditional distribution of productivity levels differs fundamentally between financially constrained and unconstrained firms. For unconstrained firms the conditional distribution looks still very similar to the unconditional probability distribution (in percent from low to high productivity: 25-50-25 versus 14-58-28, see column three in Table 44. Hence, 58 percent of the unconstrained firms are located in intermediate productivity levels where their conditional probability of adjustment is relatively low and their overall probability of adjustment is mainly driven by these intermediate productivity firms. The conditional distribution of productivity levels looks very different for financially constrained firms (in percent from low to high productivity: 47-34-19, see column five in Table 4. One can show that the probability to be financially constrained is generally decreasing in productivity (not shown). And, almost half of the financially constrained firms have a low productivity realization. As for these firms price adjustment is still substantial and it is very high for the high productivity constrained firms, the overall price adjustment for financially constrained firms exceeds the probability of price adjustment of unconstrained firms. ${ }^{27}$

\section{Aggregate Implications}

In this section, we study the implications of aggregate nominal demand shocks on the fraction of price changes, inflation and output. Due to the partial equilibrium nature of our model, one can best view this exercise as the response of a single sector to an aggregate nominal shock or the response of a small open economy to a sudden shift in the nominal value of demand from the rest of the world (e.g. due to a monetary impulse abroad). To study the relative contribution of the financial friction, respectively, we compare the responses for our benchmark model with a counter-factual scenario in which we shut down the financial constraints (our model (2) in Table 3). For details on how impulse responses are constructed, see Appendix A.3.

\subsection{Shocks to Nominal Aggregate Demand}

Figure 4 shows the response of the fraction of firms that change prices to a positive one-standard deviation shock to nominal demand. In the chart, panel (a) depicts the case of an expansionary disturbance while panel (b) refers to a contractionary shock. As can be seen, the presence of financial frictions substantially increases the responsiveness of the share of price adjusting firms relative to the standard menu cost model without financial frictions. The difference in the response of the fraction of price adjusting firms is mainly due to the model-specific shape of the price gap distribution. As discussed by Midrigan (2011), the probability mass concentrated at the lower and upper inaction bounds and the slope of the distribution function in the neighbourhood of those bounds is particularly important.

In a demand expansion, the price gap distribution shown in Figure 3 shifts to the left ${ }^{28}$. Changes in

\footnotetext{
${ }^{27} \mathrm{~A}$ similar decomposition can be made with price decreases and increases, respectively, which we have omitted for space considerations.

${ }^{28}$ Figure A-10 in the Appendix illustrates this shift
} 
Figure 4: Fraction of price changes, all firms

a) Positive nominal demand shock

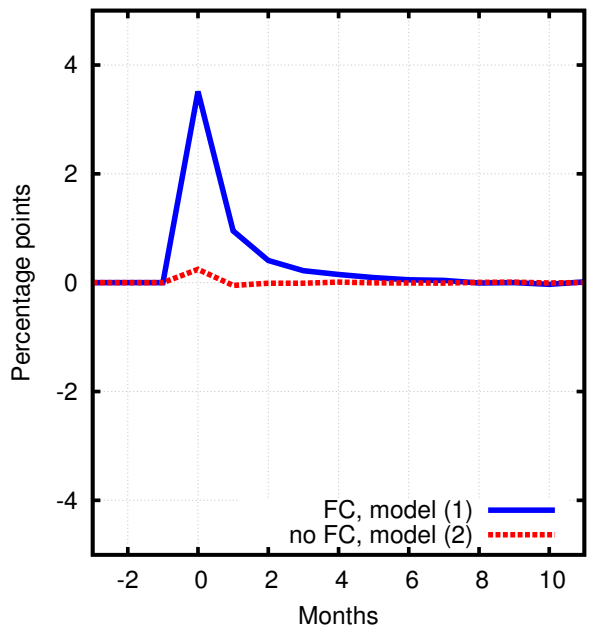

b) Negative nominal demand shock

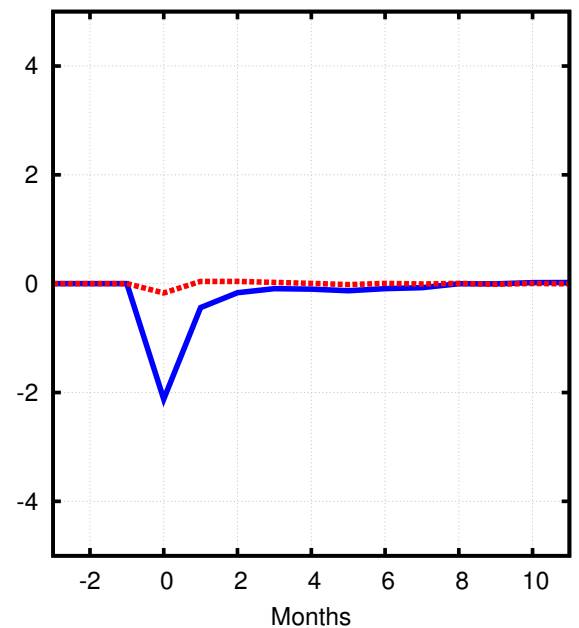

both the intensive and extensive margin of prices refer to changes in the distribution to the left and to the right of the inaction thresholds. Absent financial constraints, the distribution shifts symmetrically. More firms adjust their prices upwards while less firms adjust downwards. Due to the near symmetry of the distribution, the increase in the fraction of firms increasing their price almost offsets the decrease in the fraction of price reductions. Therefore, the overall fraction of price changes reacts only very mildly to aggregate shocks. As noted in Section 3.2 the presence of financial constraints implies an asymmetric price gap distribution such that the mass is not concentrated in the center of the inaction region and such that the slope at the left inaction threshold is higher than the slope at the right inaction threshold. This means that the increase in the number of firms that adjust prices upwards is stronger than the drop in the number of firms who adjust prices downwards after a positive shock. Hence, the fraction of price changes goes up. Due to this asymmetry, the frequency of price adjustments decline after a negative demand shock (but the effect is smaller compared to the positive shock). These changes in the composition of price adjusting firms are at the heart of the so called selection effect emphasized in Golosov and Lucas (2007), Midrigan (2011) and others.

Figure 5 depicts the responses of inflation and output, averaged over all firms. Average inflation is defined as the monthly percentage change of the average price $\bar{P}_{t}=\sum_{i=1}^{N} p_{i t}$, where $N$ is the number of firms. Similarly, average output is $\bar{y}_{t}=\sum_{i=1}^{N} y_{i t}$. As can be seen, the presence of menu costs induces some degree of non-neutrality of the aggregate shock - the response of average inflation is weaker than the nominal shock itself which translates into a non-zero reaction in average output. This nonneutrality substantially increases when firms are subject to the working capital constraint. The latter attenuates the reaction of average inflation by about one third while almost doubling the response of output. To understand these results, Appendix A.5 decomposes the impact response of average inflation and output into changes in the extensive and intensive margin. It is evident from that both models' response of inflation is almost entirely driven by the extensive margin (see Tables A-12 and A-13). In the economy without financial frictions, the extensive margin of price increasers, whose number increases, contributes almost equally strong to average inflation as the extensive margin of price lowering firms, whose number declines. In our benchmark model, the contribution of the extensive margin of price increasers is much larger as the rise in their fraction is significantly stronger than the drop in the number of price decreases as was already discussed above. The inaction regions and price gap distribution of firms at different productivity levels are similarly affected by the introduction of the credit constraint ${ }^{29}$. Thus, the behavior of the extensive margin in our benchmark model is not only driven by firms in regions where the maximum of the value function is associated with a binding working capital constraint, but

\footnotetext{
${ }^{29}$ In particular, we can show that firms with below average productivity $(\log (z) \in[-0.10,-0.03])$, medium productivity $(\log (z) \in[-0.03,0.03])$ and above average productivity $(\log (z) \in[0.03,0.1])$ provide an almost equal contribution to the change in the extensive margin. These price gap distributions are available upon request from the authors.
} 
also by firms for which the corresponding maximum implies a slack financial restriction.

However, although the fraction of price adjusters in the benchmark model exhibit a much stronger positive reaction than the corresponding fractions in the economy without financial frictions, the benchmark model implies a weaker reaction of average inflation. This is due to the smaller steady-state magnitude of price changes in the benchmark economy which more than compensates the substantially more pronounced selection effect compared to the model without financial constraints. In fact, a positive aggregate nominal demand shock reduces average price changes even further in the economy with financial frictions, while it increases average price changes in the economy without financial frictions. The reason is that the price gap distribution is more compressed with more mass at the lower bound of the inaction region (see panel (d) in Figure 3). As a result of this distributional asymmetry, a large mass of firms increase prices by very small amounts as their prices lie only slightly below the optimal reset price. Since many more firms now increase prices by very little, the average price increase falls. Likewise, the mass of firms with small price decreases now declines, since these firms now optimally choose not to adjust their price. This results in an rise of the average price decrease. However, the latter effect is weaker as the mass at the inaction cutoff below the optimal reset price is smaller than to above. On the contrary, the fatter-tailed and more evenly dispersed price gap distribution in the economy without financial frictions is associated with an amplification of upward and an attenuation of downward price adjustments in the case of an expansionary aggregate shock. Put differently, surprising changes in the aggregate nominal price $P_{t}$ are passed through to the average nominal price to a larger extent in the economy without financial frictions.

Finally, to understand why the benchmark model implies a relatively stronger output reaction to nominal aggregate shocks, note that the two models are identical regarding the economy wide demand schedule. The latter is governed by only one parameter, the demand elasticity $\theta$, and one exogenous variable, the aggregate nominal price level $P_{t}$. Moreover, the financial friction leaves the demand side of the economy completely unaffected. Hence, the aggregate shock shifts the demand schedule by exactly the same amount in each of the two models. Along identical demand curves, a weaker inflation increase can be only associated with a more pronounced increase in output and vice versa. The implied flattening of the supply curve means that financial constraints alter a central trade-off faced by the central bank: In order to engineer an increase in inflation by a certain amount the monetary authority needs to generate larger changes in nominal demand. At the same time, it needs to take into account that larger changes in nominal demand induce even stronger responses of average real output.

\subsection{Comparison to other models of price stickiness}

In this section, we compare the response of our partial equilibrium economy with a fixed menu cost to one with two different sources of price rigidity: convex price adjustment costs (Rotemberg (1982)) or a Calvotype nominal friction, i.e. an exogenous probability of being allowed to adjust prices (Calvo (1983)). While the aggregate supply curve becomes flatter in our benchmark economy, the introduction of our financial constraint makes the aggregate supply curve steeper in the presence of Rotemberg adjustment costs or Calvo frictions. Table 5 compares the on impact impulse responses to an aggregate positive nominal shock of the benchmark menu cost model to the Calvo model and the Rotemberg model. In contrast to the benchmark menu cost model, in the Calvo and Rotemberg model the inclusion of our borrowing constraint weakens the response of average output while amplifying (or leaving unchanged in the Calvo model) the reaction of average inflation to aggregate nominal demand shocks. ${ }^{30}$

From this, one can draw two main conclusions. First, the precise modeling of price stickiness is of crucial importance when discussing the effects of working capital constraints. Second, the qualitative difference between the menu-cost model and the Rotemberg/Calvo specifications suggests that allowing for an endogenous probability of price adjustment with the associated selection effect is of primary importance. Recall that, in the presence of menu costs, the introduction of a credit constraint affects the average fraction of firms that change prices as well as - via altering the strength of the selection effect the intensive margin of price adjustment. In the Rotemberg model the fraction of price adjusting firms is always equal to $100 \%$, while price adjusters are selected randomly with an exogenously fixed probability in the Calvo model. Hence, in these frameworks, there is no link between the presence of a financial

\footnotetext{
${ }^{30}$ See Appendix A.6 for details of the models, the calibration and Figure A-11 for full impulse-responses regarding the comparison of the three sources of price rigidity.
} 
Figure 5: Average inflation and output

(a) Average prices

a) Positive nominal demand shock

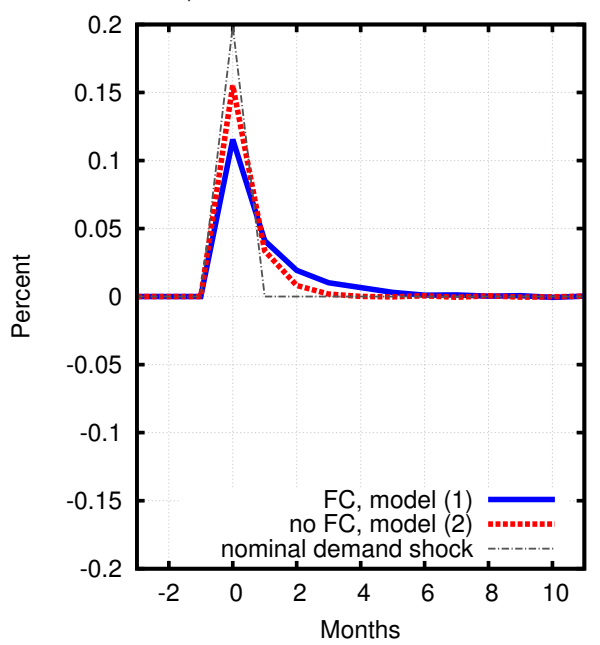

b) Negative nominal demand shock

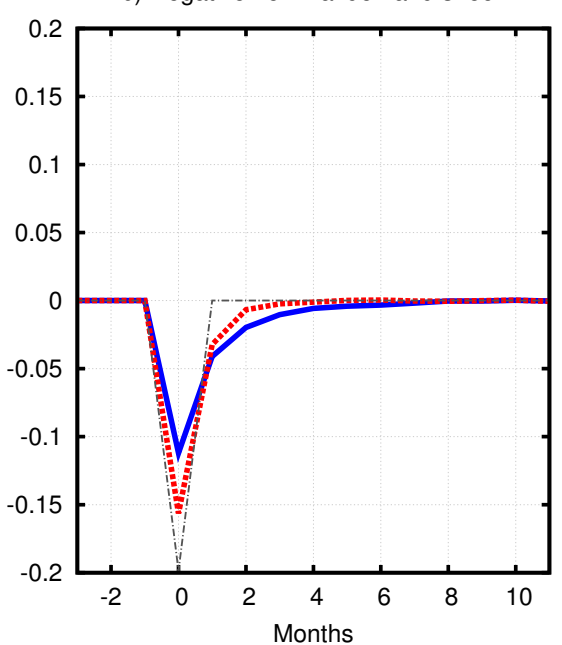

(b) Average (real) output

a) Positive nominal demand shock

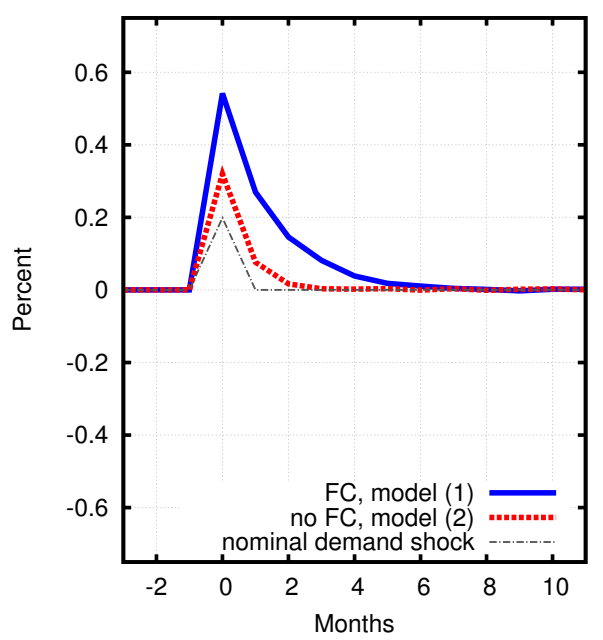

b) Negative nominal demand shock

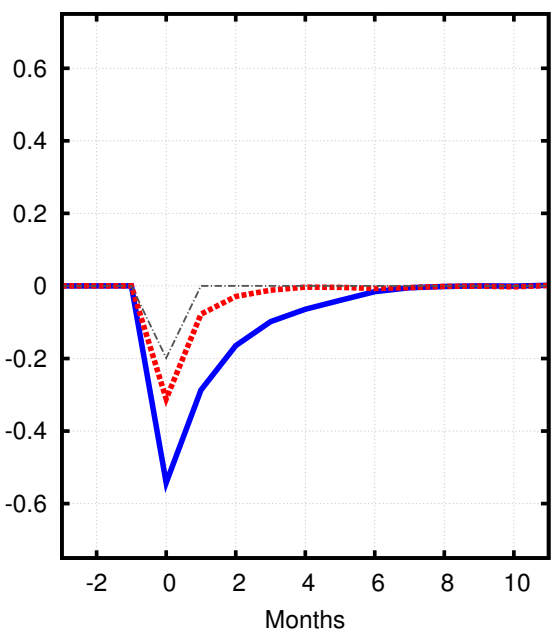


Table 5: On impact impulse responses of aggregate variables, model comparison

\begin{tabular}{lllllll}
\hline & \multicolumn{2}{c}{ Fraction of price adj. } & \multicolumn{2}{c}{ Av. inflation } & \multicolumn{2}{c}{ Av. output } \\
& FC & No FC & FC & No FC & FC & No FC \\
\hline Benchmark & 3.41 & 0.23 & 0.12 & 0.15 & 0.53 & 0.33 \\
Calvo & 0.00 & 0.00 & 0.04 & 0.04 & 0.71 & 1.15 \\
Rotemberg & 0.00 & 0.00 & 0.09 & 0.04 & 0.55 & 1.15 \\
\hline Notes: This table shows the on impact impulse responses to a positive aggregate nominal demand shock. We just show the on
\end{tabular}

impact responses because the dynamics are qualitatively very similar across models. For dynamics of the impulse responses, see Appendix. The label 'FC' refers to the simulated model with financial constraints, 'no FC' refers to the model without financial constraint (leaving all other parameter values constant).

constraint on the one hand and the extensive margin of price adjustment and a selection effect on the other.

While the dynamics in the Rotemberg model and Calvo model are similar, the underlying mechanism is inherently different. ${ }^{31}$ Since price adjusting firms are randomly selected in the Calvo model and the probability of price adjustment is exogenous, there exists no interaction between financial constraints and the composition of price adjusting firms. Furthermore, the firms allowed to change prices completely pass through permanent increases in nominal aggregate demand to their individual prices, irrespective of whether they are financially constrained or not. As a consequence, the inflation response to aggregate nominal shocks is independent of whether firms face a borrowing constraint or not. This can be seen in Table 5. The difference between the economy with and the one without financial frictions then only concerns aggregate output and stems solely from the behavior of firms who are not allowed to adjust prices in the period of the shock and its immediate aftermath. In particular, in the presence of our borrowing constraint, the non-adjusters that face a binding credit restriction will be forced to produce off their demand schedule and ration output. The fraction of such firms tends to increase when positive aggregate nominal shocks hit the economy and the fraction of price adjusters cannot adjust at the same time. The opposite happens for negative demand shocks. These time varying output losses due to rationing dampen the output response relative to a Calvo-economy without financial frictions.

In the case of Rotemberg adjustment costs, firms facing a binding financial constraint pass changes in the aggregate price level completely through to their individual prices. The reason is that the borrowing restriction acts as a capacity limit. As soon as "full capacity" is reached, the firm-specific supply curve is approximately vertical and any further demand increases can only be accompanied by raising prices. In contrast, the degree of pass-through is incomplete for unconstrained firms. Accordingly, as long as the fraction of financially constrained firms is larger than zero, the pass-through of economy-wide nominal demand shocks to the average price level will be stronger relative to an economy without financial frictions. Consequently, the response of average output will be lower in an economy with compared to one without financial frictions. To summarize, price-adjusting firms in the Calvo model pass-through nominal shocks completely independent of their financial status, but ration output when financially constrained. In the Rotemberg model, no firm rations output, but financially constrained firms pass through nominal shocks to a larger extent than unconstrained firms, as shown in the appendix.

\subsection{Robustness}

We have conducted a wide variety of robustness checks for two purposes. First, to understand which parameters/model elements are important to qualitatively and quantitatively explain the moments from the micro data we have documented in the empirical section of this paper. Second, whether and how the aggregate implications are affected by different parameter values. Here we just summarize the main findings. The robustness section in Appendix A.7 reports detailed tables on the calibrated parameter values, the implied moments, the model fit to the micro data, and the implied on impact impulse responses to an aggregate demand shock for all model versions considered here.

Myopic firms. A model with myopic firms $(\beta=0)$ is instructive because it shows whether considering a dynamic model is important in order to match the micro evidence documented in the empirical section

\footnotetext{
${ }^{31}$ See also Appendix $\mathrm{A} .6$ for a more detailed discussion.
} 
of this paper and how important that is for the aggregate implications of the model. Both regarding the micro moments and the aggregate implications, the model is very similar to the dynamic benchmark model. However, the model with myopic firms displays a lower fit to the targeted micro moments. Regarding the pricing implications, the model with myopic firms predicts that financially constrained firms adjust prices more often than unconstrained firms in line with the benchmark model. However, the myopic model model only predicts that financially constrained firms adjust prices more often downwards but not upwards. The reason was already mentioned in Section 3 above: The myopic model implies that more productive firms are more likely to be financially constrained, i.e. those firms that have strong incentives to decrease their prices.

Persistence of the idiosyncratic productivity shock. The persistence of the shocks are important to explain the moments in the data, in particular the relative price adjustment frequencies of financially constrained and unconstrained firms. When the persistence of the shock is very high, the dynamic model behaves very similar to a model with myopic firms. That is, the slower the mean reversion, the more important are current profits relative to expected profits for the optimal price decision of the firm. Ceteris paribus, higher persistence levels are associated with more price adjustment of all firms because with higher persistence the unconditional volatility of the idiosyncratic shock increases. For all persistence parameters considered, financially constrained firms adjust prices more often, however, it seems that there is a non-monotonic relationship between the persistence and how much more often financially constrained firms adjust.

Model where sales are not collateralizable. With this robustness check we investigate the role of sales as collateral. Sales as collateral are qualitatively and quantitatively important to explain the firm level pricing moments, in particular to explain the fact that financially constrained firms adjust prices more often upwards than unconstrained firms. The reason is related to the discussion above. Sales in the constraint change the elasticity of the optimal constrained reset prices with respect to idiosyncratic shocks. And this is important in a model with forward looking firms.

Elasticity of substitution. A crucial parameter in this model is the elasticity of substitution. We repeat the calibration exercise for a lower and a higher demand elasticity, so that implied average markups in those alternative calibrations are 12.5 and 20 percent, respectively. The model fit does not improve compared to the benchmark model. Furthermore, the model with lower demand elasticity generates quantitatively too much price adjustment of financially constrained firms while the model with higher demand elasticity generates too little price adjustment of financially constrained firms (in particular upward adjusters) relative to unconstrained firms and therefore performs less well in this respect than the benchmark model. The aggregate implications are qualitatively similar to the benchmark model.

Idiosyncratic financial shocks. In the Appendix, we show a model version with both idiosyncratic productivity and idiosyncratic financial shocks. For the benchmark targets, in particular targeting a fraction of 32 percent of financially constrained firms (see Table 1 section 'bank lending') this does not improve the model fit. However, when targeting a fraction of financially constrained firms that is lower (the fraction of constrained firms is equal to 6 percent, see section labeled 'production constrained' in Table 1) idiosyncratic financial shocks help to reconcile model and the data. In particular, the model with idiosyncratic financial shocks makes sure that financially constrained and unconstrained firms are similar in terms of average sales as in the data. Regarding the pricing behavior, the model performs very similar to the benchmark model: Financially constrained firms adjust price more often upwards and downwards. Quantitatively, however, the model with financial shocks overestimate the fraction of constrained firms that adjust upwards and downwards and therefore the overall difference between financially constrained and unconstrained firms. The aggregate implications are qualitatively similar to the benchmark model. ${ }^{32}$

\footnotetext{
${ }^{32}$ The impulse responses of the model with idiosyncratic financial shocks are available upon request.
} 


\section{Conclusion}

This paper investigates how financial market imperfections and nominal rigidities interact. Based on new firm-level evidence for Germany, we document that financially constrained firms adjust prices more often than their unconstrained counterparts, both upward and downward. We show that these empirical patterns are consistent with a partial equilibrium menu-cost model with a working capital constraint. Our results suggest that the presence of financial constraints is associated with a higher degree of nominal rigidities, i.e. lower frequency of price changes, higher prices and lower output. Furthermore, the presence of financial constraints results in a time varying frequency of price adjustments. In particular, we find that, due to the asymmetry in the price distribution, firms adjust prices more often in boom and less often in a recession when financial constraints are present. In addition, due to the lower average frequency of price adjustment, monetary policy shocks induce a smaller change in inflation and a stronger reaction of output relative to an economy without credit market imperfections. Accordingly financial constraints alter a central trade-off faced by the central bank: In order to raise inflation by a certain amount the monetary authority needs to accept relatively stronger responses of average output. In contrast, we show that other sources of nominal rigidities such as exogenous probabilities of price adjustment as in Calvo (1983) or convex price adjustment costs as in Rotemberg (1982) generate the opposite result, i.e. the inclusion of financial frictions generates larger inflation and smaller output responses to aggregate shocks with compared to without financial frictions. Hence, menu costs and the associated endogenous link between reaction of the fraction of price adjusters and the presence of financial imperfections are important. 


\section{References}

Alvarez, F. AND F. Lippi (2014): "Price setting with menu cost for multiproduct firms," Econometrica, $82,89-135$.

Asplund, M., R. Eriksson, And N. Strand (2005): "Prices, Margins and Liquidity Constraints: Swedish Newspapers, 1990-1992," Economica, 72, 349-359.

AzARIADis, C. AND L. KAAs (2012): "Capital misallocation and aggregate factor productivity," Working Papers 2012-046, Federal Reserve Bank of St. Louis.

Bachmann, R., B. Born, S. Elstner, and C. Grimme (2013): "Time-Varying Business Volatility, Price Setting, and the Real Effects of Monetary Policy," NBER Working Papers 19180, National Bureau of Economic Research, Inc.

BARro, R. J. (1972): "A theory of monopolistic price adjustment," The Review of Economic Studies, $39,17-26$.

Bhaskar, V., S. Machin, And G. C. Reid (1993): "Price and Quantity Adjustment over the Business Cycle: Evidence from Survey Data," Oxford Economic Papers, 45, 257-68.

Buera, F., B. Moll, And Y. Shin (2013): "Well-Intended Policies," Review of Economic Dynamics, $16,216-230$.

Calvo, G. A. (1983): "Staggered prices in a utility-maximizing framework," Journal of Monetary Economics, 12, 383-398.

Caplin, A. S. And D. F. Spulber (1987): "Menu Costs and the Neutrality of Money," The Quarterly Journal of Economics, 102, 703-25.

Carpenter, R. E., S. M. Fazzari, and B. C. Petersen (1994): "Inventory Investment, InternalFinance Fluctuations, and the Business Cycle," Brookings Papers on Economic Activity, 2, 75-138.

Chevalier, J. A. And D. S. Scharfstein (1996): "Capital market imperfections and countercyclical markups: Theory and evidence," American Economic Review, 86, 703-25.

Christopoulou, R. And P. Vermeulen (2012): "Markups in the Euro area and the US over the period 1981-2004: a comparison of 50 sectors," Empirical Economics, 42, 53-77.

Cooley, T. F. And V. QuAdrini (2001): "Financial Markets and Firm Dynamics," American Economic Review, 91, 1286-1310.

DeutscheBundesbank (2013): "Financial accounts for Germany 2007 to 2012," Special statistical publication 4, Deutsche Bundesbank.

(2014): "Financial accounts for Germany 2008 to 2013," Special statistical publication 4, Deutsche Bundesbank.

Dotsey, M., R. King, And A. Wolman (1999): "State-Dependent Pricing And The General Equilibrium Dynamics Of Money And Output," The Quarterly Journal of Economics, 114, 655-690.

Dotsey, M. And R. G. King (2005): "Implications of state-dependent pricing for dynamic macroeconomic models," Journal of Monetary Economics, 52, 213-242.

Gilchrist, S., R. Schoenle, And E. Zakrajsek (2013): "Inflation Dynamics During the Financial Crisis," in 2013 Meeting Papers, Society for Economic Dynamics, 826.

Golosov, M. And R. E. Lucas (2007): "Menu Costs and Phillips Curves," Journal of Political Economy, 115, 171-199.

Gottfries, N. (1991): "Customer markets, credit market imperfections and real price rigidity," Economica, 58, 317-23. 
(2002): "Market shares, financial constraints and pricing behaviour in the export market," Economica, 69, 583-607.

Guerrieri, L. AND M. IACOviello (2015): "OccBin: A toolkit for solving dynamic models with occasionally binding constraints easily," Journal of Monetary Economics, 70, 22-38.

Jermann, U. And V. Quadrini (2012): "Macroeconomic Effects of Financial Shocks," American Economic Review, 102, 238-71.

Khan, A. And J. K. Thomas (2013): "Credit Shocks and Aggregate Fluctuations in an Economy with Production Heterogeneity," Journal of Political Economy, 121, 1055 - 1107.

Kimball, M. S. (1995): "The Quantitative Analytics of the Basic Neomonetarist Model," Journal of Money, Credit and Banking, 27, 1241-1277.

Kleemann, M. And M. Wiegand (2014): "Are Real Effects of Credit Supply Overestimated? Bias from Firms' Current Situation and Future Expectations," ifo Working Paper 192, ifo institute.

Lundin, N. AND L. Yun (2009): "International Trade and Inter-Industry Wage Structure in Swedish Manufacturing: Evidence from Matched Employer-Employee Data*," Review of International Economics, 17, 87-102.

Midrigan, V. (2011): "Menu Costs, Multiproduct firms, and Aggregate Fluctuations," Econometrica, 79, 1139-1180.

Midrigan, V. AND D. Y. Xu (2014): "Finance and Misallocation: Evidence from Plant-Level Data," American Economic Review, 104, 422-58.

Nakamura, E. And J. Steinsson (2008): "Five Facts about Prices: A Reevaluation of Menu Cost Models," The Quarterly Journal of Economics, 123, 1415-1464.

- (2010): "Monetary non-neutrality in a multisector menu cost model," The Quarterly Journal of Economics, 125, 961-1013.

Rotemberg, J. J. (1982): "Monopolistic Price Adjustment and Aggregate Output," Review of Economic Studies, 49, 517-531.

Strasser, G. (2013): "Exchange rate pass-through and credit constraints," Journal of Monetary Economics, 60, 25-38.

Tauchen, G. (1986): "Finite state markov-chain approximations to univariate and vector autoregressions," Economics letters, 20, 177-181.

VAVRA, J. (2013): "Inflation dynamics and time-varying uncertainty: New evidence and an ss interpretation," The Quarterly Journal of Economics, forthcoming.

Vermeulen, P., D. A. Dias, M. Dossche, E. Gautier, I. Hernando, R. Sabbatini, and H. Stahl (2012): "Price Setting in the Euro Area: Some Stylized Facts from Individual Producer Price Data," Journal of Money, Credit and Banking, 44, 1631-1650. 


\section{A Appendix}

\section{A.1 Additional empirical evidence}

The empirical papers in this subsection document additional empirical results and robustness checks. These robustness checks reveal that the main finding of the paper is robust to all specifications we have considered: financially constrained firms are associated with on average more price adjustment compared to financially unconstrained firms. Tables A-1 and A-2 exhibit information about the financing structure in Germany in general and in the ifo dataset in particular. Figure A-1 shows a time-series plot of the fraction of constrained firms according to both measures of financial constraints, our benchmark survey question on bank lending and the other survey measure based on the question whether firms' domestic operations are restricted due to financing problems. Table A-3 shows that firms have restrictive access to bank lending are not significantly smaller than other firms in terms of employment, sales or total assets. Figure A-2 shows the fraction of constrained firms (according to the benchmark bank lending measure) by sector and shows that the fraction of constrained firms varies greatly between sectors. Table A-3 shows that liquidity ratios are a little lower for firms that are constrained according to our survey questions. Figure A-3 documents that the overlap between the conventional balance-sheet based measure (defining firms to be financially constrained if they are below the median liquidity ratio with respect to all firms in the sample) and both of our survey questions is very small.

Table A-1: Financing structure Germany and the US

\begin{tabular}{lrr}
\hline & $\begin{array}{r}\text { Germany } \\
\text { OECD/BB }\end{array}$ & US \\
& & \\
& & \\
equity & 49.8 & 51.8 \\
securities/bonds & 2.9 & 15.5 \\
loans & 30.7 & 6.7 \\
other & 16.7 & 26.0 \\
\hline
\end{tabular}

Notes: Sources: Germany - OECD, "Financial Balance Sheets, SNA 1993: Consolidated stocks, annual (Edition 2015)", http://dx.doi.org/10.1787/da313c3b-en. US - Board of Governors of the Federal Reserve System , "Z.1 Financial Accounts of the United States (First Quarter 2016)", http://www.federalreserve.gov/releases/Z1/default.htm

Table A-2: Financing structure in the ifo data

\begin{tabular}{|c|c|c|c|}
\hline equity & 30.7 & 30.7 & 30.7 \\
\hline liabilities & 69.3 & & \\
\hline bank debt & & 18.1 & \\
\hline provisions and other debt & & 51.2 & \\
\hline short-term debt & & & 33.7 \\
\hline long-term debt & & & 16.4 \\
\hline provisions & & & 19.2 \\
\hline
\end{tabular}

Figures A-4 to A-6 show time-series plots of pricing decisions of financially constrained and unconstrained firms respectively using the survey measures. First, there is a lot of variation in price changes, hence changes in nominal rigidities over time. One can see that all firms (both financially unconstrained and constrained firms) decrease prices more often and increase prices less often in a recession. Over time, financially constrained firms decrease prices more often than unconstrained firms, regardless of the business cycle state (see also Table 1).

Table A-4 adds various control variables that could affect both price setting and whether firms are financially constrained or not. Table A-5 addresses robustness to the specification. Here, we add seasonal (quarterly) fixed effects and an interaction term between sector $j$ and seasonal fixed effects. Table A-6 in the Appendix further documents that our results do not depend on the specification being linear, as logit model estimation leaves the results virtually unchanged. Tables A-7 to A-9 show the results 
Table A-3: Financial constraints and firm characteristics unconstrained constrained

\begin{tabular}{lcc} 
Bank lending & & \\
firm size (employees) & & 1191.6 \\
average & 1009.1 & 114.0 \\
median & 120.0 & \\
sales (in million euros) & & 329.0 \\
average & 44.8 & 42.4 \\
median & & \\
balance sheet information & 196 & 191 \\
total assets (in million euros) & 0.11 & 0.09 \\
liquidity ratio & & \\
\hline & & \\
Production constraints & 1582.1 & 207.4 \\
firm size (employees) & 140.0 & 60.0 \\
average & & \\
median & 406.9 & 57.2 \\
sales (in million euros) & 64.4 & 14.5 \\
average & & \\
median & & \\
balance sheet information & 281 & 36 \\
total assets (in million euros) & 0.09 & 0.05 \\
liquidity ratio &
\end{tabular}

Notes: Sources: EBDC-BEP (2012): Business Expectations Panel. Total assets are end of year. Liquidity ratio measured as cash and cash equivalents over total assets (end of year)

Table A-4: Financial Constraints and Price Setting

\begin{tabular}{|c|c|c|c|c|c|c|c|}
\hline & baseline & firm size & short-time work & curr SofB & $\exp \mathrm{CoOp}$ & lag SofB & orders \\
\hline$\rightarrow$ & $\begin{array}{c}-0.036^{* * *} \\
(0.000)\end{array}$ & $\begin{array}{c}-0.036^{* * *} \\
(0.000)\end{array}$ & $\begin{array}{c}-0.034^{* * *} \\
(0.000)\end{array}$ & $\begin{array}{c}-0.028^{* * *} \\
(0.000)\end{array}$ & $\begin{array}{c}-0.034^{* * *} \\
(0.000)\end{array}$ & $\begin{array}{c}-0.029^{* * *} \\
(0.000)\end{array}$ & $\begin{array}{c}-0.033^{* * *} \\
(0.000)\end{array}$ \\
\hline$\uparrow$ & $\begin{array}{c}0.008^{* * * *} \\
(0.000)\end{array}$ & $\begin{array}{c}0.008^{* * * *} \\
(0.000)\end{array}$ & $\begin{array}{c}0.009 * * * \\
(0.000)\end{array}$ & $\begin{array}{c}0.012^{* * * *} \\
(0.000)\end{array}$ & $\begin{array}{c}0.009^{* * *} \\
(0.000)\end{array}$ & $\begin{array}{c}0.009^{* * * *} \\
(0.000)\end{array}$ & $\begin{array}{c}0.013^{* * *} \\
(0.000)\end{array}$ \\
\hline$\downarrow$ & $\begin{array}{c}0.028^{* * * *} \\
(0.000)\end{array}$ & $\begin{array}{c}0.028^{* * *} \\
(0.000)\end{array}$ & $\begin{array}{c}0.025 * * * \\
(0.000)\end{array}$ & $\begin{array}{c}0.016^{* * *} \\
(0.000)\end{array}$ & $\begin{array}{c}0.025^{* * *} \\
(0.000)\end{array}$ & $\begin{array}{c}0.020^{* * *} \\
(0.000)\end{array}$ & $\begin{array}{c}0.020 * * * \\
(0.000)\end{array}$ \\
\hline Observations & 180871 & 180871 & 61957 & 180791 & 180440 & 180777 & 180080 \\
\hline
\end{tabular}

Notes: Survey dataset. Sample: 2002:1 - 2014:12. OLS estimation with time $t$ and sector $j$ fixed effects. Adding firms-specific controls: Firm size in number of employees, short-time work dummy (1 if firm receives stw subsidies), current and lagged state of business, expected commercial operations and orders (improved, unchanged, worsened). Standard errors in parentheses, ${ }^{* * *} \mathrm{p}<0.01,{ }^{* *} \mathrm{p}<0.05, * \mathrm{p}<0.1$. 
Table A-5: Financial Constraints and Price Setting: Specification robustness

\begin{tabular}{|c|c|c|c|c|c|c|c|}
\hline & baseline & seas FE & seassec FE & sec clust & ind $\mathrm{FE}$ & LC panel & bal panel \\
\hline$\rightarrow$ & $\begin{array}{c}-0.036^{* * *} \\
(0.000)\end{array}$ & $\begin{array}{c}-0.036^{* * *} \\
(0.000)\end{array}$ & $\begin{array}{c}-0.041^{* * *} \\
(0.000)\end{array}$ & $\begin{array}{c}-0.036^{* * *} \\
(0.000)\end{array}$ & $\begin{array}{c}-0.021^{* * *} \\
(0.000)\end{array}$ & $\begin{array}{c}-0.038^{* * *} \\
(0.000)\end{array}$ & $\begin{array}{c}-0.166^{* * *} \\
(0.000)\end{array}$ \\
\hline$\uparrow$ & $\begin{array}{c}0.008^{* * *} \\
(0.000)\end{array}$ & $\begin{array}{c}0.008^{* * *} \\
(0.000)\end{array}$ & $\begin{array}{c}0.003^{* *} \\
(0.033)\end{array}$ & $\begin{array}{c}0.008 * * \\
(0.017)\end{array}$ & $\begin{array}{c}0.004^{* *} \\
(0.049)\end{array}$ & $\begin{array}{c}0.012^{* * *} \\
(0.000)\end{array}$ & $\begin{array}{l}0.047^{*} \\
(0.067)\end{array}$ \\
\hline$\downarrow$ & $\begin{array}{c}0.028^{* * * *} \\
(0.000)\end{array}$ & $\begin{array}{c}0.028^{* * *} \\
(0.000)\end{array}$ & $\begin{array}{c}0.038^{* * *} \\
(0.000)\end{array}$ & $\begin{array}{c}0.028^{* * *} \\
(0.000)\end{array}$ & $\begin{array}{c}0.017^{* * *} \\
(0.000)\end{array}$ & $\begin{array}{c}0.026^{* * *} \\
(0.000)\end{array}$ & $\begin{array}{c}0.119^{* * *} \\
(0.000)\end{array}$ \\
\hline Observations & 180871 & 180871 & 180871 & 180871 & 181167 & 113048 & 728 \\
\hline
\end{tabular}

Notes: Survey dataset. Sample: 2002:1 - 2014:12. OLS estimation with time $t$ and sector $j$ fixed effects. Specifications: sector $j$ and seasonal (quarterly) fixed effects, interaction between sector $j$ and seasonal FE, sector $j$ FE with standard errors clustered at sectoral level, individual FE, individual FE with se clustered at sectors not shown in the table, but available upon request. Long-coverage panel (firms are in panel at least 8 years), balanced panel. Standard errors in parentheses, *** $\mathrm{p}<0.01,{ }^{* *} \mathrm{p}<0.05,{ }^{*} \mathrm{p}<0.1$.

using our production constraint measures instead of the bank lending measure for financial constrainedness. Generally, the difference in the frequency of price adjustment between financially constrained and unconstrained firms is slightly larger in this measure. As before, financially constrained firms adjust prices more often than unconstrained firms, but the difference is now equally driven by upward as by downward price adjusters. Table A-10 shows the results when using the liquidity ratio (measured as described above) in order to measure financial constrainedness. 
Table A-6: Financial Constraints and Price Setting: OLS versus Logit

\begin{tabular}{|c|c|c|c|c|}
\hline & PM: base, no price lag & PM: logit & BL: base, no price lag & BL: logit \\
\hline$\rightarrow$ & $\begin{array}{c}-0.061^{* * *} \\
(0.000)\end{array}$ & $\begin{array}{c}-0.055^{* * *} \\
(0.000)\end{array}$ & & \\
\hline$\rightarrow$ & & & $\begin{array}{c}-0.037^{* * *} \\
(0.000)\end{array}$ & $\begin{array}{c}-0.036^{* * * *} \\
(0.000)\end{array}$ \\
\hline$\uparrow$ & $\begin{array}{c}0.033^{* * * *} \\
(0.000)\end{array}$ & $\begin{array}{c}0.031^{* * * *} \\
(0.000)\end{array}$ & & \\
\hline$\uparrow$ & & & $\begin{array}{l}-0.001 \\
(0.615)\end{array}$ & $\begin{array}{l}-0.001 \\
(0.524)\end{array}$ \\
\hline$\downarrow$ & $\begin{array}{c}0.028 * * * \\
(0.000)\end{array}$ & $\begin{array}{c}0.023^{* * * *} \\
(0.000)\end{array}$ & & \\
\hline$\downarrow$ & & & $\begin{array}{c}0.038^{* * *} \\
(0.000)\end{array}$ & $\begin{array}{c}0.033^{* * *} \\
(0.000)\end{array}$ \\
\hline Observations & 133131 & 132922 & 198382 & 198185 \\
\hline
\end{tabular}

Notes: Survey dataset. Sample: 2002:1 - 2014:12. OLS estimation with time $t$ and sector $j$ fixed effects. LOGIT shows average marginal effects and bootstrapped standard errors. Standard errors in parentheses, ${ }^{* * *} \mathrm{p}<0.01, * * \mathrm{p}<0.05, * \mathrm{p}$ $<0.1$.

Table A-7: Financial Constraints and Price Setting: Production constraints I

\begin{tabular}{|c|c|c|c|c|c|c|c|}
\hline & baseline & firm size & short-time work & curr SofB & $\exp \mathrm{CoOp}$ & lag SofB & orders \\
\hline$\rightarrow$ & $\begin{array}{c}-0.056^{* * *} \\
(0.000)\end{array}$ & $\begin{array}{c}-0.056^{* * *} \\
(0.000)\end{array}$ & $\begin{array}{c}-0.057^{* * *} \\
(0.000)\end{array}$ & $\begin{array}{c}-0.049^{* * *} \\
(0.000)\end{array}$ & $\begin{array}{c}-0.056^{* * *} \\
(0.000)\end{array}$ & $\begin{array}{c}-0.050 * * * \\
(0.000)\end{array}$ & $\begin{array}{c}-0.053^{* * *} \\
(0.000)\end{array}$ \\
\hline$\uparrow$ & $\begin{array}{c}0.034^{* * *} \\
(0.000)\end{array}$ & $\begin{array}{c}0.034^{* * *} \\
(0.000)\end{array}$ & $\begin{array}{c}0.036^{* * *} \\
(0.000)\end{array}$ & $\begin{array}{c}0.038^{* * *} \\
(0.000)\end{array}$ & $\begin{array}{c}0.034^{* * *} \\
(0.000)\end{array}$ & $\begin{array}{c}0.035^{* * *} \\
(0.000)\end{array}$ & $\begin{array}{c}0.037 * * * \\
(0.000)\end{array}$ \\
\hline$\downarrow$ & $\begin{array}{c}0.023^{* * *} \\
(0.000)\end{array}$ & $\begin{array}{c}0.023^{* * *} \\
(0.000)\end{array}$ & $\begin{array}{c}0.021^{* * *} \\
(0.000)\end{array}$ & $\begin{array}{c}0.011^{* * *} \\
(0.005)\end{array}$ & $\begin{array}{c}0.022^{* * *} \\
(0.000)\end{array}$ & $\begin{array}{c}0.015^{* * *} \\
(0.000)\end{array}$ & $\begin{array}{c}0.015^{* * *} \\
(0.000)\end{array}$ \\
\hline Observations & 119871 & 119871 & 114478 & 119831 & 119531 & 119816 & 119283 \\
\hline
\end{tabular}

Notes: Survey dataset. Sample: 2002:1 - 2014:12. OLS estimation with time $t$ and sector $j$ fixed effects. Adding firms-specific controls: Firm size in number of employees, short-time work dummy (1 if firm receives stw subsidies), current and lagged state of business, expected commercial operations and orders (improved, unchanged, worsened).

Standard errors in parentheses, ${ }^{* * *} \mathrm{p}<0.01,{ }^{* *} \mathrm{p}<0.05,{ }^{*} \mathrm{p}<0.1$. 
Table A-8: Financial Constraints and Price Setting: Production constraints II

\begin{tabular}{|c|c|c|c|c|c|c|c|}
\hline & baseline & SMEs & west & exporting & post 2009 & pre 2009 & single product \\
\hline$\rightarrow$ & $\begin{array}{c}-0.056^{* * *} \\
(0.000)\end{array}$ & $\begin{array}{c}-0.049^{* * *} \\
(0.000)\end{array}$ & $\begin{array}{c}-0.072^{* * *} \\
(0.000)\end{array}$ & $\begin{array}{c}-0.069 * * * \\
(0.000)\end{array}$ & $\begin{array}{c}-0.068^{* * *} \\
(0.000)\end{array}$ & $\begin{array}{c}-0.046^{* * *} \\
(0.000)\end{array}$ & $\begin{array}{c}-0.056^{* * *} \\
(0.000)\end{array}$ \\
\hline$\uparrow$ & $\begin{array}{c}0.034^{* * *} \\
(0.000)\end{array}$ & $\begin{array}{c}0.031^{* * *} \\
(0.000)\end{array}$ & $\begin{array}{c}0.041^{* * *} \\
(0.000)\end{array}$ & $\begin{array}{c}0.039 * * * \\
(0.000)\end{array}$ & $\begin{array}{c}0.036^{* * *} \\
(0.000)\end{array}$ & $\begin{array}{c}0.032^{* * *} \\
(0.000)\end{array}$ & $\begin{array}{c}0.033^{* * *} \\
(0.000)\end{array}$ \\
\hline$\downarrow$ & $\begin{array}{c}0.023^{* * *} \\
(0.000)\end{array}$ & $\begin{array}{c}0.018^{* * *} \\
(0.003)\end{array}$ & $\begin{array}{c}0.031^{* * *} \\
(0.000)\end{array}$ & $\begin{array}{c}0.030 * * * \\
(0.000)\end{array}$ & $\begin{array}{c}0.032^{* * *} \\
(0.000)\end{array}$ & $\begin{array}{c}0.015^{* * *} \\
(0.003)\end{array}$ & $\begin{array}{c}0.023^{* * *} \\
(0.000)\end{array}$ \\
\hline Observations & 119871 & 49050 & 97301 & 95324 & 54697 & 65174 & 117850 \\
\hline
\end{tabular}

Notes: Survey dataset. Sample: 2002:1 - 2014:12. OLS estimation with time $t$ and sector $j$ fixed effects. Considering subsamples: small and medium-sized firms only (50-250 employees), west only, exporting firms only, before and after 2009, single product firms. Results including very small firms (below 250) are not shown in the table, but available upon request. Standard errors in parentheses, ${ }^{* * *} \mathrm{p}<0.01,{ }^{* *} \mathrm{p}<0.05,{ }^{*} \mathrm{p}<0.1$.

Table A-9: Financial Constraints and Price Setting: Production constraints III

\begin{tabular}{|c|c|c|c|c|c|c|c|}
\hline & baseline & seas FE & seassec FE & sec clust & ind $\mathrm{FE}$ & LC panel & bal panel \\
\hline$\rightarrow$ & $\begin{array}{c}-0.056^{* * *} \\
(0.000)\end{array}$ & $\begin{array}{c}-0.056^{* * *} \\
(0.000)\end{array}$ & $\begin{array}{c}-0.059^{* * *} \\
(0.000)\end{array}$ & $\begin{array}{c}-0.056^{* * *} \\
(0.000)\end{array}$ & $\begin{array}{c}-0.048^{* * *} \\
(0.000)\end{array}$ & $\begin{array}{c}-0.061^{* * *} \\
(0.000)\end{array}$ & $\begin{array}{c}-0.326^{* * *} \\
(0.000)\end{array}$ \\
\hline$\uparrow$ & $\begin{array}{c}0.034^{* * *} \\
(0.000)\end{array}$ & $\begin{array}{c}0.034^{* * *} \\
(0.000)\end{array}$ & $\begin{array}{c}0.032^{* * *} \\
(0.000)\end{array}$ & $\begin{array}{c}0.034^{* * *} \\
(0.000)\end{array}$ & $\begin{array}{c}0.035^{* * *} \\
(0.000)\end{array}$ & $\begin{array}{c}0.041^{* * *} \\
(0.000)\end{array}$ & $\begin{array}{c}0.209^{* * *} \\
(0.005)\end{array}$ \\
\hline$\downarrow$ & $\begin{array}{c}0.023^{* * *} \\
(0.000)\end{array}$ & $\begin{array}{c}0.023^{* * *} \\
(0.000)\end{array}$ & $\begin{array}{c}0.027^{* * *} \\
(0.000)\end{array}$ & $\begin{array}{c}0.023^{* * *} \\
(0.000)\end{array}$ & $\begin{array}{c}0.013^{* * *} \\
(0.006)\end{array}$ & $\begin{array}{c}0.020^{* * *} \\
(0.000)\end{array}$ & $\begin{array}{l}0.117^{*} \\
(0.064)\end{array}$ \\
\hline Observations & 119871 & 119871 & 119871 & 119871 & 120069 & 75543 & 449 \\
\hline
\end{tabular}

Notes: Survey dataset. Sample: 2002:1 - 2014:12. OLS estimation with time $t$ and sector $j$ fixed effects. Specifications: sector $j$ and seasonal (quarterly) fixed effects, interaction between sector $j$ and seasonal FE, sector $j$ FE with standard errors clustered at sectoral level, individual FE, individual FE with se clustered at sectors not shown in the table, but available upon request. Long-coverage panel (firms are in panel at least 8 years), balanced panel. Standard errors in parentheses, *** $\mathrm{p}<0.01, * * \mathrm{p}<0.05,{ }^{*} \mathrm{p}<0.1$. 
Table A-10: Financial Constraints and Price Setting: Liquidity constraints

\begin{tabular}{|c|c|c|c|c|c|}
\hline & baseline & long coverage panel & balanced panel & base, no price lag & $\operatorname{logit}$ \\
\hline$\rightarrow$ & $\begin{array}{c}-0.007^{* *} \\
(0.019)\end{array}$ & $\begin{array}{c}0.001 \\
(0.870)\end{array}$ & $\begin{array}{c}-0.011 \\
(0.249)\end{array}$ & $\begin{array}{c}-0.009 * * * \\
(0.002)\end{array}$ & $\begin{array}{c}-0.009^{* * *} \\
(0.002)\end{array}$ \\
\hline$\uparrow$ & $\begin{array}{c}0.005^{* *} \\
(0.022)\end{array}$ & $\begin{array}{c}0.003 \\
(0.259)\end{array}$ & $\begin{array}{c}0.008 \\
(0.289)\end{array}$ & $\begin{array}{c}0.008^{* * *} \\
(0.001)\end{array}$ & $\begin{array}{c}0.009^{* * *} \\
(0.000)\end{array}$ \\
\hline$\downarrow$ & $\begin{array}{c}0.002 \\
(0.269)\end{array}$ & $\begin{array}{c}-0.004^{*} \\
(0.094)\end{array}$ & $\begin{array}{c}0.003 \\
(0.578)\end{array}$ & $\begin{array}{c}0.001 \\
(0.509)\end{array}$ & $\begin{array}{c}0.001 \\
(0.535)\end{array}$ \\
\hline Observations & 68364 & 42675 & 8102 & 72458 & 72241 \\
\hline
\end{tabular}

Notes: Balance sheet dataset. Sample: 2002:1 - 2011:12. OLS and LOGIT estimation with time $t$ and sector $j$ fixed effects. Long-coverage panel (firms are in panel at least 8 years), balanced panel. Standard errors in parentheses, ${ }^{* * *} \mathrm{p}<$ $0.01,{ }^{* *} \mathrm{p}<0.05,{ }^{*} \mathrm{p}<0.1$. 
Figure A-1: Fraction of constrained firms over time
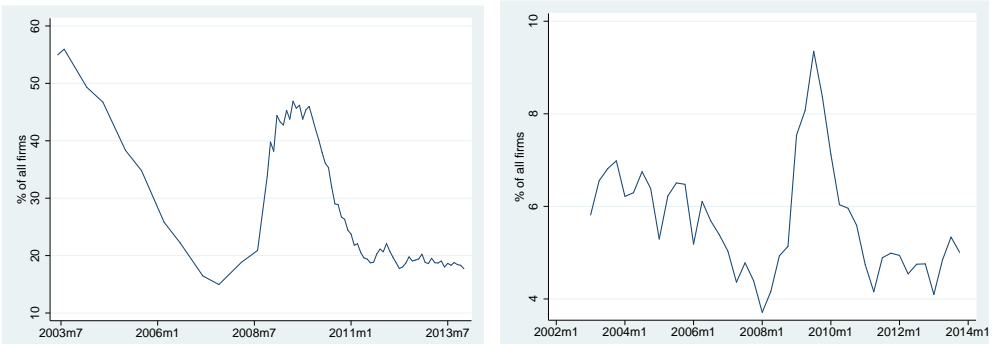

Notes: Fraction of constrained firms according to bank lending measure (left panel) and production constraint measure (right panel) in all firms in a given month.

Figure A-2: Share of financially constrained firms across sectors
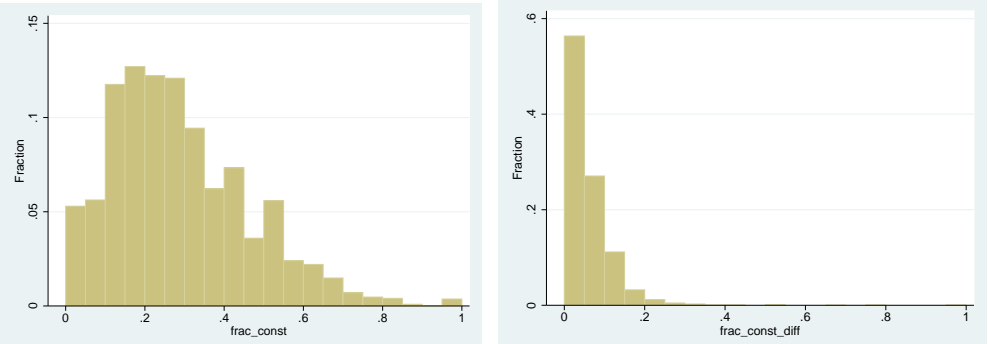

Figures show the histogram of various shares of financially constrained firms for wz93 classification of sectors. Examples for very constrained $(90-100 \%)$ in bank lending: textile manufacturing ( 17150 and 17300 according to wz93 classification). Examples for not very constrained (below 26240 (ceramics for technical use) $33 \%, 36200$ (jewelery) $34 \%$

Figure A-3: Survey measures and balance sheet information
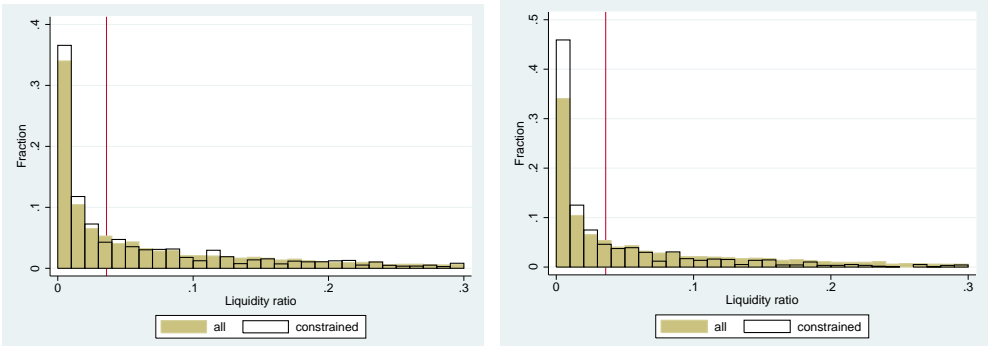

Figures show the histogram of liquidity ratios for all firms and firms that are constrained according to the survey measures. The median liquidity ratio of all firms is equal to 0.036 . For fin constrained according to the production constraint measure, the median liquidity ratio is 0.014

Figure A-4: Fraction of prices constant over time
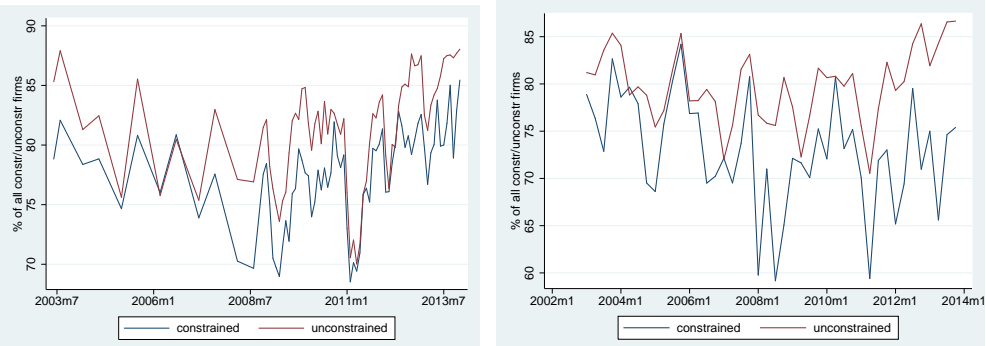

Notes: Fraction of firms not changing prices within constrained and unconstrained firms. Left panel: Bank lending survey measure. Right panel: Production constraint survey measure. 
Figure A-5: Fraction of price increases over time
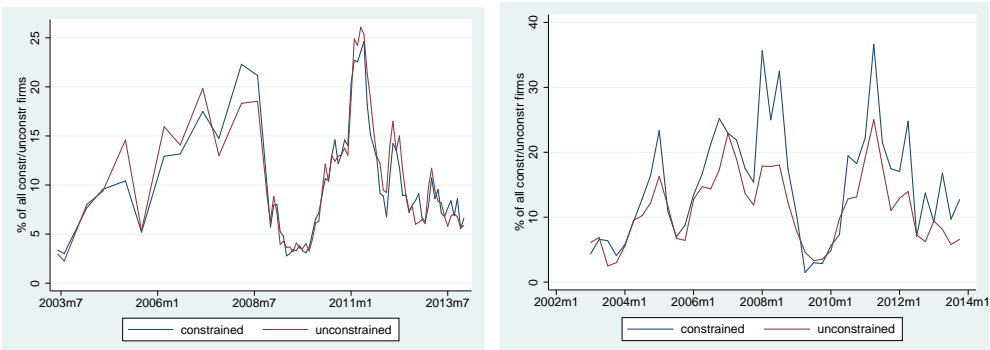

Notes: Fraction of firms increasing prices within restricted and unrestricted firms using the bank lending survey question.

Figure A-6: Fraction of price decreases over time
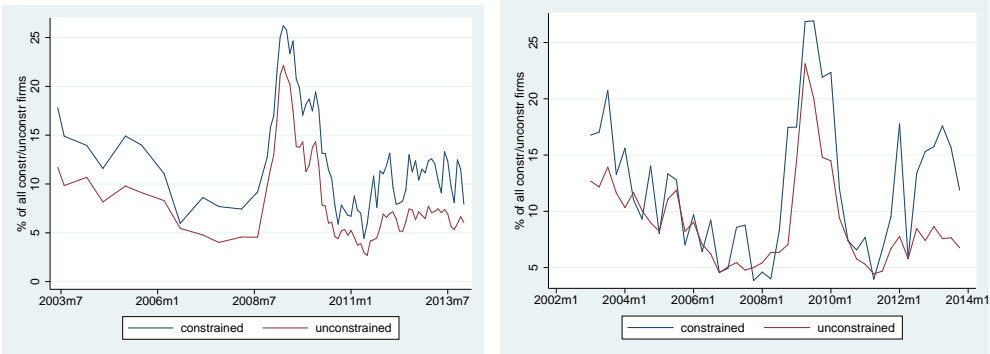

Notes: Fraction of firms decreasing prices within constrained and unconstrained firms. Left panel: Bank lending survey measure. Right panel: Production constraint survey measure. 


\section{A.2 The model with myopic firms}

The purpose of this subsection is threefold. First, we provide the formal proofs to the claims in the main text for the simplified model with $\beta=0$. Second, we show that there is no unambiguous relationship between firm productivity and a binding financial constraint. In fact, this depends crucially on whether the firm decides to adjust the price or not; in case of no price adjustment, low productivity firms are more likely to be financially constrained, while in the case of price adjustment, firms with relatively higher productivity will be more likely financially constrained. Third, we show that financially constrained firms that optimally adjust the price charge a mark-up over marginal costs that is increasing in productivity. This implies that financially constrained firms, on average, have higher mark-ups.

\section{A.2.1 Problem of the firm}

For simplicity, we normalize the aggregate price level $P=1$. Hence, the firm's nominal price is also its real price. To save on notation, we drop all time indices. In addition, we normalize the aggregate consumption level $C=1$. Also recall that we have normalized real wages by $w=(\theta-1) / \theta$. The problem of the firm can then be written as

$$
V(p, z)=\max \left\{V^{a}(p, z), V^{n a}(p, z)\right\}
$$

where the value of price adjustment is given by

$$
V^{A}(p, z)=\max _{h, q \neq p}\left\{z h\left(q-\frac{w}{z}\right)-f w\right\}
$$

subject to

$$
\begin{aligned}
z h & \leq q^{-\theta} \\
w h & \leq \xi(1+q z h)
\end{aligned}
$$

and the value of not adjusting the price is given by

$$
V^{N A}(p, s)=\max _{h} \quad z h\left(p-\frac{w}{z}\right)
$$

subject to

$$
\begin{aligned}
z h & \leq p^{-\theta} \\
w h & \leq \xi(1+p z h)
\end{aligned}
$$

where as in the main text we have normalized capital, $k_{i}=1$ for all $i$.

\section{A.2.2 No price adjustment}

Conditional on not adjusting the price, the firm chooses hours to maximize profits. The first order conditions read as

$$
\begin{aligned}
0 & =\left(p-\frac{w}{z}\right)-\phi+\mu\left(\xi p-\frac{w}{z}\right) \\
z h & \leq p^{-\theta} \quad \perp \quad \phi \geq 0 \\
w h & \leq \xi(1+p z h) \quad \perp \quad \mu \geq 0
\end{aligned}
$$

For $z \leq w / p$ the optimal solution is $h=y=\phi=\mu=0$. That is, for a given price, firms with sufficiently low productivity do not produce. In what follows assume $p z>w$ and consider the following cases: 
1. Demand holds with equality while the financial constraint is slack. Complementary slackness requires $\mu=0$. From the demand equation we have

$$
\begin{aligned}
h & =\frac{1}{z} p^{-\theta} \\
\phi & =\left(p-\frac{w}{z}\right)
\end{aligned}
$$

Note that in this case it has to be true that

$$
z>\frac{w}{\xi\left(p^{\theta}+p\right)}
$$

that is, firms with sufficiently high productivity (given the price) are unconstrained. Notice that this condition only gets some bite if we further assume that $\frac{w}{\xi\left(p^{\theta}+p\right)}>w / p$ or $\xi<\frac{p}{p^{\theta}+p}$ at least for some $p$. Otherwise, A.1 would be always the trivially satisfied for all firms (recall by assumption $p z>w)$.

2. Demand is slack while the financial constraint is binding. Complementary slackness requires $\phi=0$. Then we have

$$
\begin{aligned}
h & =\frac{\xi}{w-\xi p z} \\
\mu & =\frac{p z-w}{w-\xi p z}
\end{aligned}
$$

This solution assumes that $\phi=0$. This is the case whenever $z \leq \frac{w}{\xi\left(p^{\theta}+p\right)}$ which is just the complement of the requirement in case 1 above. Notice that when this condition is met, it is also true that $z<\frac{w}{p \xi}$ which is the requirement for $\mu \geq 0$. This means that for given $p$ and $\xi$, firms productivity below this threshold are constrained. Furthermore, inspecting equation A.2 reveals that for a given price, the Lagrange multiplier $\mu$ is increasing in productivity $z$. This is intuitive because for higher productivity firms the shadow value of relaxing the financial constraint marginally is higher than for firms with relatively less productivity (more precisely the gradient of the Lagrange function increases for higher productivity because the profit function is increasing in $z$ ). However, once productivity is high enough the firm needs so little labor input to satisfy the demand at the current price that the financial constraint is no longer binding. The Lagrange multiplier then falls to zero.

To summarize, it is worth highlighting that conditional on not adjusting the price, the firms with low productivity are financially constrained. On the other hand, firms with sufficiently high productivity above a certain threshold are financially unconstrained.

\section{A.2.3 Price adjustment}

In case the firm chooses to adjust the price optimally, i.e. conditional on paying the fix cost, the first order conditions for prices, hours, and output are given by

$$
\begin{aligned}
0 & =z h+\mu \xi z h-\phi \theta q^{-\theta-1} \\
0 & =\left(q-\frac{w}{z}\right)-\phi-\mu\left(\frac{w}{z}-\xi p\right) \\
z h & \leq q^{-\theta} \perp \phi \geq 0 \\
w h & \leq \xi(1+p z h) \perp \mu \geq 0
\end{aligned}
$$

Consider the following cases:

1. The financial constraint is binding and the demand function is slack. In this case, by hypothesis 
$\phi=0$ and

$$
\begin{aligned}
h & =\frac{\xi}{w-\xi q z} \\
0 & =z h(1+\xi \mu) \\
\mu & =\left(\frac{w}{z}-\xi q\right)^{-1}\left(\left(q-\frac{w}{z}\right)\right) .
\end{aligned}
$$

This implies $h=0$, a contradiction unless $\xi=0$, assuming that productivity is always positive $z>0$ and focusing on positive prices $q>0$ (which is without loss of generality as demand is infinite for a zero price). Henceforth, we exclude this case by assuming that $\xi>0$. Therefore, in case the firm finds it optimal to adjust its price, it will always satisfy demand.

2. The financial constraint is not binding and demand is satisfied. This implies that $\mu=0$ and

$$
\begin{aligned}
h & =\frac{1}{z} q^{-\theta} \\
0 & =z h-\phi \theta q^{-\theta-1} \\
\phi & =\left(q-\frac{w}{z}\right)
\end{aligned}
$$

so that

$$
0=1-\theta\left(q-\frac{w}{z}\right) q^{-1}
$$

or

$$
q=\frac{\theta}{\theta-1} \frac{w}{z}
$$

which is the familiar result that optimal price is a constant mark-up $\theta /(\theta-1)$ over marginal costs $w / z$.

3. Both, the demand function and the financial constraint are satisfied with equality. Then

$$
\begin{aligned}
h & =\frac{\xi}{w-\xi q z} \\
q^{-\theta} & =z h \\
\phi & =\frac{1}{\theta} z h q^{1+\theta}(1+\xi \mu) \\
\mu & =\left(\frac{w}{z}-\xi q\right)^{-1}\left(\left(q-\frac{w}{z}\right)-\phi\right) .
\end{aligned}
$$

Hence, the price of the constrained firm solves

$$
q^{-\theta}=\frac{\xi z}{w-\xi q z}
$$

Alternatively, as in the main text, the optimal constrained adjusting price can be expressed in terms of the Lagrange multiplier that is attached to the financial constraint:

$$
q=\frac{(1+\mu)}{(1+\mu \xi)} \frac{\theta}{\theta-1} \frac{w}{z}
$$

where the Lagrange multiplier $\mu$ solves equation (A.4). Notice that in principle equation A.5 can have multiple and complex solutions. However, as this equation is a polynomial of degree $\theta$ 
with only one sign change, there is at most one positive solution. ${ }^{33}$ So any other (complex or real) solutions to equation A.5 are non-positive. We can exclude solutions involving negative prices because in that case the Lagrange multiplier $\mu$ is negative, clearly a contradiction. Henceforth, we focus on positive real solutions to equation A.5. ${ }^{34}$ It is straightforward to show that the solution to equation A.5 that is consistent with a positive Lagrange multiplier $\mu \geq 0$ lies in the interval $q \in\left[\frac{1}{z}, \frac{1}{\xi z}\right)$ if and only if $\xi<1{ }^{35}$ With other words, $\xi<1$ is a necessary and sufficient condition for the existence of a unique positive solution to equations A.5 that is consistent with a positive Lagrange-multiplier.

We now are ready to show that the Lagrange multiplier $\mu$ is increasing in productivity. First, we use a change of variables $x=q z$ and rewrite A.4 as $\mu(1-\xi x)=(x-1)$. Notice that $x \in[1,1 / \xi)$ whenever $\xi<1$ (see above). Taking the total derivative and rearranging we obtain

$$
d \mu=\frac{1+\xi \mu}{1-\xi x} d x
$$

which says that the Lagrange multiplier is increasing in $x$ for $\xi<1$. Using the same change of variables and taking the total derivative of equation A.5 we obtain the result that $x$ is increasing in $z$ :

$$
d x=\xi \frac{x}{1-\xi x}\left(\frac{x}{z}\right)^{\theta} d z
$$

Recall that $\theta>1$ and $x \in[1,1 / \xi)$ for $\xi<1$, so that the right side is positive for positive changes in $z$. This means that $x=p z-$ the revenue per unit labor employed - is increasing in productivity. Finally, combining $($ A.6) and $($ A.7) gives the result that the Lagrange multiplier is increasing in productivity. With other words, the mark-up of financially constrained firms is monotonically increasing in productivity because the mark-up depends on the Lagrange multiplier which is increasing in productivity.

Finally, together with the result that the mark-up of unconstrained price adjusting firms is constant (see equation (A.3), this implies that there is a productivity cut-off for which the firms become financially constrained: only firms with sufficiently high productivity $z \geq \tilde{z}$ are financially constrained. One can solve for the threshold productivity $\tilde{z}$ by equating the unconstrained price with the financially constrained price and then using A.5 to solve for productivity. Formally, firms are financially constrained if and only if

$$
z \geq\left(\frac{\xi}{w-\xi}\right)^{\frac{1}{\theta-1}}
$$

and unconstrained otherwise (case 2. above). Notice that this threshold productivity is strictly positive if and only if $\xi<w$ where by normalization $w<1$. In all calibrations in the main text we assume that $\xi<w .{ }^{36}$

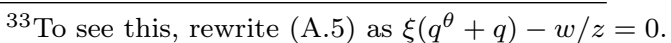

${ }^{34}$ For $\theta=2$ we can solve for the price analytically and show that there are two real solutions, one negative and one positive. Abstracting from the negative solution (as this would imply a negative Lagrange multiplier), the optimal adjusting price is given by $q=0.5(\sqrt{(1+4 w /(\xi z))}-1)$ which is strictly positive for any $w, \xi, z>0$. In addition, at this price hours worked are positive $(h>0)$ for any $w, \xi, z>0$.

${ }^{35}$ Suppose $\xi<1$. First we show that $q z<1 / \xi$ so that the inverse term on the right hand side of equation A.4 is well defined and strictly positive. Combine equations A.4 and A.5 and use the normalization of wages $w=(\theta-1) / \theta$ to get

$$
q z<\frac{1}{\xi} \quad \Leftrightarrow \quad \frac{(1+\mu)}{(1+\mu \xi)}<\frac{1}{\xi} \quad \Leftrightarrow \quad \xi<1
$$

where we have used the fact that $\mu \geq 0$ by assumption. Second, we show that $q z \geq 1$. Use the normalization of wages and rewrite equation A.4 as

$$
\mu=\left(\frac{1}{z}-\xi q\right)^{-1}\left(q-\frac{1}{z}\right)
$$

The first inverse term is strictly positive for $\xi<1$ as shown above. This implies that $\mu \geq$ requires $q \geq 1 / z$.

${ }^{36}$ To be more precise, for all calibrations the guess of $\xi$ for the numerical solver is set to a value below $w$. In all simulations and all iterations, the numerical solver always selected lower values of $\xi$ and never considered selected values close or above $w$.
} 
The last remark concerns the pass-through of idiosyncratic shocks: the optimal price of financially constrained firms responds less to productivity shocks than the price of adjusting unconstrained firms. To see this, note that equation A.3 implies that revenue per unit labor $x^{u c}=q^{u c} z$ does not change when productivity changes, or formally $d x^{u c}=d z=0$; this is only possible if unconstrained optimal prices decrease (increase) one for one with positive (negative) productivity shocks. On the other hand, in equation A.7), we have shown that for constrained firms $d x^{f c}=d z>0$. This means the constrained price $q^{f c}$ changes less than one for one with productivity shocks, or $\left|d q^{f c}\right|<|d z|$. With other words, for financially constrained firms, there is incomplete pass-through of idiosyncratic shocks. This result is key for understanding the stationary price distribution and the transmission of aggregate nominal shocks. We provide more intuition in the following subsection.

\section{A.2.4 Summary and intuition}

In case the firm does not adjust the price, for example because the menu cost is large, condition A.1 tells us that firms with sufficiently low productivity levels are financially constrained. The intuition behind this result is the following. For low productivity levels, firms need a relatively large amount of labor input in order to produce the amount that is demanded at the given price. For those firms the wage bill that has to be financed is relatively high and it is therefore more likely that those low productivity firms face a binding constraint. Once productivity increases, the required labor input decreases, the wage bill that has to be financed decreases, and this relaxes the financial constraint. If productivity is large enough the constraint becomes eventually non-binding.

In case of price adjustment, firms with higher productivity levels are likely to be more constrained. This is an implication from the fact that the Lagrange multiplier is increasing in productivity $z$, as shown analytically above. As mentioned above, for firms with higher productivity, the optimal constrained price lies further away from the optimal unconstrained price (the latter exhibiting a constant markup). The reason for the positive relationship between $\mu$ and $z$ can be understood by noting that the Lagrangean multiplier $\mu$ measures the marginal rise in profits resulting from an infinitesimal loosening of a binding financial constraint. To see this, recall that when both, the financial and the demand constraint bind, the first derivative of firm $i$ 's Lagrange function with respect to the individual nominal price $p_{i}$ imply

$$
\mu_{i}=\underbrace{\frac{\partial \Pi_{i}}{\partial p_{i}}}_{A} \cdot \overbrace{\left(\frac{1}{\frac{w}{z} \frac{\partial D_{i}}{\partial p_{i}}}\right)}^{B},
$$

where $\Pi_{i}$ and $D_{i}$ denote firm $i$ ' profits and demand respectively. Note further, that the term in brackets $B$ equals the amount of the nominal price decrease which becomes possible due to an infinitesimal loosening of the credit constraint. The term $A$ measures the change in profits induced by an unit infinitesimal change in $p_{i}$. It is easy to show, that both, $\frac{\partial \Pi_{i}}{\partial p_{i}}$ and $\frac{w}{z} \frac{\partial D_{i}}{\partial p_{i}}$ increase in absolute value in the level of idiosyncratic productivity $z_{i}$. However, the slope of the profit function $\frac{\partial \Pi_{i}}{\partial p_{i}}$ is substantially more sensitive to variation in $z_{i}$ than the marginal change in $\operatorname{costs} \frac{w}{z} \frac{\partial D_{i}}{\partial p_{i}}$. To see this, note first, that a higher $z_{i}$ allows to lower the nominal price which, in turn is associated with an increase in demand $D_{i}$ and a much larger increase in the steepness of the demand function $\partial D_{i} / \partial p_{i}$. However, the amount of the possible price decrease is relatively small. To see this consider the simpler case of the financial constraint omitting the sales on the right hand side, or $w h \leq \xi$. When the financial constraint is binding, we have $p_{i}=\left(\frac{w}{\xi z_{i}}\right)^{\frac{1}{\theta}} P$ instead of $p_{i}=\frac{\theta}{\theta-1} \frac{w}{z_{i}} P$. This incomplete pass-through of idiosyncratic shocks dampens the increase in the slope of demand $\frac{\partial D_{i}}{\partial p_{i}}$. The latter is in fact largely offset by the decrease in marginal costs $w / z_{i}$. In contrast, the same incomplete pass-through implies that a lower $z_{i}$ is associated with higher unit profits $p_{i}-w / z_{i}$. Since the slope of the profit function is given by

$$
\frac{\partial \Pi_{i}}{\partial p_{i}}=\frac{\partial D_{i}}{\partial p_{i}}\left(p_{i}-\frac{w}{z_{i}}\right)+D_{i},
$$

the increase in the steepness of demand $\frac{\partial D_{i}}{\partial p_{i}}$ is not offset but rather scaled up by the increase in unit profits. Note further that the sensitivity of the level of demand $D_{i}$ with respect to $p_{i}$ is an order of 
magnitude smaller than that of the slope $\frac{\partial D_{i}}{\partial p_{i}}$. Consequently, a higher productivity level $z_{i}$ translates into a substantially steeper profit function, driven by the increase in the term $\frac{\partial D_{i}}{\partial p_{i}}\left(p_{i}-\frac{w}{z_{i}}\right)$. The intuition in the case of a financial constraint given by $w h_{i} \leq \xi\left(1+p_{i} z_{i} h_{i}\right)$ is similar.

\section{A.3 Details on the numerical simulation}

\section{A.3.1 Details on the simulation of the model and calibration}

To simulate the dynamic model of section 3, we iterate the Bellman operator in equation (7) on a logarithmic grid of productivity $z_{i t}$ and the firm's real initial period price (before price adjustment) $p_{i t} / P_{t}$. The grid for the price is chosen such that an increment is no greater than $0.01 \%$ change in the price (typically around 4000 grid points). The grid for productivity is chosen such that an increment is no greater than $0.1 \%$ in productivity (typically around 500 grid points) and so it covers \pm 4.5 unconditional standard deviations for the stochastic shock. There are two shocks to the model for which firms have to form expectations. First, the aggregate price level $P_{t}$ follows a random walk with $\operatorname{drift} \ln \left(P_{t}\right)=$ $\ln (\pi)+\ln \left(P_{t-1}\right)+\eta_{t}$ where $\eta_{t}$ is a normal distributed random variable. Furthermore throughout the simulations, we assume $C_{t}=1$ for all $t$. With these assumptions, aggregate nominal demand $S_{t}=P_{t} C_{t}$ follows the same process as the aggregate price level. Second, firms face idiosyncratic productivity shocks that follow the $\operatorname{AR}(1)$ process $\ln \left(z_{i t}\right)=\rho_{z} \ln \left(z_{i t-1}\right)+\varepsilon_{i t}$. We assume that realizations of the productivity shock are stochastically independent from realizations of the aggregate shock. Given the grid for productivity and the real price level, we obtain the transition matrix of exogenous shocks using the Tauchen (1986) method.

Given the grid and the transition matrices, we iterate the Bellman operator to find policy functions given initial price and productivity level. Once we have the firm's policy functions, we then simulate a panel of firms similar to the one in the empirical section of the paper. More precisely, all reported moments come from a panel of 5000 firms of 144 months where aggregate shocks are drawn randomly. We first simulate the model for 1000 adjustment periods so that the moments stationary distribution is not affected by initial conditions. The stationary price gap distributions come from the pooled cross-section of the simulated panel (in total 720000 observations). We then repeat the same regressions in the model as in the empirical section. In particular, we control for aggregate time dummies or the aggregate shocks directly but including them or not had no effect on the quantitative results.

For one robustness check we also add idiosyncratic financial shocks. We assume that the collateralizable fraction $\xi$ follows a stochastic process $\log \left(\xi_{i t}\right)=\rho_{\xi} \log \left(\xi_{i, t-1}\right)+\varepsilon_{\xi, i, t}$. This is a reduced form way to capture that heterogeneity in firm financing possibilities even after controlling for capital and sales. Alternatively, we could have assumed that firm's capital resale value $k_{i, t}$ follows an exogenous process and obtain similar results. For the results reported in this appendix, the grid of the financial shock has 9 grid points and spans \pm 3 of the unconditional standard deviation; the transition matrix was obtained using Tauchen (1986) procedure.

\section{A.3.2 Details on the impulse responses}

Here we describe in more detail on how we construct the impulse responses that are in Section4 Impulse response in period $t$ of economic variables like the nominal price level and output are computed as the differences of the period $t$ average $\log$ price (log output), averaged over $N$ firms, coming from a model simulation with aggregate shock and the period $t$ average log price (log output) of a model simulation without the aggregate shocks. Impulse responses of probabilities are shown as the absolute difference of the probabilities in the model simulation with aggregate shock and the probabilities in the simulation without shock. Averages are computed over $N=5000$ firms and the impulse responses are averaged over $K=1000$ simulations.

Formally, the evolution of variable $x$ in period $t$ are computed as follows:

$$
\Delta x_{t}=\frac{1}{K} \sum_{k=1}^{K}\left(\frac{1}{N} \sum_{i=1}^{N} \ln \left(x_{i t k}^{S}\right)-\frac{1}{N} \sum_{i=1}^{N} \ln \left(x_{i t k}^{N S}\right)\right) \quad t=0, \ldots, T
$$




$$
\Delta x_{t}=\frac{1}{K N} \sum_{k=1}^{K} \sum_{i=1}^{N}\left(\ln \left(x_{i t k}^{S}\right)-\ln \left(x_{i t k}^{N S}\right)\right) \quad t=0, \ldots, T
$$

where the superscript $S$ denotes values of $x$ from the model simulation with aggregate shock and $N S$ denotes values of $x$ from the model simulation absent aggregate shocks. For each simulation $k$, the model with and without aggregate shock are simulated using the same set of $N$ random draws of idiosyncratic productivity. For any simulation $k_{1} \neq k_{2}$ the random draws of the idiosyncratic shock are allowed to differ.

Analogously we compute the impulse response of probability of event $A, \operatorname{Pr}(A)$, in period $t$ as

$$
\left.\Delta \operatorname{Pr}(A)_{t}=\frac{1}{K} \sum_{k=1}^{K}(\operatorname{Pr} \hat{(A})_{t k}^{S}-\operatorname{Pr} \hat{(A)_{t k}^{N S}}\right) \quad t=0, \ldots, T .
$$

The probability in each simulation are estimated using the relative frequencies of occurrence of the event. For example, the change in the probability of price adjustment is computed as

$$
\Delta \operatorname{Pr}(a d j)_{t}=\frac{1}{K} \sum_{k=1}^{K}\left(\frac{N_{a d j, t, k}^{S}}{N}-\frac{N_{a d j, t, k}^{N S}}{N}\right) \quad t=0, \ldots, T .
$$

where $N_{a d j, t, k}^{S}$ denotes the number of firms that adjust their price in period $t$ in the model simulation with aggregate shocks (denoted by the superscript $S$ ); analogously, $N_{a d j, t, k}^{N S}$ denotes the number of firms that adjust their price in period $t$ in the model simulation without aggregate shocks. 


\section{A.4 Profit plots and price gap distributions for different productivity levels}

Figure A-7: Value function for myopic firms $(\beta=0)$ at different productivity ranges

(a) No FC, low productivity

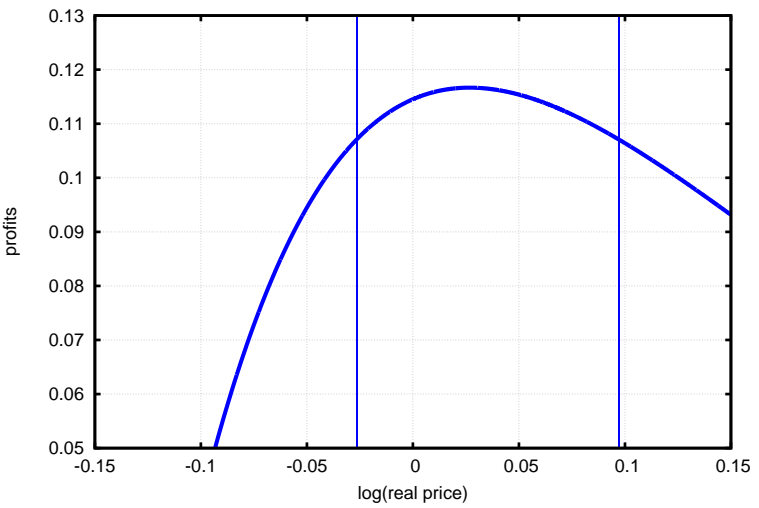

(c) No FC, medium productivity

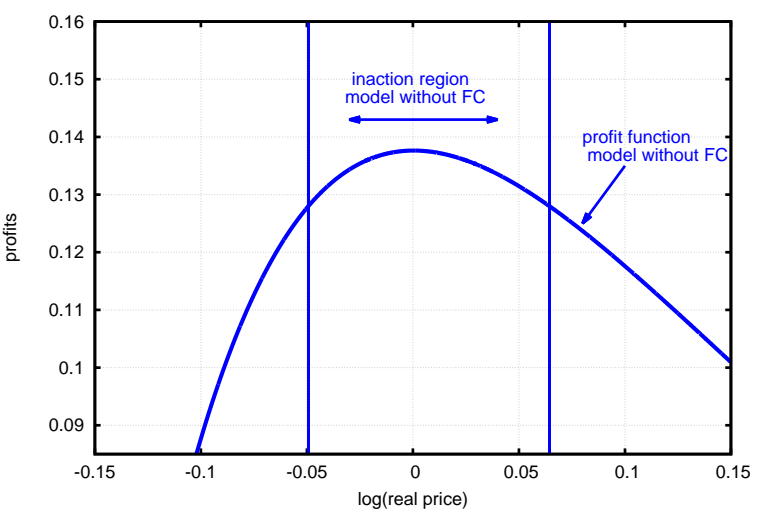

(e) No FC, high productivity

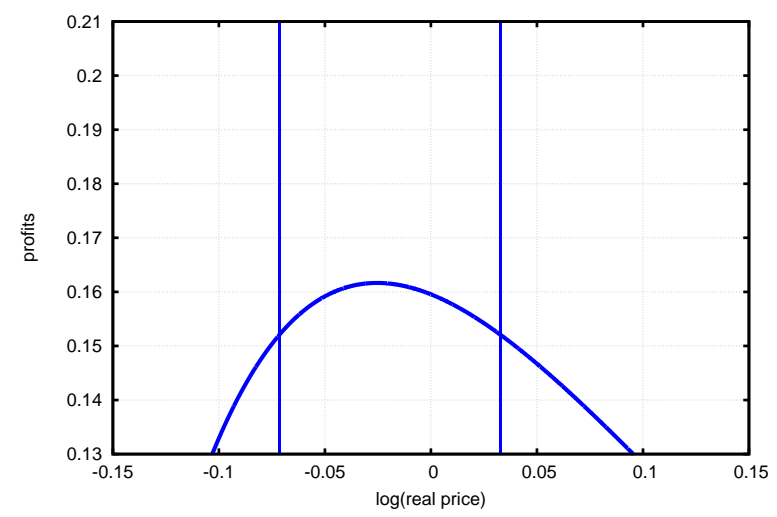

(b) FC, low productivity

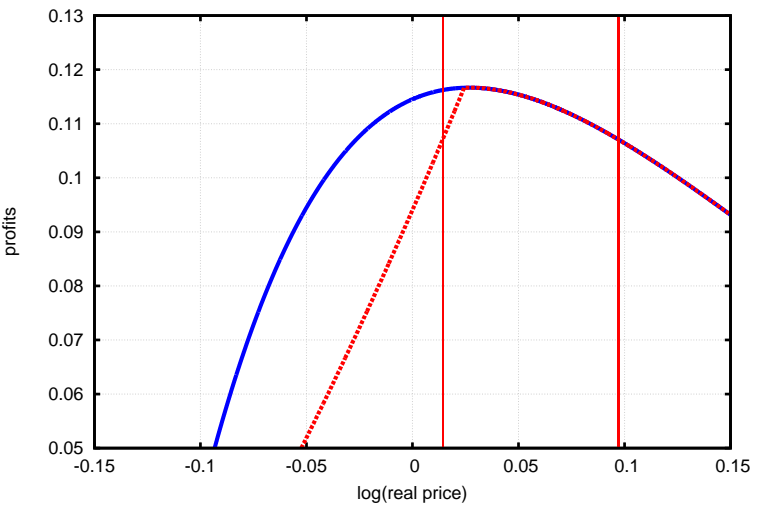

(d) FC, medium productivity

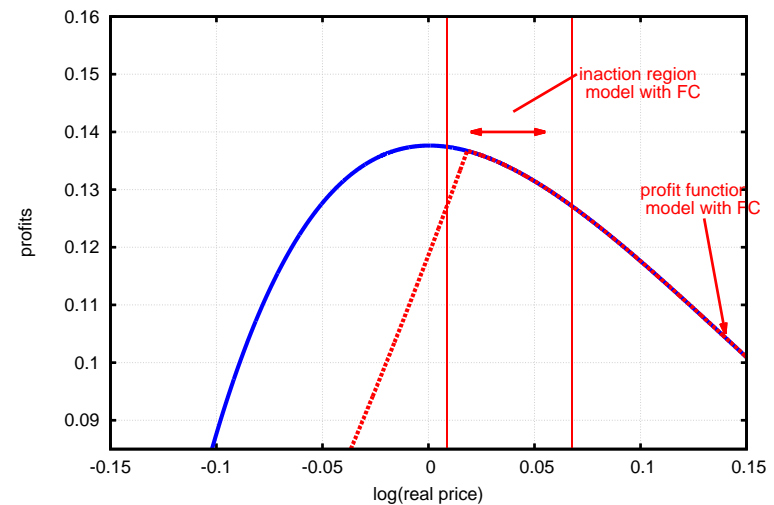

(f) FC, high productivity

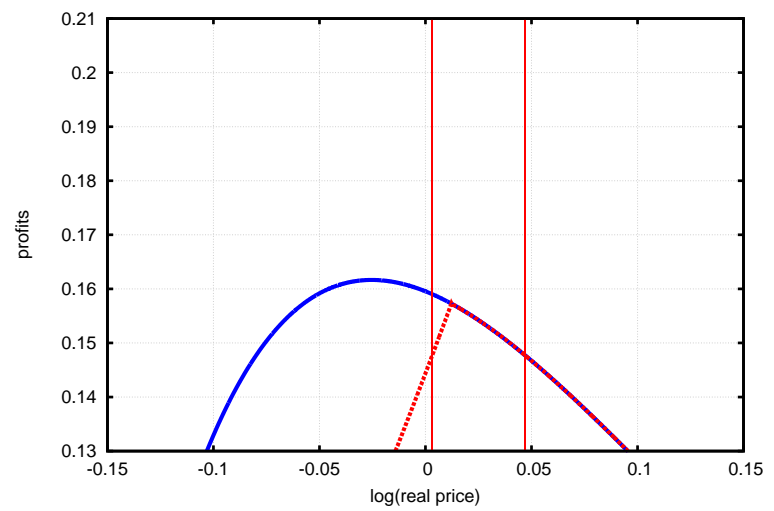

Notes: The left-hand side column shows value function plots for the myopic model without financial constraints, the right-hand side column repeats the same value function (blue line) and compares it with the corresponding plot in the myopic model with financial constraints (red line).

The plots show averages for three productivity levels: All firms below the first quartile (labeled low productivity), firms between the first and the third quartile (labeled medium productivity) and firms above the third quartile (labeled high productivity) of the productivity distribution. 
Figure A-8: Real price distributions (before adjustment) in the myopic model with and without financial constraint by productivity level

(a) Model without financial constraint, low productivity

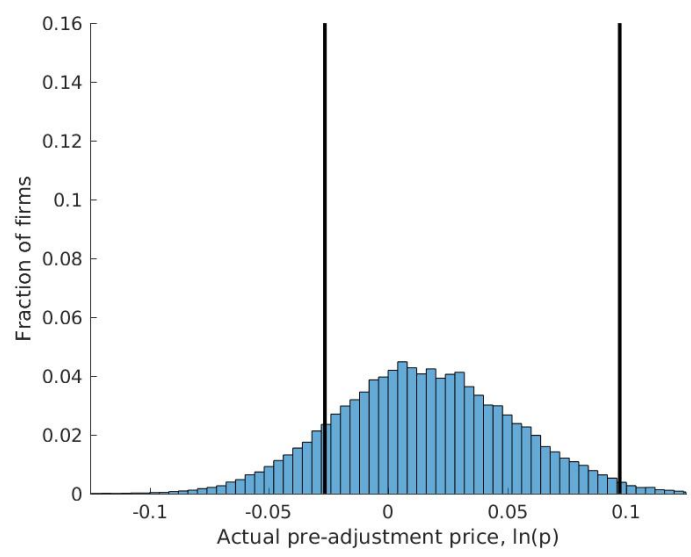

(c) Model without financial constraint, medium productivity

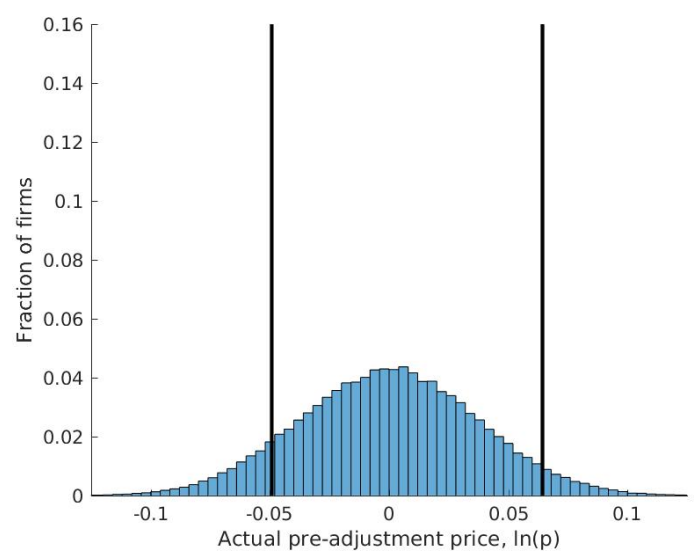

(e) Model without financial constraint, high productivity

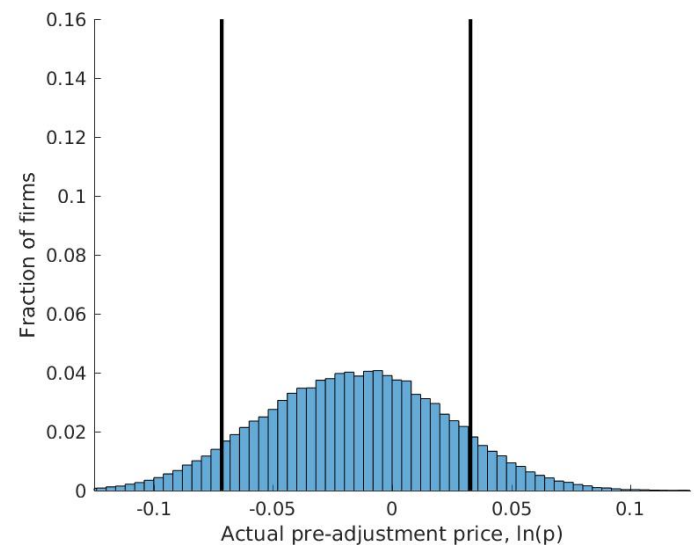

(b) Model with financial constraint, low productivity

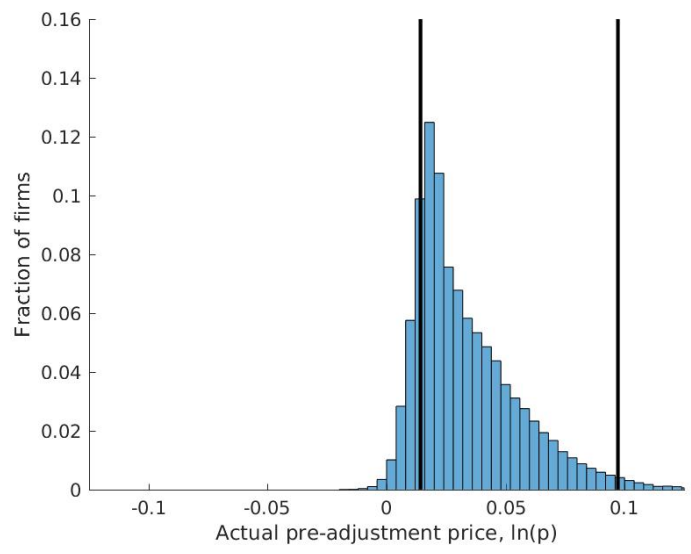

(d) Model with financial constraint, medium productivity

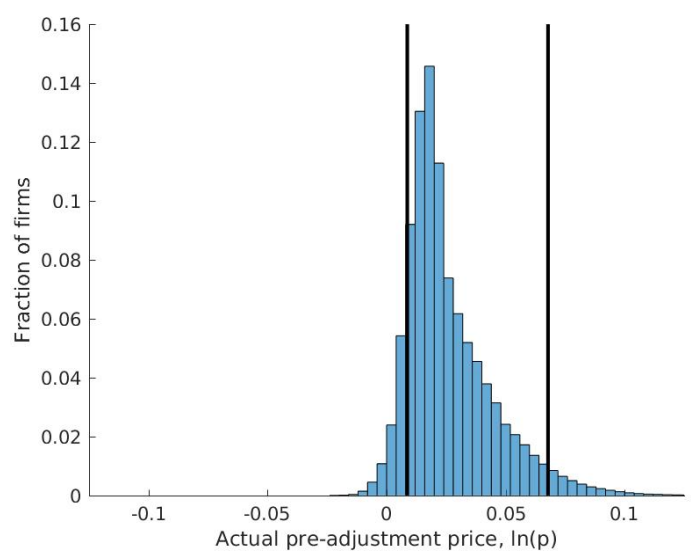

(f) Model with financial constraint, high productivity

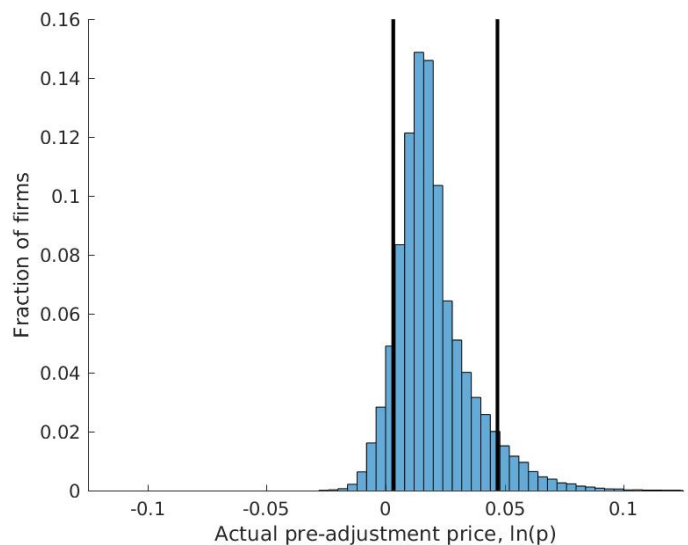

Notes: The histograms display the distribution of real prices $\log \left(p_{i}\right)$, where $p_{i}$ is firm $i$ 's price before price adjustment. The solid vertical lines mark the respective inaction region for firms exactly at the cutoff. Unlike in Figure 3 in the main text, the distributions are not normalized by the optimal reset price.

The left-hand side column shows plots for the myopic model without financial constraints, the right-hand side column documents the corresponding plot in the myopic model with financial constraints.

All firms below the first quartile (labeled low productivity), firms between the first and the third quartile (labeled medium productivity) and firms above the third quartile (labeled high productivity) of the productivity distribution. 
Figure A-9: Real price distributions (before adjustment) in the dynamic model with and without financial constraint by productivity level

(a) Model without financial constraint, low productivity

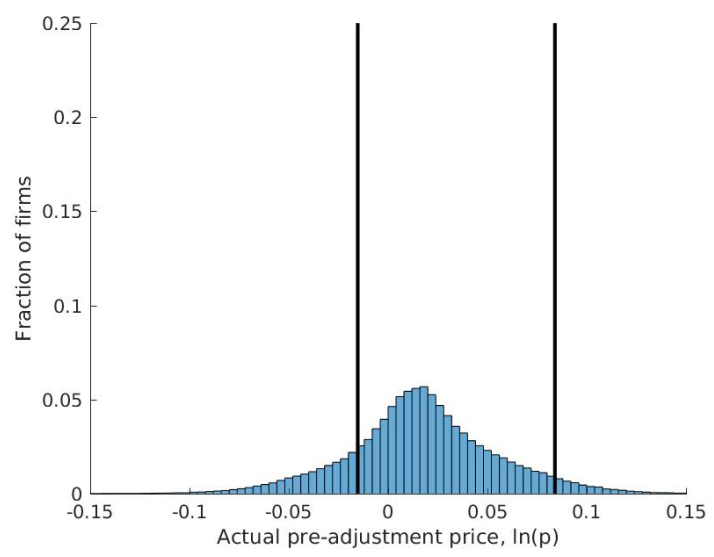

(c) Model without financial constraint, medium productivity

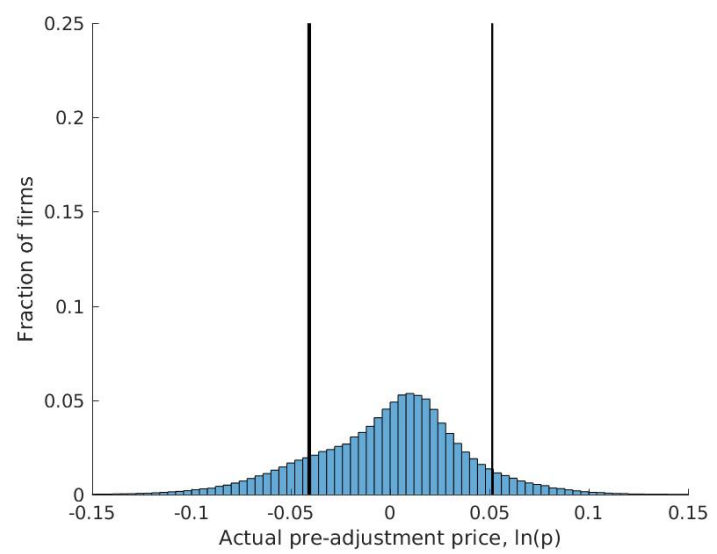

(e) Model without financial constraint, high productivity

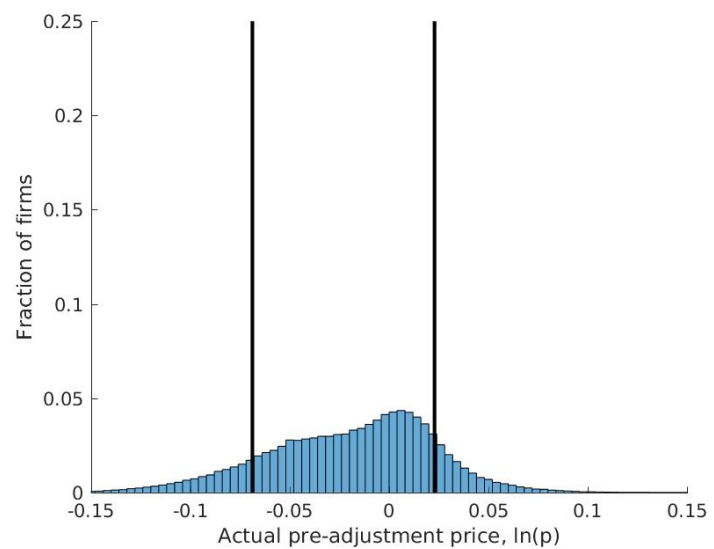

(b) Model with financial constraint, low productivity

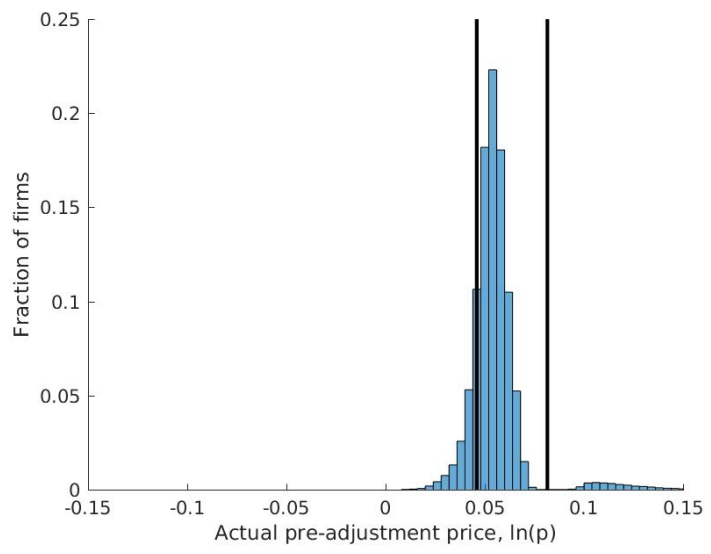

(d) Model with financial constraint, medium productivity

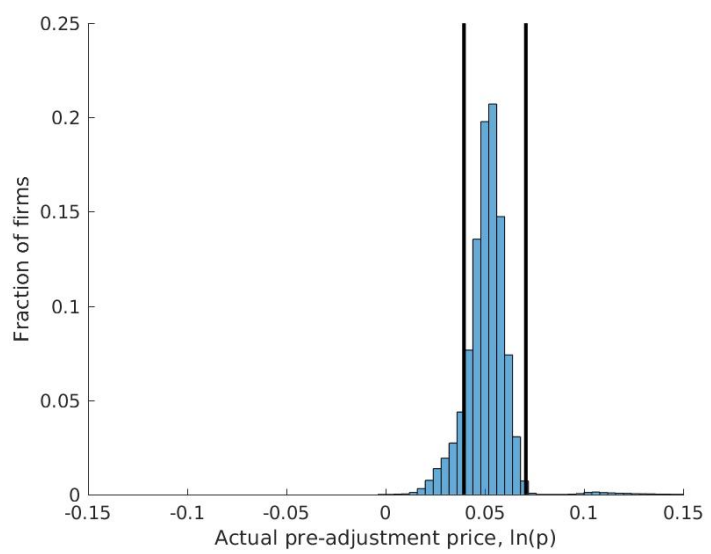

(f) Model with financial constraint, high productivity

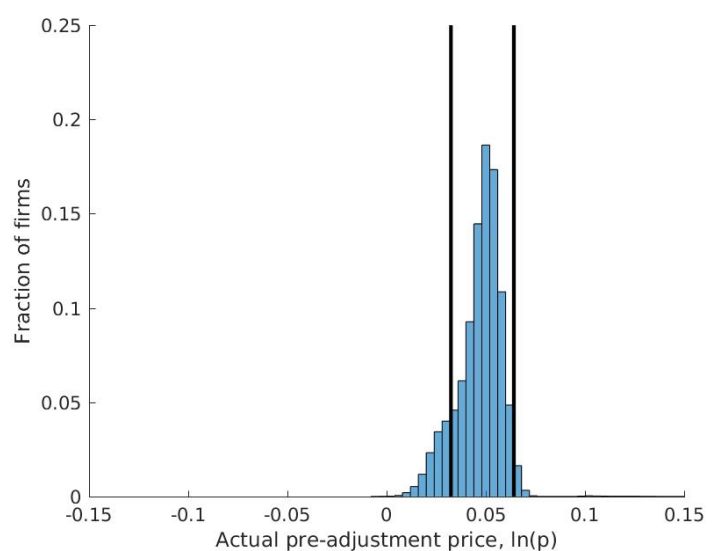

Notes: The histograms display the distribution of real prices $\log \left(p_{i}\right)$, where $p_{i}$ is firm $i$ 's price before price adjustment. The solid vertical lines mark the respective inaction region for firms exactly at the cutoff. Unlike in Figure 3 in the main text, the distributions are not normalized by the optimal reset price.

The left-hand side column shows plots for the myopic model without financial constraints, the right-hand side column documents the corresponding plot in the myopic model with financial constraints.

All firms below the first quartile (labeled low productivity), firms between the first and the third quartile (labeled medium productivity) and firms above the third quartile (labeled high productivity) of the productivity distribution. 
Table A-11: Decomposition of price adjustment in the benchmark model with financial frictions

\begin{tabular}{cllll}
\hline & $(1)$ & $(2)$ & $(3)$ & \\
& $\Delta p>0$ & $\Delta p<0$ & $\Delta p=0$ & Sum Cols (1)-(3) \\
\hline $\begin{array}{l}\text { Model with financial constraint } \\
\text { All }\end{array}$ & 14.90 & 5.38 & 79.72 & 100.00 \\
a. high prod & 1.36 & 4.40 & 19.24 & 25.00 \\
FC & 0.85 & 3.43 & 1.93 & 6.22 \\
UC & 0.51 & 0.97 & 17.30 & 18.78 \\
b. mid prod & 5.70 & 0.62 & 43.92 & 50.24 \\
FC & 0.56 & 0.14 & 10.16 & 10.87 \\
UC & 5.14 & 0.48 & 33.76 & 39.38 \\
c. low prod & 7.83 & 0.35 & 16.57 & 24.76 \\
FC & 3.98 & 0.15 & 11.08 & 15.20 \\
UC & 3.86 & 0.20 & 5.49 & 9.55 \\
\hline
\end{tabular}

Notes: This table shows a decomposition of price adjustment and non-adjustment for the benchmark model, see column (1) of table 3 The values refer to the respective joint probabilities of price adjustment, financial constraint status and productivity level. The marginal distributions, i.e. the fraction of each subgroup relative to all firms, is shown in the last column. Low productivity are all productivity levels smaller than the first quartile in the productivity distribution (i.e. 25 percent of all firms). Middle productivity levels are all productivity levels within the first and the third quartile, corresponding to 50 percent of all firms. High productivity levels refer to productivity levels above the third quartile of the productivity distribution (25 percent of all firms).

In this subsection we report results on the profits, price gap distribution, and decomposition of the extensive price adjustment margin for firms with different productivity levels. We divide firms into three productivity brackets: low productivity firms are all firms with a productivity level below the first quartile of the productivity distribution, medium productivity firms are all firms whose productivity level falls between the first and the third quartile and firms above the third quartile are labeled high productivity firms. Figure A.4 plots the profit functions for the different productivity levels for the model without financial constraint (left panels) and the model with financial constraints (right panels) against the firm's real price on the x-axis. In this figure firms are myopic, therefore the profit functions correspond at the same time to the firms value functions for a given real price and productivity level.

Figure A-8 shows the corresponding distributions of individual firms' pre-adjustment real prices, conditional on different productivity levels, in the model with myopic firms. Hence, in contrast to the price gap distributions in the main text, we have not normalized the real pre-adjustment prices by the optimal reset price. Analogously, Figure A-9 plots the pre-adjustment price distributions in the benchmark model.

Table A-11 decomposes the extensive margin of price adjustment for the firms with low, medium, and high productivity, and also by financial constrained status within each productivity bracket. These numbers are the basis of the numbers in table $\mathrm{A}-11$ in the main text. 


\section{A.5 Price distribution and decomposition of aggregate effects in the bench- mark model}

Figure A-10: Price distribution and positive demand shocks

(a) Model without financial constraint

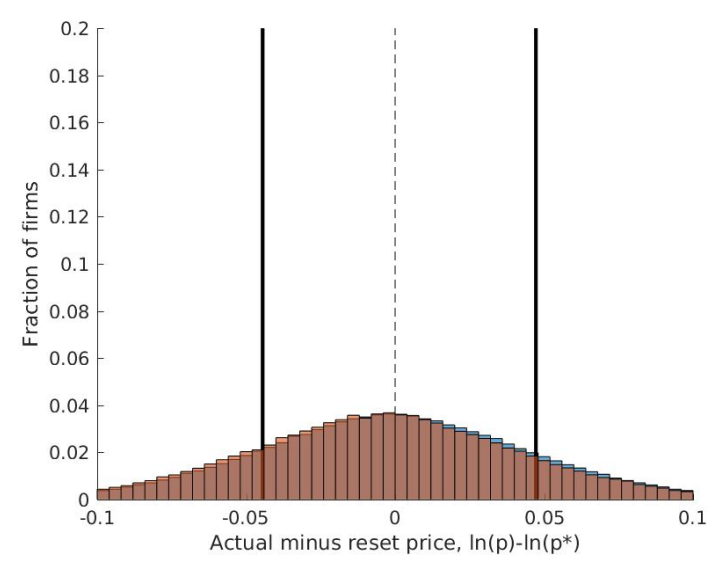

(b) Model with financial constraint

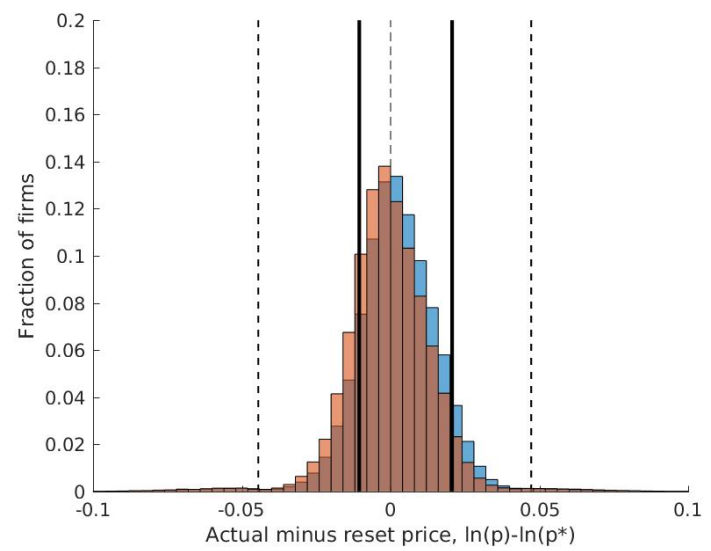

Notes: The histograms display the price gap distribution, defined as the actual (pre-adjustment) price minus the optimal reset price, or $\log \left(p_{i}\right)-\log \left(p_{i}^{*}\right)$, where $p_{i}^{*}$ is firm $i$ 's optimal reset price and $p_{i}$ is firm $i$ 's price before price adjustment. The solid vertical lines mark the inaction region for a firm with average productivity (i.e. $\log (z)=0)$ in the model with and without financial constraint, respectively. The dashed line at zero shows the location of the optimal reset price. The dotted lines in panel (b) are the same as the vertical solid lines for the 'No FC'-model shown in Panel (a). The blue bars show the ergodic distribution. The red bars show the distribution conditional on high demand (nominal demand greater or equal to one-standard deviation above average). 
Table A-12: Decomposition of Inflation Response: Benchmark Model

\begin{tabular}{|c|c|c|c|c|}
\hline & $\Delta p>0$ & $\Delta p<0$ & $\Delta p=0$ & All firms \\
\hline \multicolumn{5}{|l|}{ No shock } \\
\hline 1. Frac & 14.22 & 5.00 & 80.78 & 100.00 \\
\hline 2. $\Delta \ln (p)$ & 1.85 & -3.29 & 0.00 & 0.10 \\
\hline \multicolumn{5}{|l|}{ Positive demand shock } \\
\hline 3. $d(F r a c)$ & 4.63 & -1.12 & -3.51 & \\
\hline 4. $d(\Delta \ln (p))$ & -0.02 & -0.06 & 0.00 & \\
\hline 5. Ext. Marg. $(3 . \times 2)$. & 0.09 & 0.04 & -0.00 & \\
\hline 6. Int. Marg. $(1 . \times 4)$. & -0.00 & -0.00 & 0.00 & \\
\hline 7. Ext. + Int. $(5 .+6)$. & 0.08 & 0.03 & 0.00 & 0.12 \\
\hline \multicolumn{5}{|l|}{ Negative demand shock } \\
\hline 8. $d($ Frac $)$ & -3.68 & 1.55 & 2.12 & \\
\hline 9. $d(\Delta \ln (p))$ & 0.03 & 0.05 & 0.00 & \\
\hline 10. Ext. Marg. $(8 . \times 2)$. & -0.07 & -0.05 & 0.00 & \\
\hline 11. Int. Marg. (1. × 9.) & 0.00 & 0.00 & 0.00 & \\
\hline 12. Ext. + Int. $(10 .+11)$. & -0.06 & -0.05 & 0.00 & -0.11 \\
\hline
\end{tabular}

Decomposition of the impact response of average inflation according to

$$
d(\text { inflation })=\widetilde{\Delta \ln (p)} \cdot d(\text { Frac })+\widetilde{\operatorname{Frac}} \cdot d(\Delta \ln (p)),
$$

Here, the first component refers to changes in the extensive margin and the second refers to changes in the intensive margin. Frac - fraction of price adjustments in the particular direction, $\Delta \ln (p)$ - average price adjustment in the particular direction, $d(F r a c)$ - change in the fraction of price changes in the particular direction, $d(\Delta \ln (p))$ - change in the average price adjustment in the particular direction, Ext.Marg. - extensive margin, Int.Marg. - intensive margin.

Table A-13: Decomposition of Inflation Response: Model without FC

\begin{tabular}{|c|c|c|c|c|}
\hline & $\Delta p>0$ & $\Delta p<0$ & $\Delta p=0$ & All firms \\
\hline \multicolumn{5}{|l|}{ No shock } \\
\hline 1. Frac & 16.78 & 14.55 & 68.66 & 100.00 \\
\hline 2. $\Delta \ln (p)$ & 6.97 & -7.36 & 0.00 & 0.10 \\
\hline \multicolumn{5}{|l|}{ Positive demand shock } \\
\hline 3. $d(F r a c)$ & 1.13 & -0.89 & -0.24 & \\
\hline 4. $d(\Delta \ln (p))$ & 0.03 & 0.04 & 0.00 & \\
\hline 5. Ext. Marg. $(3 . \times 2)$. & 0.08 & 0.07 & -0.00 & \\
\hline 6. Int. Marg. $(1 . \times 4)$. & 0.01 & 0.01 & 0.00 & \\
\hline 7. Ext. + Int. $(5 .+6)$. & 0.08 & 0.07 & 0.00 & 0.16 \\
\hline \multicolumn{5}{|l|}{ Negative demand shock } \\
\hline 8. $d($ Frac $)$ & -1.11 & 0.94 & 0.17 & \\
\hline 9. $d(\Delta \ln (p))$ & -0.03 & -0.04 & 0.00 & \\
\hline 10. Ext. Marg. $(8 . \times 2)$. & -0.08 & -0.07 & 0.00 & \\
\hline 11. Int. Marg. $(1 . \times 9)$. & -0.00 & -0.01 & 0.00 & \\
\hline 12. Ext. + Int. $(10 .+11)$. & -0.08 & -0.07 & 0.00 & -0.16 \\
\hline
\end{tabular}

Decomposition of the impact response of average inflation according to

$$
d(\text { inflation })=\widetilde{\Delta \ln (p)} \cdot d(\text { Frac })+\widetilde{\operatorname{Frac}} \cdot d(\Delta \ln (p)),
$$

Here, the first component refers to changes in the extensive margin and the second refers to changes in the intensive margin. Frac - fraction of price adjustments in the particular direction, $\Delta \ln (p)$ - average price adjustment in the particular direction, $d(F r a c)$ - change in the fraction of price changes in the particular direction, $d(\Delta \ln (p))$ - change in the average price adjustment in the particular direction, Ext.Marg. - extensive margin, Int.Marg. - intensive margin. 
Table A-14: Decomposition of Output Response: Benchmark Model

\begin{tabular}{|c|c|c|c|c|}
\hline & $\Delta p>0$ & $\Delta p<0$ & $\Delta p=0$ & All firms \\
\hline \multicolumn{5}{|l|}{ No shock } \\
\hline 1. Frac & 14.22 & 5.00 & 80.78 & 100.00 \\
\hline 2. $\Delta \ln (y)$ & -11.29 & 24.69 & 0.47 & 0.01 \\
\hline \multicolumn{5}{|l|}{ Positive demand shock } \\
\hline 3. $d(F r a c)$ & 4.63 & -1.12 & -3.51 & \\
\hline 4. $d(\Delta \ln (y))$ & 1.60 & 1.89 & 1.27 & \\
\hline 5. Ext. Marg. $(3 . \times 2)$. & -0.52 & -0.28 & -0.02 & \\
\hline 6. Int. Marg. $(1 . \times 4)$. & 0.23 & 0.09 & 1.03 & \\
\hline 7. Ext. + Int. $(5 .+6)$. & -0.30 & -0.18 & 1.01 & 0.54 \\
\hline \multicolumn{5}{|l|}{ Negative demand shock } \\
\hline 8. $d($ Frac $)$ & -3.68 & 1.55 & 2.12 & \\
\hline 9. $d(\Delta \ln (y))$ & -1.69 & -1.80 & -1.27 & \\
\hline 10. Ext. Marg. $(8 . \times 2)$. & 0.42 & 0.38 & 0.01 & \\
\hline 11. Int. Marg. (1. × 9.) & -0.24 & -0.09 & -1.03 & \\
\hline 12. Ext. + Int. $(10 .+11)$. & 0.18 & 0.29 & -1.02 & -0.54 \\
\hline
\end{tabular}

Decomposition of the impact response of average output according to

$$
d(\text { output })=\widetilde{\Delta \ln (y)} \cdot d(\text { Frac })+\widetilde{\text { Frac }} \cdot d(\Delta \ln (y))
$$

Here, the first component refers to changes in the extensive margin and the second refers to changes in the intensive margin. Frac - fraction of output adjustments in the particular direction, $\Delta \ln (y)$ - average output adjustment in the particular direction, $d($ Frac $)$ - change in the fraction of output changes in the particular direction, $d(\Delta \ln (y))$ - change in the average output adjustment in the particular direction, Ext.Marg. - extensive margin, Int.Marg. - intensive margin.

Table A-15: Decomposition of Output Response: Model without FC

\begin{tabular}{|c|c|c|c|c|}
\hline & $\Delta p>0$ & $\Delta p<0$ & $\Delta p=0$ & All firms \\
\hline \multicolumn{5}{|l|}{ No shock } \\
\hline 1. Frac & 16.78 & 14.55 & 68.66 & 100.00 \\
\hline 2. $\Delta \ln (y)$ & -49.83 & 54.06 & 0.72 & 0.00 \\
\hline \multicolumn{5}{|l|}{ Positive demand shock } \\
\hline 3. $d(F r a c)$ & 1.13 & -0.89 & -0.24 & \\
\hline 4. $d(\Delta \ln (y))$ & 1.21 & 1.16 & 1.45 & \\
\hline 5. Ext. Marg. $(3 . \times 2)$. & -0.56 & -0.48 & -0.00 & \\
\hline 6. Int. Marg. $(1 . \times 4)$. & 0.20 & 0.17 & 0.99 & \\
\hline 7. Ext. + Int. $(5 .+6)$. & -0.36 & -0.31 & 0.99 & 0.32 \\
\hline \multicolumn{5}{|l|}{ Negative demand shock } \\
\hline 8. $d($ Frac $)$ & -1.11 & 0.94 & 0.17 & \\
\hline 9. $d(\Delta \ln (y))$ & -1.24 & -1.16 & -1.45 & \\
\hline 10. Ext. Marg. $(8 . \times 2)$. & 0.55 & 0.51 & 0.00 & \\
\hline 11. Int. Marg. $(1 . \times 9)$. & -0.21 & -0.17 & -0.99 & \\
\hline 12. Ext. + Int. $(10 .+11)$. & 0.34 & 0.34 & -0.99 & -0.31 \\
\hline
\end{tabular}

Decomposition of the impact response of average output according to

$$
d(\text { output })=\widetilde{\Delta \ln (y)} \cdot d(\text { Frac })+\widetilde{\operatorname{Frac}} \cdot d(\Delta \ln (y)),
$$

Here, the first component refers to changes in the extensive margin and the second refers to changes in the intensive margin. Frac - fraction of output adjustments in the particular direction, $\Delta \ln (y)$ - average output adjustment in the particular direction, $d($ Frac $)$ - change in the fraction of output changes in the particular direction, $d(\Delta \ln (y))$ - change in the average output adjustment in the particular direction, Ext.Marg. - extensive margin, Int.Marg. - intensive margin. 


\section{A.6 Partial equilibrium models with alternative mechanisms to generate price stickiness}

The subsection discusses the implications for price adjustment of working capital constraints in a model with nominal rigidities in the tradition of Calvo (1983) and a model with convex price adjustment costs as in Rotemberg (1982). The first purpose of this subsection is to show analytically why in these type of models aggregate output responds less when financial frictions are present compared to the situation when the financial constraint is removed. For this purpose we use log-linearization techniques. Second, we briefly describe how we numerically implement and parameterize the models.

\section{A.6.1 Exogenous Probability of Price Adjustment (Calvo (1983))}

In this subs section, we replace the fixed menu cost of price adjustment by nominal rigidities in the tradition of Calvo (1983) which means that every firm faces an exogenously given probability $f \in(0,1)$ per period for not being allowed to adjust its price. With probability $(1-f)$ the firm is allowed to optimally reset its price. Adjustments are assumed to be costless irrespective of their magnitude. $f$ corresponds to the so called Calvo parameter. Non-adjusters simply continue to sell their products at previous period's price: $p_{i t}^{n a}=p_{i t-1}$. When choosing the optimal price $p_{i t}^{a}$, adjusters take into account that with certain probability, the nominal price chosen today will be retained in the future, e.g. $p_{i t+1}=p_{i t}^{a}$ with probability $f$. The law of large numbers implies that in each period the fraction of non-adjusters is equal to $f$ and their average price is equal to previous period's economy-wide average nominal price, i.e. $\bar{P}_{t}^{n a}=\bar{P}_{t-1}$.

The Lagrangean for the problem of a firm allowed to adjust its price in period $t$ reads

$$
\begin{aligned}
L & =E_{t} \sum_{j=0}^{\infty} \beta^{j} f^{j}\left\{\frac{p_{i t}}{P_{t+j}} z_{i t+j} h_{i t+j}-w h_{i t+j}\right\} \\
& +E_{t} \sum_{j=0}^{\infty} \beta^{j} f^{j}\left\{\gamma_{i t+j}\left(\xi+\xi \frac{p_{i t}}{P_{t+j}} z_{i t+j} h_{i t+j}-w h_{i t+j}\right)\right\} \\
& +E_{t} \sum_{j=0}^{\infty} \beta^{j} f^{j}\left\{\delta_{i t+j}\left(\left(\frac{p_{i t}}{P_{t+j}}\right)^{-\theta} C_{t+j}-z_{i t+j} h_{i t+j}\right)\right\},
\end{aligned}
$$

where $\delta_{i t}$ denotes the Lagrangean multiplier associated with the demand constraint, $E_{t}$ is the expectation operator conditional on period $t$ information, $h_{i t}$ is labor input of fimr $i, z_{i t}$ denotes the productivity shock of firm $i$, and $P_{t}, C_{t}$ denote the aggregate nominal price level and aggregate demand, respectively. The first order conditions with respect to $h_{i t}$ and $p_{i t}$ read:

$$
\begin{gathered}
\delta_{i t}=\left(1+\gamma_{i t} \xi\right) \frac{p_{i t}}{P_{t}}-\left(1+\gamma_{i t}\right) \frac{w}{z_{i t}} \\
E_{t} \sum_{j=0}^{\infty} \beta^{j} f^{j}\left\{\left(1+\gamma_{i t+j} \xi\right) \frac{z_{i t+j} h_{i t+j}}{P_{t+j}}-\theta \delta_{i t+j}\left(\frac{p_{i t}}{P_{t+j}}\right)^{-\theta-1} \frac{C_{t+j}}{P_{t+j}}\right\}=0 \\
\gamma_{i t}\left\{\xi\left(1+\frac{p_{i t}}{P_{t}} z_{i t} h_{i t}\right)-w h_{i t}\right\}=0 \\
\gamma_{i t} \geq 0, \quad \xi\left(1+\frac{p_{i t}}{P_{t}} z_{i t} h_{i t}\right) \geq w h_{i t} .
\end{gathered}
$$




$$
\begin{aligned}
& \delta_{i t}\left\{\left(\frac{p_{i t}}{P_{t}}\right)^{-\theta} C_{t}-z_{i t} h_{i t}\right\}=0 \\
& \delta_{i t} \geq 0, \quad\left(\frac{p_{i t}}{P_{t}}\right)^{-\theta} C_{t} \geq z_{i t} h_{i t} .
\end{aligned}
$$

Since we focus on the reaction to an unexpected change in the aggregate price level $P_{t}$, we assume that idiosyncratic productivity does not deviate from the path expected prior to the occurrence of the aggregate shock. For simplicity, we assume $\left\{z_{i t+j}\right\}_{j=0}^{\infty}=z$. Replacing this flat profile by a given but non-constant path, will make the derivations considerably more tedious without delivering different implications or further insights. Next, recall that by assumption, nominal aggregate demand $S_{t}=$ $P_{t} C_{t}$ follows a Random Walk with drift $\mu, \log S_{t}=\mu+\log S_{t-1}+\eta_{t}$. Since throughout the paper we assume $C_{t}=C \forall t$, the disturbances $\eta_{t}$ correspond to one-time shifts in the aggregate inflation rate $\log P_{t}-\log P_{t-1}$ and, at the same time, to permanent shifts in the nominal price level $P_{t}$. The permanent nature of the changes in $P_{t}$ combined with the purely static structure of the two constraints on the one hand and the assumption on the path of $z_{i t}$, implies that if a constraint is binding (non-binding) today it will be expected to be binding (non-binding) over the entire future. Furthermore, it is straightforward to show that, as in the menu-cost model as well as the Rotemberg model, a price adjuster will always decide to be located on her demand schedule, i.e. will avoid rationing.

Accordingly, we have $\left(\frac{p_{i t}}{P_{t}}\right)^{-\theta} C_{t}=z_{i t} h_{i t}$ while equation A.9p simply determines the value of the Lagrangean multiplier $\delta_{i t}$ for given paths of the other endogenous variables. Moreover, we can reduce the system A.9p through A.12 to

$$
\begin{aligned}
& (\theta-1) E_{t} \sum_{j=0}^{\infty} \beta^{j} f^{j}\left\{\left(1+\gamma_{i t+j} \xi\right)\left(\frac{p_{i t}}{P_{t+j}}\right)^{-\theta} \frac{C_{t+j}}{P_{t+j}}\right\}= \\
= & \theta E_{t} \sum_{j=0}^{\infty} \beta^{j} f^{j}\left\{\left(1+\gamma_{i t+j}\right) \frac{w}{z_{i t+j}}\left(\frac{p_{i t}}{P_{t+j}}\right)^{-\theta-1} \frac{C_{t+j}}{P_{t+j}}\right\},
\end{aligned}
$$

and

$$
\begin{aligned}
& \gamma_{i t}\left\{\xi\left(1+\left(\frac{p_{i t}}{P_{t}}\right)^{1-\theta} C_{t}\right)-\frac{w}{z_{i t}}\left(\frac{p_{i t}}{P_{t}}\right)^{-\theta} C_{t}\right\}=0 \\
& \gamma_{i t} \geq 0, \quad \xi\left(1+\left(\frac{p_{i t}}{P_{t}}\right)^{1-\theta} C_{t}\right) \geq \frac{w}{z_{i t}}\left(\frac{p_{i t}}{P_{t}}\right)^{-\theta} C_{t} .
\end{aligned}
$$

To derive the dynamics resulting from A.13 and $\mathrm{A}$.14 , we log-linearize these conditions and view the system as a piecewise linear one in the sense of Guerrieri and Iacoviello (2015). Without loss of generality, we $\log$-linearize around $p_{i}=P$ and $z_{i}=1$. There are two relevant cases: a slack and a binding financial constraint. In the former, the Lagrange multiplier $\left\{\gamma_{i t+j}\right\}_{j=0}^{\infty}=0$ and A.13 reduces to its well known form lying at the heart of the New Keynesian Phillips Curve:

$$
(\theta-1) E_{t} \sum_{j=0}^{\infty} \beta^{j} f^{j}\left\{\left(\frac{p_{i t}}{P_{t+j}}\right)^{-\theta} \frac{C_{t+j}}{P_{t+j}}\right\}=\theta E_{t} \sum_{j=0}^{\infty} \beta^{j} f^{j}\left\{\frac{w}{z_{i t+j}}\left(\frac{p_{i t}}{P_{t+j}}\right)^{-\theta-1} \frac{C_{t+j}}{P_{t+j}}\right\}
$$


Log-linearizing and rearranging yields

$$
\frac{1}{1-\beta f} \hat{p}_{i t}=\sum_{j=0}^{\infty} \beta^{j} f^{j} E_{t} \hat{P}_{t+j}-\sum_{j=0}^{\infty} \beta^{j} f^{j} E_{t} \hat{z}_{i t+j} .
$$

Thus, if $\hat{z}_{i t}=0 \forall t$ and the shock to the aggregate price level is permanent, i.e. $\hat{P}_{t}=\hat{P}_{t+j} \forall j \geq 1$, we obtain

$$
\hat{p}_{i t}=\hat{P}_{t}-(1-\beta f) \sum_{j=0}^{\infty} \beta^{j} f^{j} E_{t} \hat{z}_{i t+j} .
$$

In other words, unconstrained adjusters approximately completely pass-through permanent shifts in $P_{t}$ to their individual nominal prices $p_{i t}$. The same holds for price adjusters facing a binding borrowing constraint. For in that case the choice of the optimal price is restricted by A.14 with $\xi\left(1+\left(\frac{p_{i t}}{P_{t}}\right)^{1-\theta} C_{t}\right)=$ $\frac{w}{z_{i t}}\left(\frac{p_{i t}}{P_{t}}\right)^{-\theta} C_{t}$ while A.13 simply determines the path of the Lagrangean multiplier $\gamma_{i t}$ for a given path of the individual nominal price. Log-linearization and rearranging yields

$$
\hat{p}_{i t}=\hat{P}_{t}-\frac{w}{\xi(1-\theta)+\theta w} \hat{z}_{i t} .
$$

In sum, price adjusters choose a complete pass-through of changes in the aggregate price level $P_{t}$ to their individual prices $p_{i t}$, irrespective of whether they face a slack or a binding financial constraint. In fact, independent of the presence of a financial constraint, the average price $\bar{P}_{t}$ responds to permanent changes in $P_{t}$ as follows: $\hat{\bar{P}}_{t}=(1-f) \hat{P}_{t}, \hat{\bar{P}}_{t+1}=f(1-f) \hat{P}_{t}, \hat{\bar{P}}_{t+2}=f^{2}(1-f) \hat{P}_{t}$ and so on. This is the case since in each period, a new fraction $(1-f)$ of the firms who had not yet been able to react to the shock in $P_{t}$ are given this opportunity. They respond by applying complete pass-through.

The only difference between the economy with and the one without the financial friction results from non-adjusters. In a world without credit market frictions, each firm operates at its demand curve. If, however, firm's behavior is restricted by a borrowing limit, some non-adjusters - those facing a binding financial constraint - will have to produce off their demand schedule and thus ration demand. Since the fraction of such firms increases in the case of a positive innovation to the aggregate price level $P_{t}$, output losses due to rationing increase, causing the output to increase by less than in a world without financial frictions.

\section{A.6.2 Convex Price-Adjustment Costs (Rotemberg (1982)}

In this section, we replace the fixed menu cost of price adjustment by a convex price-adjustment cost function like in Rotemberg (1982). Everything else remains unchanged. For simplicity and as usually done in the literature, we assume that the price-adjustment cost function is quadratic and equal across firms. In particular, each change of the individual nominal price is associated with costs amounting to $\frac{\kappa}{2}\left(\frac{p_{i t}}{p_{i t-1}}-\Pi\right)^{2} C_{t}$ where $\kappa>0$ and $C_{t}$ is aggregate demand. The parameter $\kappa$ measures the degree of price rigidity and, as we will show below, affects the slope of the individual supply curve. $\Pi=1+\mu$ is the gross rate of growth in nominal aggregate demand. ${ }^{37}$

Each firm chooses its nominal price $p_{i t}$ such that the present discounted value of current and future profits is maximized subject to the demand and the borrowing constraint. It is easy to show that the demand constraint is always binding. Thus, we can replace $y_{i t}$ by the demand function $\left(\frac{p_{i t}}{P_{t}}\right)^{-\theta} C_{t}$. The

\footnotetext{
${ }^{37}$ If $C_{t}=C \forall t$, then $\mu$ corresponds to the aggregate inflation rate.
} 
resulting Langrangean reads

$$
\begin{aligned}
L & =\left(\frac{p_{i t}}{P_{t}}\right)^{-\theta} C_{t}\left(\frac{p_{i t}}{P_{t}}-\frac{w}{z_{i t}}\right)-\frac{\kappa}{2}\left(\frac{p_{i t}}{p_{i t-1}}-\Pi\right)^{2} C_{t} \\
& +\gamma_{i t}\left(\xi\left(1+\left(\frac{p_{i t}}{P_{t}}\right)^{1-\theta} C_{t}\right)-\frac{w}{z_{i t}}\left(\frac{p_{i t}}{P_{t}}\right)^{-\theta} C_{t}\right) \\
& +E_{t}\left\{\beta\left(\ldots-\frac{\kappa}{2}\left(\frac{p_{i t+1}}{p_{i t}}-\Pi\right)^{2} C_{t+1}+\ldots\right)\right\}+\ldots
\end{aligned}
$$

where $\gamma_{i t}$ is the Lagrange multiplier associated with the financial constraint and, to save on space, we neglect terms independent of $p_{i t}$. The first order condition with respect to $p_{i t}$ reads

$$
\begin{aligned}
& (1-\theta)\left(\frac{p_{i t}}{P_{t}}\right)^{-\theta}+\theta\left(1+\gamma_{i t}\right) \frac{w}{z_{i t}}\left(\frac{p_{i t}}{P_{t}}\right)^{-\theta-1}+\gamma_{i t} \xi(1-\theta)\left(\frac{P_{i t}}{P_{t}}\right)^{-\theta}= \\
& \theta\left(\Pi_{i t}-\Pi\right) \Pi_{i t}\left(\frac{p_{i t}}{P_{t}}\right)^{-1}-\beta \theta E_{t}\left\{\left(\Pi_{i t+1}-\Pi\right) \Pi_{i t+1}\left(\frac{p_{i t}}{P_{t}}\right)^{-1} \frac{C_{t+1}}{C_{t}}\right\},
\end{aligned}
$$

and

$$
\begin{aligned}
& \gamma_{i t}\left\{\xi\left(1+\left(\frac{p_{i t}}{P_{t}}\right)^{1-\theta} C_{t}\right)-\frac{w}{z_{i t}}\left(\frac{p_{i t}}{P_{t}}\right)^{-\theta} C_{t}\right\}=0 \\
& \gamma_{i t} \geq 0, \quad \xi\left(1+\left(\frac{p_{i t}}{P_{t}}\right)^{1-\theta} C_{t}\right) \geq \frac{w}{z_{i t}}\left(\frac{p_{i t}}{P_{t}}\right)^{-\theta} C_{t} .
\end{aligned}
$$

where $\Pi_{i t}=p_{i t} / p_{i t-1}$ is the firm-specific gross rate of inflation. Equations (A.16) and A.17) represent the firm specific supply curve. If the financial constraint does not bind, the optimal pricing decision is determined by (A.16) with $\gamma_{i t}=0$. In contrast, if the financial constraint binds, $p_{i t}$ is derived from A.17 with $\xi\left(1+\left(\frac{p_{i t}}{P_{t}}\right)^{1-\theta} C_{t}\right)=\frac{w}{z_{i t}}\left(\frac{p_{i t}}{P_{t}}\right)^{-\theta} C_{t}$ while A.16 determines the value of the Lagrange multiplier $\gamma_{i t}$.

The easiest way to derive the main tendencies implied by $(A .16)$ and $(A .17)$ is by log-linearizing them and viewing the system as a piecewise linear one in the sense of Guerrieri and Iacoviello (2015). Without loss of generality, we $\log$-linearize around $p_{i}=P$ and $z_{i}=1$. In addition, since we focus on the effects of unexpected changes in $P_{t}$, we assume that $z_{i t}$ does not deviate from its initial value $z_{i}$. If the financial constraint is not binding, the optimal pricing decision is approximately determined according to the $\log$-linear version of (A.16) with $\gamma_{i t}=0$ :

$$
\begin{aligned}
\hat{p}_{i t} & =\frac{\theta-1}{\theta-1+\kappa(1+\beta)}\left(\hat{P}_{t}-\hat{z}_{i t}\right) \\
& +\frac{\kappa}{\theta-1+\phi(1+\beta)} \hat{p}_{i t-1}+\frac{\beta \kappa}{\theta-1+\kappa(1+\beta)} E_{t} \hat{p}_{i t+1},
\end{aligned}
$$

where $\hat{x}_{t}=\left(x_{t}-x\right) / x$ denotes a relative deviation from the point around which we linearize. It is easily seen from A.18 that in the short run, temporary as well as permanent shocks to the aggregate price level $P_{t}$ are incompletely passed through to changes in the individual nominal price $p_{i t}$ since the coefficient in front of $\hat{P}_{t}, \frac{\theta-1}{\theta-1+\kappa(1+\beta)}$, lies within the open interval $(0,1) .{ }^{38}$ In contrast, when the financial constraint

\footnotetext{
${ }^{38}$ Note that the short-run pass-through of movements in $P_{t}$ to changes in $p_{i t}$ is incomplete even if the shift in $P_{t}$ is permanent as is the case with our assumed process for $P_{t}$, i.e. $\log \left(S_{t}\right)=\mu+\log \left(S_{t-1}\right)+\eta_{t}$ where nominal demand $S_{t}=P_{t} C_{t}$ and $C_{t}=$ const. To see this, consider two polar cases: $E_{t} \hat{p}_{i t+1}=\hat{P}_{t}$ and $E_{t} \hat{p}_{i t+1}=\hat{p}_{i t}$. In the former, the coefficient linking $\hat{p}_{i t}$ and $\hat{P}_{t}$ in the short run becomes $\frac{\theta-1+\beta \kappa}{\theta-1+f(1+\beta)}$ which is strictly larger than zero and smaller than
} 
binds, the firm sets its price according to the constraint itself,

$$
\xi\left(1+\left(\frac{p_{i t}}{P_{t}}\right)^{1-\theta} C_{t}\right)=\frac{w}{z_{i t}}\left(\frac{p_{i t}}{P_{t}}\right)^{-\theta} C_{t} .
$$

Log-linearizing the last equation yields

$$
\hat{p}_{i t}=\hat{P}_{t}-\frac{w}{\xi(1-\theta)+\theta w} \hat{z}_{i t} .
$$

Obviously, A.19 implies that if the firm is restricted by its borrowing limit, its optimal pricing decision will be approximately associated with full pass-through of movements in the aggregate price level $P_{t}$ to changes in the individual price $p_{i t}$. The intuition is as follows: The borrowing limit actually works as a capacity constraint imposing an upper bound on the quantity the firm is able to produce. As soon as full capacity is reached, the individual supply curve becomes approximately (up to a linear approximation) vertical. Any further increases of demand can only be accommodated by raising firm's prices but not by expanding production. In other words, any shifts of the demand curve - due to changes in the economywide variables $P_{t}$ or in $C_{t}$ - represent shifts along an approximately vertical individual supply schedule and thus, are associated with no quantity but a relatively strong price reaction.

Based on the discussion in this section, it is easy to understand why an economy free of financial frictions will respond to exogenous permanent shifts in the aggregate price level $P_{t}$ differently from an economy subject to our borrowing constraint. In the former, each firm sets its optimal nominal price according to A.18). Hence, the shock to $P_{t}$ is not fully transmitted to the average price level $\bar{P}_{t}=\sum_{i=1}^{N} p_{i t}$, where $N$ is the number of firms, with the degree of pass-through being approximately equal across firms. In contrast, if the economy is subject to our financial friction and there is a strictly positive fraction of firms facing a binding constraint, only part of the firms - the unconstrained ones - will set prices according to A.18). The rest - for which the constraint binds - will choose to fully pass the shift in $P_{t}$ through to their individual prices $p_{i t}$. Accordingly, the pass-through from $P_{t}$ to the average nominal price level $\bar{P}_{t}$ will be relatively more complete. Consequently, given the downward sloping demand curve, the average output response in an economy subject to the financial constraint will tend to be relatively weaker. Note further, that in the case of positive shocks to $P_{t}$, the difference between the two economies is further magnified as the fraction of financially constrained firms increases. The opposite happens - the difference between the economy with and the one without financial frictions becomes smaller - when there is a permanent drop in $P_{t}$ since the number of firms with a binding credit constraint decreases.

\section{A.6.3 Numerical Implementation and Parametrization}

For the results reported in the main text we solve both the Calvo and the Rotemberg model by value function iteration. To be more precise, we solve a version of the Calvo model as in Nakamura and Steinsson (2010) where firms with probability $1-\alpha$ draw a fix cost $\left(f_{H}\right)$ and with probability $\alpha$ draw a low fix cost $\left(f_{L}\right)$. We then solve the model by value. In practice we set $f_{L}=0$ and $f_{H}$ to a very high value, so that firms that draw the high fix cost never adjust prices and firms that draw the zero fix cost always adjust. We then calibrate the fraction $1-\alpha$ to match the average frequency of price adjustment in our data.

For the Rotemberg model, we set the menu cost to zero but introduce quadratic adjustment costs. Given the firm's beginning of period nominal price $p_{i t}$, the end-of-period nominal price $q_{i t}$, the aggregate price level $P_{t}$, and idiosyncratic productivity $z_{i t}$, the value function of firm $i$ in the Rotemberg model is given by

$$
V\left(p_{i t} / P_{t}, z_{i t}\right)=\max _{q_{i t}, h_{i t}}\left\{\begin{array}{l}
\left(\frac{q_{i t}}{P_{t}}-\frac{w}{z_{i t}}\right) z_{i t} h_{i t}-\frac{\kappa}{2}\left(\frac{q_{i t}}{p_{i t}}-e^{\mu}\right)^{2} C+\beta E_{t} V\left(q_{i t} / P_{t+1}, z_{i t+1}\right) \\
\text { s.t. } z_{i t} h_{i t} \leq \frac{q_{i t}}{P_{t}} C \\
w h_{i t} \leq \xi\left(1+\frac{q_{i t}}{P_{t}} z_{i t} h_{i t}\right)
\end{array}\right\}
$$

unity. In the case $E_{t} \hat{p}_{i t+1}=\hat{p}_{i t}$, the corresponding coefficient becomes $\frac{\theta-1}{\theta-1+f}$ which also lies within $(0,1)$. 
Figure A-11: Impulse responses of aggregate variables, Calvo and Rotemberg model versus menu cost benchmark model

(a) Average inflation
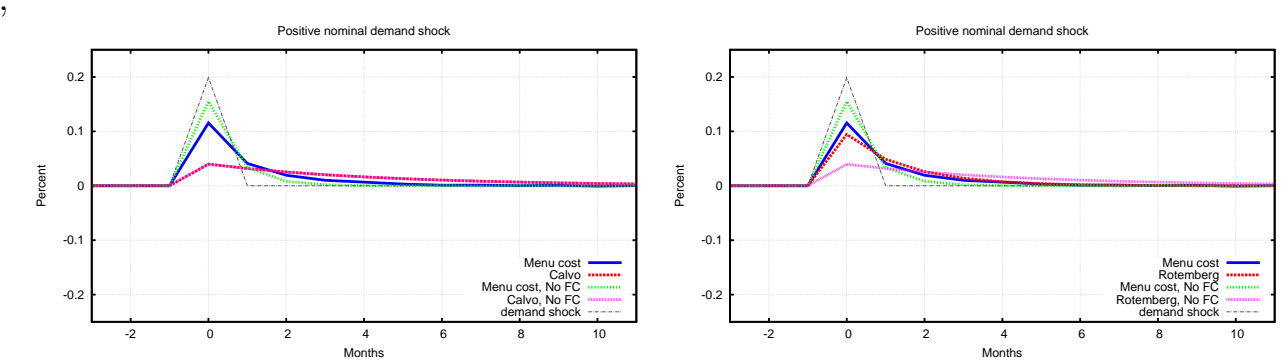

(b) Average (real) output
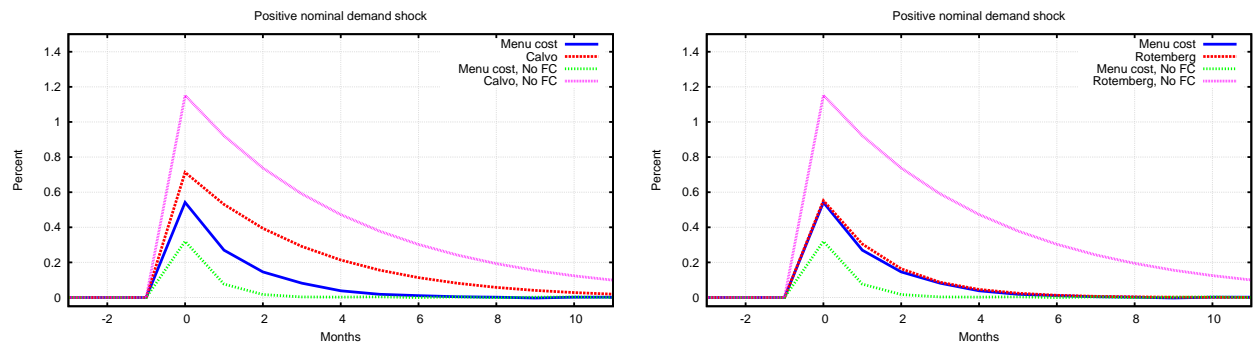

where we have assumed that $C_{t}=C$ for all $t$ and that the adjustment costs are defined relative to the average gross inflation rate $e^{\mu}$. As in the benchmark model, we solve both models presented here using value function iteration on a discretized productivity and price grid.

We have parameterized the models in the following way. The discount factor and the demand elasticity are calibrated as in the benchmark model, equal to 7.25 and $0.96^{1 / 12}$, respectively. For simplicity, the parameters of the shock process are calibrated as in the benchmark model. The probability of price adjustment in the Calvo model is set to $(1-\alpha)=0.22$ to match the empirical moment from our data. The adjustment cost parameter in the Rotemberg model $\kappa$ is set such that the Calvo model and the Rotemberg model imply the same level of aggregate nominal rigidity in the absence of financial constraints.

\section{A.6.4 Impulse responses}

Figure A-11 show the impulse responses of average output and inflation to a positive nominal demand shock in the Calvo and Rotemberg model, respectively, and compare them to the impulse responses of the benchmark menu cost model. 


\section{A.7 Robustness}

\section{A.7.1 Profit and policy functions for different parameter values}

Figure A-12: Pricing policy functions

(a) High persistence

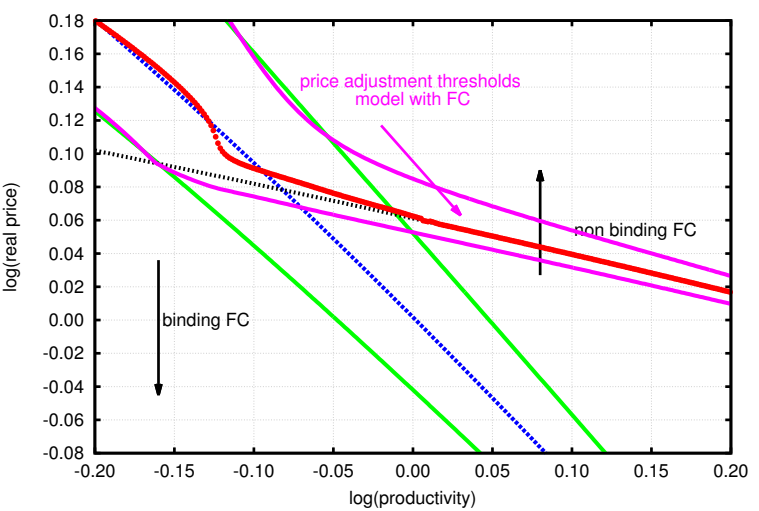

(b) Sales not collateralizable

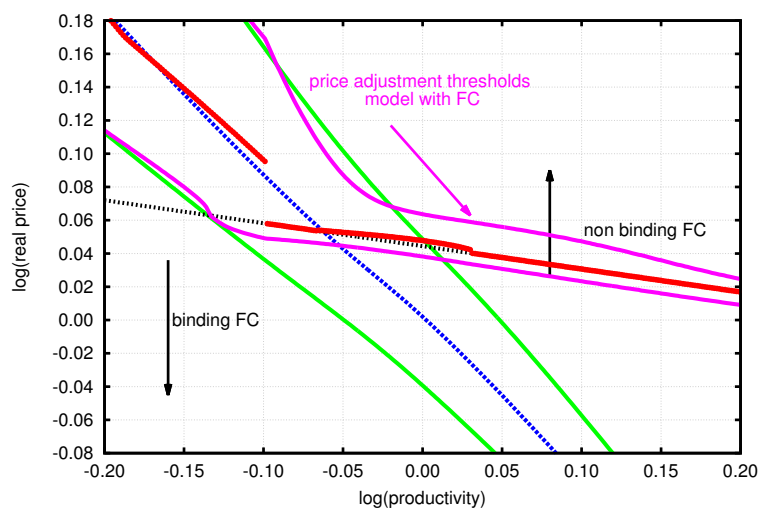

Notes: The x-axis displays the logarithm of the productivity levels $z_{i}$ and the y-axis shows the logarithm of the real price of the firm $\tilde{p_{i}}=p_{i} / P$ (or $\tilde{q_{i}}=q_{i} / P$ if the price is changed). The blue dashed line is the optimal price of the adjusting firm in case there is no financial constraint. The green lines limit the inaction region in the model without financial friction; i.e. a firm with a pair $(z, p)$ the interval spanned by the green lines will not adjust its price. The dashed black line is the maximum feasible price of a firm that is financially constrained and adjusting its price (hence, the price where both the financial constraint and demand are binding with equality). The red line displays the optimal adjusting price policy in the model with a financial constraint. The purple lines limit the inaction region in the model with financial constraint.

Panel (a) of Figure A-12 shows the pricing policy function for a calibration with high persistence. The policy looks generally similar to our benchmark model. With high persistence, the expectation component in the value function becomes less important and current profits become more important. Therefore, firms with low productivity choose a price above the dashed black line such that for these firms the working capital constraint does not bind unlike in the benchmark economy. Panel b) of Figure A-12 shows the pricing policy function for the model where sales are not collateralizable, i.e. for the model where the financial constraint is given by $w h \leq \xi$. Qualitatively, it looks very similar to the benchmark model.

Figure A-13 plots the current profit function for a firm with average profits $(z=1)$ and for different values of the demand elasticity of substition, namely for $\theta=7.25$ (our benchmark value) and $\theta=6$. For lower values of $\theta$, that is the less elastic the demand function with respect to price changes, the flatter and more symmetric the firm's profit function around the profit maximum (see red dashed line). As a consequence of the flattening of the profit function, the price adjustment thresholds lie more symmetrically around the profit maximizing price. Put differently, the higher the demand elasticity the more asymmetric the profit function becomes around the profit maximizing price (compare the blue solid line and the red dashed line). In particular, the profit function becomes steeper to the left of the maximum which implies that the lower threshold lies closer the profit maximizing price than the upper threshold.

\section{A.7.2 Calibration of different model versions}

Table A-16 shows robustness of our calibration results to various model specifications. In particular, in column (2) we contrast the benchmark calibration to the model version with myopic firms. This version performs surprisingly well in matching the calibration targets (slightly worse distance measure after second digit, not shown). Also the calibrated values for the key parameters are very similar. In terms of pricing behavior, the model with myopic firms predicts that financially constrained firms adjust more often than unconstrained firms, see row 5. However, it overestimates the fraction of constrained firms that decreases the price and underestimates the fraction of constrained firms that decrease the price. This reflects the positive link between productivity and being financially constrained for price adjusting firms in this version of the model. For the same reason, the ratio of sales of constrained firms relative to 
Figure A-13: Profit function for $z=1, \beta=0$ and different values of $\theta$

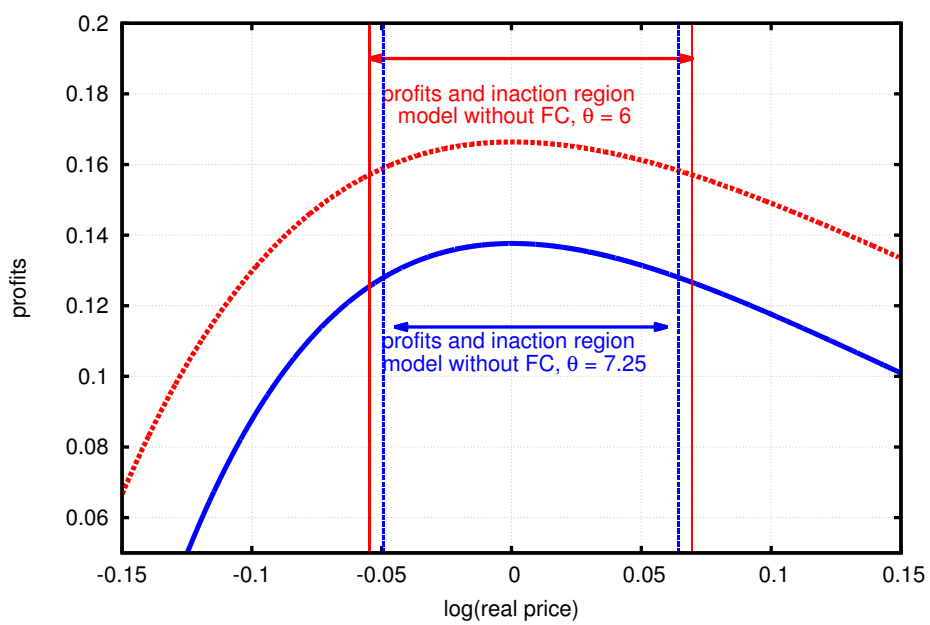

Notes: The figure displays the firms' current profits as a function of the real price in logarithms for different values of the elasticity of substitution $\theta$. The hump-shaped blue solid line are firm profits for $\theta=6$ and the the dashed vertical blue lines are the corresponding boundaries of the inaction region. The hump-shaped dashed red line are firm profits for $\theta=7.25$ and the solid red vertical lines are the corresponding boundaries of the inaction region.

sales of unconstrained firms is larger than one and hence larger than in the benchmark model, see row 12 .

In column (3) we truncate the grid for $\log$ productivity between $\left[-2 \sigma_{z}, 2 \sigma_{z}\right]$; we do so in order to exclude productivity levels for which the value function is potentially double peaked. The results are virtually unchanged relative to the benchmark model.

Column (4) show robustness with respect to sales as collateral in the financial constraint. Including sales as collateral is quantitatively important in order to match the targeted moments (compare rows 1 to 4 in model (1) and model (4)) and in order to generate regression coefficients with the correct sign (in particular for upward adjusters, compare row 6 in columns (1) and (4)).

Column (5) recalibrates the model to the alternative measure of being financially constrained in the data: the production shortage survey question. According to this measure around 6 percent of the firms are constrained on average. The model has a similar fit in terms of targeted moments as the benchmark. The model predicts that financially constrained firms adjust more often than unconstrained firms, see row 5. However, it overestimates the fraction of constrained firms that decreases the price and underestimates the fraction of constrained firms that decrease the price. The reason is the same as in the model with myopic firms: There is a strong positive link between productivity and being financially constrained for price adjusting firms. Due to the low fraction of constrained firms, the constraint is not tight enough to affect the intertemporal decision of firms with productivity levels around the mean. Accordingly, the ratio of sales of constrained firms relative to sales of unconstrained firms is larger than one and hence larger than in the benchmark model, see row 12.

Columns (6) and (7) show the calibration results when we consider values for the elasticity of demand that are lower and higher, respectively, as compared to the benchmark. The model implications are similar to the benchmark model. However, the model (6) largely overestimates the fraction of constrained firms that increase their price (row 6) and therefore overestimates the price adjustment probability of financially constrained firms (row 5). The model with higher elasticity of substitution underestimates the upward price adjustment of financially constrained firms relative to unconstrained firms (row 6) while leaving the downward price adjustment of financially constrained firms unaffected (row 7) compared to the benchmark.

Table A-17 reports robustness results with respect to the idiosyncratic shock persistence. Here, we increase the shock persistence leaving all other parameters as in the benchmark calibration in order to show the ceteris paribus effect of higher persistence. Two results stand out: First, the only targeted moments that are sensitive to different values of shock persistence are the fractions of price changes. This 
is intuitive as a ceteris paribus change in the persistence changes the variance of the productivity shock. Hence, higher persistence means larger shocks and a higher probability to be outside the inaction region if menu costs stay the same. Second, shock persistence affects quantitatively our regressions results (see row 5-7). The main conclusion however is unaffected: for all productivity levels, the model predicts that financially constrained firms adjust prices more often than unconstrained firms.

Table A-18 reports the results for a model version where we allow for two types of idiosyncratic shocks: productivity and financial shocks. Financial shocks are modeled as shocks to $\xi$, i.e. the collateralizable fraction of capital and sales. In particular $\log (\xi)$ follows an $\operatorname{AR}(1)$ process with standard deviation $\sigma_{\xi}$ and persistence $\rho_{\xi} \cdot{ }^{39}$ In the calibration shown here we assume that financial and productivity shocks have the same persistence $\rho_{z}=\rho_{\xi}$. We calibrate the variance of the financial shock so that median sales are the same for financially constrained and unconstrained firms, see row 5 . Column (1) uses the benchmark calibration strategy targeting a fraction of 32 percent of financially constrained firms. This model does not perform better than the benchmark without financial shocks. Column (2) uses the alternative target of 6 percent of constrained firms as suggested by the production shortage question in the survey data. In this case, the model performance improves as the model now also predicts that financially constrained firms adjust more often than unconstrained firms, see regression coefficient in row 7. These are likely firms that are hit by a negative financial shock and therefore have to increase their price as the unconstrained price is no longer attainable given their productivity level.

\section{A.7.3 Aggregate implications of different model versions}

Table A-19 shows the on impact impulse responses to a positive aggregate nominal demand shock comparing the different model versions to the benchmark model. All models have the same qualitative message: the model with financial constraints exhibits smaller inflation responses and larger output responses than the model without financial constraint. In all model versions the fraction of price adjusting firms increases significantly in response to the shocks in contrast to the models without financial constraints.

Table A-19: On impact impulse responses to positive nominal demand shock, model robustness

\begin{tabular}{llllllc}
\hline & \multicolumn{2}{c}{ Fraction of price adj. } & \multicolumn{2}{c}{ Av. inflation } & \multicolumn{2}{c}{ Av. output } \\
& FC & No FC & FC & No FC & FC & No FC \\
\hline Benchmark & 3.41 & 0.23 & 0.12 & 0.15 & 0.53 & 0.33 \\
Myopic & 3.40 & 0.30 & 0.13 & 0.14 & 0.44 & 0.41 \\
Trunc. $z$ & 3.61 & 0.24 & 0.12 & 0.16 & 0.54 & 0.34 \\
No sales & 5.72 & 0.23 & 0.12 & 0.17 & 0.48 & 0.19 \\
Prod. shortage & 2.34 & 0.30 & 0.14 & 0.14 & 0.40 & 0.41 \\
Low demand elast. & 2.97 & 0.27 & 0.11 & 0.13 & 0.47 & 0.41 \\
High demand elast. & 4.69 & 0.28 & 0.13 & 0.17 & 0.55 & 0.27 \\
\hline \multicolumn{2}{l}{ Notes: This table shows the on impact impulse responses to a positive aggregate nominal demand shock for different model versions. }
\end{tabular}

We just show the on impact responses because the dynamics are qualitatively very similar across models.

\footnotetext{
${ }^{39}$ Theoretically $\log (\xi)$ follows a truncated normal distribution, so that $\xi$ lies in the interval $(0,1)$. In practice, since we discretize the state space the bounds are not relevant for the simulation.
} 
Table A-16: Model robustness, different specifications

\begin{tabular}{|c|c|c|c|c|c|c|c|c|}
\hline & $\operatorname{Data}^{a}$ & $\begin{array}{l}(1) \\
\text { Benchm }\end{array}$ & $\begin{array}{l}(2) \\
\text { Static }\end{array}$ & $\begin{array}{l}(3) \\
\text { Trunc } \\
z\end{array}$ & $\begin{array}{l}(4) \\
\text { No } \\
\text { Sales }\end{array}$ & $\begin{array}{l}(5) \\
\text { Prod. } \\
\text { Short. }\end{array}$ & $\begin{array}{l}(6) \\
\text { Low } \\
\text { de- } \\
\text { mand } \\
\text { elast. }\end{array}$ & $\begin{array}{l}(7) \\
\text { High } \\
\text { de- } \\
\text { mand } \\
\text { elast. }\end{array}$ \\
\hline \multicolumn{9}{|l|}{ A. Parameter values } \\
\hline$\theta$ & & 7.25 & 7.25 & 7.25 & 7.25 & 7.25 & 6.00 & 9.00 \\
\hline$\beta$ & & $0.96^{1 / 12}$ & $0.00^{1 / 12}$ & $0.96^{1 / 12}$ & $0.96^{1 / 12}$ & $0.96^{1 / 12}$ & $0.96^{1 / 12}$ & $0.96^{1 / 12}$ \\
\hline$\mu$ (percent) & & 0.10 & 0.10 & 0.10 & 0.10 & 0.10 & 0.10 & 0.10 \\
\hline$\sigma_{\eta}($ percent $)$ & & 0.20 & 0.20 & 0.20 & 0.20 & 0.20 & 0.20 & 0.20 \\
\hline$C$ & & 1 & 1 & 1 & 1 & 1 & 1 & 1 \\
\hline$k$ & & 1 & 1 & 1 & 1 & 1 & 1 & 1 \\
\hline$\Delta p_{\text {grid }}$ (percent) & & 0.01 & 0.01 & 0.01 & 0.01 & 0.01 & 0.01 & 0.01 \\
\hline$\Delta z_{\text {grid }}$ (percent) & & 0.09 & 0.07 & 0.05 & 0.13 & 0.07 & 0.08 & 0.09 \\
\hline \multicolumn{9}{|l|}{ Calibrated } \\
\hline$f$ (percent of wages) & & 1.02 & 1.12 & 0.99 & 1.25 & 0.88 & 1.04 & 0.98 \\
\hline$\sigma_{\varepsilon}($ percent $)$ & & 4.34 & 3.52 & 4.26 & 7.07 & 3.61 & 4.02 & 4.50 \\
\hline$\rho_{z}$ & & 0.41 & 0.41 & 0.40 & 0.11 & 0.43 & 0.41 & 0.39 \\
\hline$\xi$ & & 0.35 & 0.40 & 0.35 & 0.64 & 0.45 & 0.34 & 0.37 \\
\hline \multicolumn{8}{|l|}{ B. Moments } & \\
\hline 1. $P(\Delta p)$ & 0.22 & 0.20 & 0.21 & 0.20 & 0.21 & 0.21 & 0.20 & 0.21 \\
\hline 2. $P(\Delta p>0)$ & 0.12 & 0.15 & 0.14 & 0.15 & 0.14 & 0.13 & 0.15 & 0.15 \\
\hline 3. $P(F C)$ & 0.32 & 0.32 & 0.32 & 0.33 & 0.32 & $0.07^{c}$ & 0.32 & 0.32 \\
\hline 4. Median price change & 0.02 & 0.02 & 0.03 & 0.02 & 0.03 & 0.04 & 0.02 & 0.02 \\
\hline Distance & & 0.03 & 0.03 & 0.04 & 0.02 & 0.02 & 0.04 & 0.03 \\
\hline \multicolumn{9}{|l|}{ Regression coefficients } \\
\hline 5. $\hat{\beta}_{F C}^{c o n s}$ & -0.04 & -0.11 & -0.07 & -0.14 & 0.04 & -0.09 & -0.19 & -0.00 \\
\hline 6. $\hat{\beta}_{F C}^{u p}$ & 0.01 & 0.01 & -0.05 & 0.07 & -0.11 & -0.11 & 0.12 & -0.09 \\
\hline 7. $\hat{\beta}_{F C}^{\text {down }}$ & 0.03 & 0.09 & 0.13 & 0.07 & 0.07 & 0.20 & 0.07 & 0.09 \\
\hline \multicolumn{9}{|l|}{ Additional Moments } \\
\hline 8. Median price incr. & 0.02 & 0.01 & 0.02 & 0.01 & 0.02 & 0.03 & 0.01 & 0.01 \\
\hline 9. Median price decr. & 0.02 & 0.03 & 0.04 & 0.03 & 0.07 & 0.04 & 0.03 & 0.03 \\
\hline 10. $P(\Delta p=0 \mid F C)$ & 0.75 & 0.72 & 0.73 & 0.70 & 0.81 & 0.70 & 0.67 & 0.78 \\
\hline 11. $P(\Delta p=0 \mid U C)$ & 0.80 & 0.84 & 0.82 & 0.85 & 0.78 & 0.80 & 0.86 & 0.80 \\
\hline 12. Sales(FC)/Sales(UC) & 0.95 & 1.00 & 1.07 & 0.99 & 1.00 & 1.08 & 0.99 & 1.01 \\
\hline
\end{tabular}

Values refer to monthly frequency unless indicated otherwise.

${ }^{a}$ Data on median price changes of German manufacturing producer prices are from Vermeulen et al. (2012). The remaining data moments come from the Ifo panel data, for details see the empirical section.

$b$ All model versions recalibrated to match data targets in rows $1-4$.

$c$ The empirical target moment for this model version is $P(F C)=0.06$. 
Table A-17: Model robustness, persistence of productivity shock

\begin{tabular}{|c|c|c|c|c|c|}
\hline & Data & $\begin{array}{l}(1) \\
\text { Benchm }\end{array}$ & $\begin{array}{l}(2) \\
\rho_{z}=0\end{array}$ & $\begin{array}{l}(3) \\
\rho_{z}=0.75\end{array}$ & $\begin{array}{l}(4) \\
\rho_{z}=0.9\end{array}$ \\
\hline \multicolumn{6}{|l|}{$\begin{array}{l}\text { A. Parameter values } \\
\text { Assigned }\end{array}$} \\
\hline$\alpha$ & & 1.00 & 1.00 & 1.00 & 1.00 \\
\hline$\theta$ & & 7.25 & 7.25 & 7.25 & 7.25 \\
\hline$\beta$ (annualized) & & 0.96 & 0.96 & 0.96 & 0.96 \\
\hline$\mu$ (percent) & & 0.10 & 0.10 & 0.10 & 0.10 \\
\hline$\sigma_{\eta}($ percent $)$ & & 0.20 & 0.20 & 0.20 & 0.20 \\
\hline$C$ & & 1 & 1 & 1 & 1 \\
\hline$k$ & & 1 & 1 & 1 & 1 \\
\hline$\Delta p_{\text {grid }}$ (percent) & & 0.01 & 0.01 & 0.01 & 0.01 \\
\hline$\Delta z_{\text {grid }}$ (percent) & & 0.09 & 0.08 & 0.12 & 0.10 \\
\hline \multicolumn{6}{|l|}{ Calibrated } \\
\hline$f$ (percent of wages) & & 1.02 & 1.02 & 1.02 & 1.02 \\
\hline$\sigma_{\varepsilon}($ percent $)$ & & 4.34 & 4.34 & 4.34 & 4.34 \\
\hline$\rho_{z}$ & & 0.41 & 0.00 & 0.75 & 0.90 \\
\hline$\xi$ & & 0.35 & 0.35 & 0.35 & 0.35 \\
\hline \multicolumn{6}{|l|}{ B. Moments } \\
\hline \multicolumn{6}{|l|}{ Used in calibration } \\
\hline 1. $P(\Delta p)$ & 0.22 & 0.20 & 0.15 & 0.28 & 0.30 \\
\hline 2. $P(\Delta p>0)$ & 0.12 & 0.15 & 0.11 & 0.19 & 0.19 \\
\hline 3. $P(F C)$ & 0.32 & 0.32 & 0.31 & 0.31 & 0.32 \\
\hline 4. Median price change & 0.02 & 0.02 & 0.02 & 0.02 & 0.02 \\
\hline Distance & & 0.03 & 0.07 & 0.09 & 0.11 \\
\hline \multicolumn{6}{|l|}{ Regression coefficients } \\
\hline 5. $\hat{\beta}_{F C}^{\text {cons }}$ & -0.04 & -0.11 & -0.13 & -0.05 & -0.18 \\
\hline 6. $\hat{\beta}_{F C}^{u p}$ & 0.01 & 0.01 & 0.06 & -0.06 & 0.04 \\
\hline 7. $\hat{\beta}_{F C}^{\text {down }}$ & 0.03 & 0.09 & 0.07 & 0.12 & 0.14 \\
\hline \multicolumn{6}{|l|}{ Additional Moments } \\
\hline 8. Median price incr. & 0.02 & 0.01 & 0.02 & 0.02 & 0.02 \\
\hline 9. Median price decr. & 0.02 & 0.03 & 0.03 & 0.03 & 0.03 \\
\hline 10. $P(\Delta p=0 \mid F C)$ & 0.75 & 0.72 & 0.76 & 0.68 & 0.57 \\
\hline 11. $P(\Delta p=0 \mid U C)$ & 0.80 & 0.84 & 0.90 & 0.74 & 0.76 \\
\hline 12. Sales $(F C) / \operatorname{Sales}(\mathrm{UC})$ & 0.95 & 1.00 & 0.99 & 1.09 & 1.18 \\
\hline
\end{tabular}

Notes: This table shows robustness with respect to productivity shocks. Keeping all other parameters the same as in the benchmark calibration the table shows simulated moments for different values of the persistence of the productivity shock. Values refer to monthly frequency unless indicated otherwise. Data on median price changes of German manufacturing producer prices are from Vermeulen et al. (2012). The remaining data moments come from the Ifo panel data, for details see the empirical section. 
Table A-18: Model robustness, model with idisyncratic productivity and financial shocks

\begin{tabular}{|c|c|c|c|}
\hline & Data & $\begin{array}{l}\text { (1) } \\
\text { Benchm }\end{array}$ & $\begin{array}{l}(2) \\
\text { Prod. short }\end{array}$ \\
\hline \multicolumn{4}{|l|}{ A. Parameter values } \\
\hline \multicolumn{4}{|l|}{ Assigned } \\
\hline$\theta$ & & 7.25 & 7.25 \\
\hline$\beta$ (annualized) & & 0.96 & 0.96 \\
\hline$\mu$ (percent) & & 0.10 & 0.10 \\
\hline$\sigma_{\eta}$ (percent) & & 0.20 & 0.20 \\
\hline$C$ & & 1 & 1 \\
\hline$k$ & & 1 & 1 \\
\hline$\Delta p_{\text {grid }}$ (percent) & & 0.01 & 0.01 \\
\hline$\Delta z_{\text {grid }}$ (percent) & & 0.10 & 0.09 \\
\hline \multicolumn{4}{|l|}{ Calibrated } \\
\hline$f$ (percent of wages) & & 1.05 & 0.88 \\
\hline$\sigma_{\varepsilon}($ percent $)$ & & 3.67 & 3.10 \\
\hline$\rho_{z}=\rho_{\xi}$ & & 0.44 & 0.42 \\
\hline$E(\xi)$ & & 0.36 & 0.44 \\
\hline$\sigma_{\xi}($ percent $)$ & & 4.00 & 4.32 \\
\hline
\end{tabular}

\section{B. Moments}

Used in calibration

$\begin{array}{llll}\text { 1. } P(\Delta p) & 0.22 & 0.21 & 0.17 \\ \text { 2. } P(\Delta p>0) & 0.12 & 0.15 & 0.12 \\ \text { 3. } P(F C) & 0.32 & 0.32 & 0.09 \\ \text { 4. Median price change } & 0.02 & 0.02 & 0.03 \\ \text { 5. Sales(FC)/Sales(UC) } & 1 & 0.99 & 1.03 \\ \text { Distance } & & 0.033 & 0.068\end{array}$

Regression coefficients

$\begin{array}{llll}\text { 6. } \hat{\beta}_{F C}^{\text {cons }} & -0.04 & -0.24 & -0.22 \\ \text { 7. } \hat{\beta}_{F C}^{\text {up }} & 0.01 & 0.14 & 0.06 \\ \text { 8. } \hat{\beta}_{F C}^{\text {down }} & 0.03 & 0.10 & 0.16\end{array}$

Additional Moments
9. Median price incr.
$0.02 \quad 0.02$
0.03
10. Median price decr.
0.02
0.03
0.05
11. $P(\Delta p=0 \mid F C)$
0.75
0.63
0.62
12. $P(\Delta p=0 \mid U C)$
0.80
0.87
0.85

Notes: This table shows robustness with respect to a model version where both idiosyncratic productivity and financial shocks are present. Financial shocks are modeled as shocks to $\xi$, i.e. the collateralizable fraction of capital and sales. In particular $\log (\xi)$ follows an $\operatorname{AR}(1)$ process with standard deviation $\sigma_{\xi}$ and persistence $\rho_{\xi}$. In the calibration shown here we assume that financial and productivity shocks have the same persistence $\rho_{z}=\rho_{\xi}$.

Values refer to monthly frequency unless indicated otherwise. Data on median price changes of German manufacturing producer prices are from Vermeulen et al. (2012). The remaining data moments come from the Ifo panel data, for details see the empirical section. 